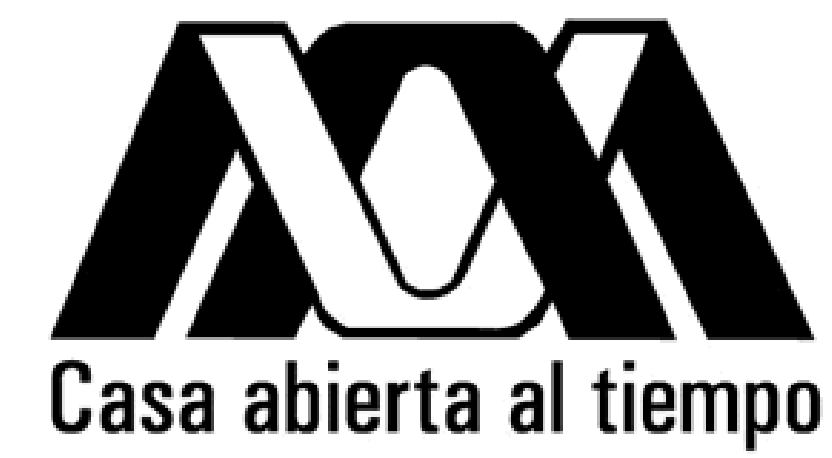

UNIVERSIDAD AUTÓNOMA METROPOLITANA

\title{
PRODUCCIÓN, CARACTERIZACIÓN PARCIAL Y EVALUACIÓN DE LA CAPACIDAD EMULSIFICANTE DE HIDROCARBUROS DEL BIOEMULSIFICANTE DE Acinetobacter bouvetii UAM25
}

\section{TESIS}

Que para obtener el grado de Doctor en Biotecnología

PRESENTA

M.C. José Luis Vázquez Vázquez

DIRECTOR

Dr. Mariano Gutiérrez Rojas

Asesores:

Dr. Sergio Huerta Ochoa

Dr. Miquel Gimeno Seco

Febrero 2018 
El Doctorado en Biotecnología de la Universidad Autónoma Metropolitana está incluido en el Programa Nacional de Posgrados de Calidad (PNPC) del CONACYT, con la referencia 001466 
Iaztapala, CDMX a 21 de febrero de 2018

El jurado designado por la división de Ciencias Biológicas y de la Salud aprobó la tesis

PRODUCCIÓN, CARACTERIZACIÓN PARCIAL Y EVALUACIÓN DE LA CAPACIDAD EMULSIFICANTE DE HIDROCARBUROS DEL BIOEMULSIFICANTE DE Acinetobacter bouvetii UAM25

Que presentó

\section{José Luis Vázquez Vázquez}

Comité tutorial:

Director: Dr. Mariano Gutiérrez Rojas Universidad Autónoma Metropolitana Asesor: Dr. Sergio Huerta Ochoa Universidad Autónoma Metropolitana Asesor: Dr. Miquel Gimeno Seco Universidad Autónoma Metropolitana

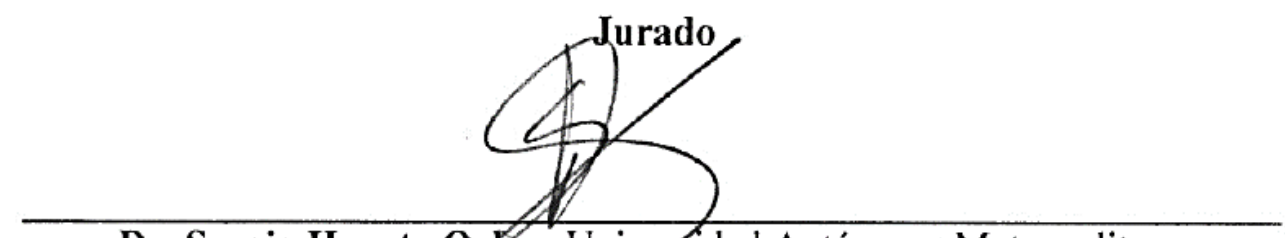

Dr. Sergio Huerta Oghoa Universidad Autónoma Metropolitana

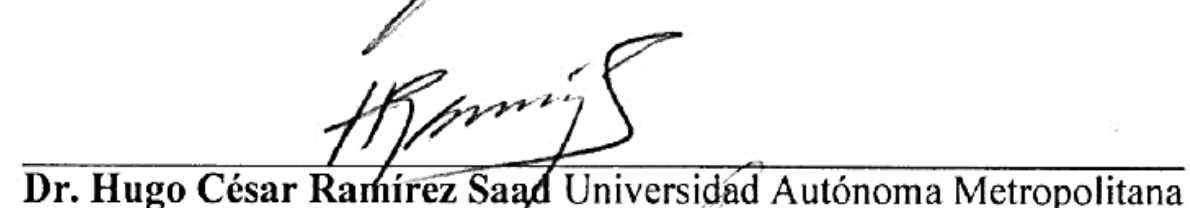

Dr. Hugo César Ramírez Saad Universidad Autónoma Metropolitana

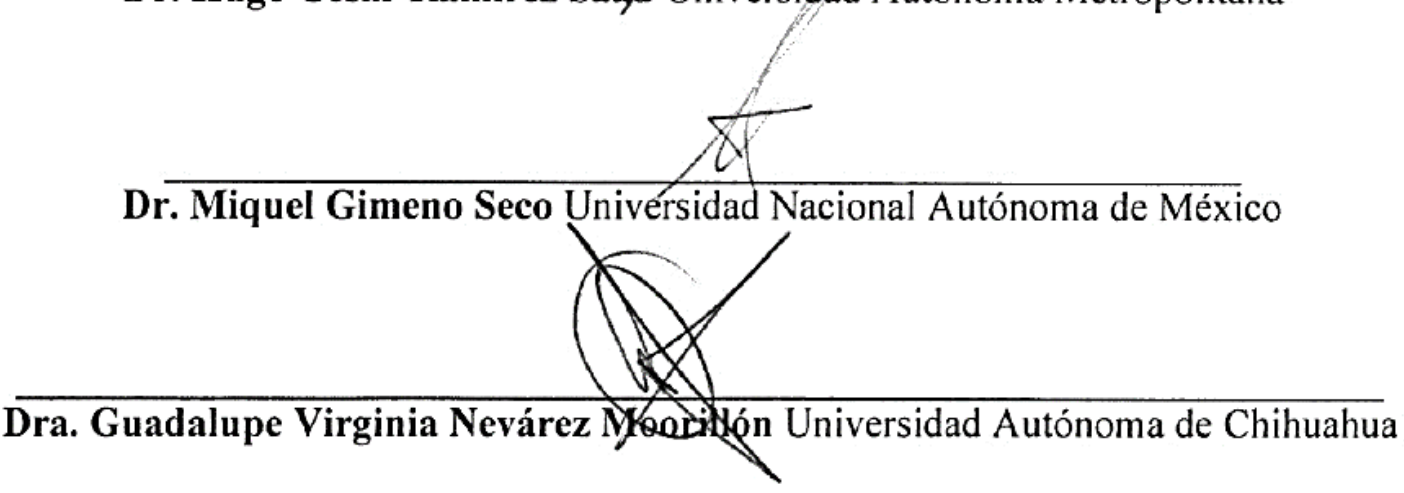


"There is nothing noble in being superior to your fellow man; true nobility is being superior to your former self." - Ernest Hemingway 


\section{Agradecimientos}

A mi amada madre, por su sabiduría y oración.

A Harlen, por siempre estar a mi lado en las buenas y en las malas.

A Marianito, por creer en mí, ser un guía y mostrarme lo que es vivir la ciencia con pasión.

A mis hermanitos académicos; Nes, Peusa y Vik, por apoyarme y darme ánimos, sin importar la distancia.

A Tania, por siempre estar cuando necesité consejo.

Al CONACyT por el apoyo económico.

Y a todo aquel que confió y me apoyó para lograr este paso, cuyo nombre esta noche no recuerdo, si lees esto haz reclamo con una sonrisa cuando me veas y te agradeceré con una mueca. 


\section{Índice General}

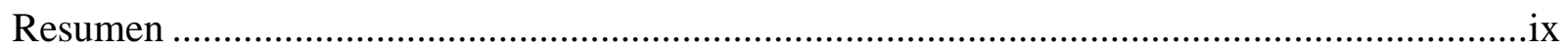

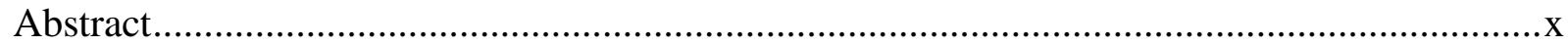

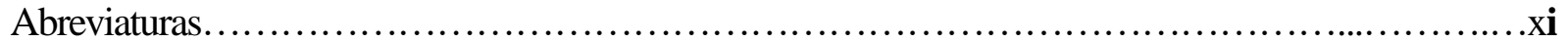

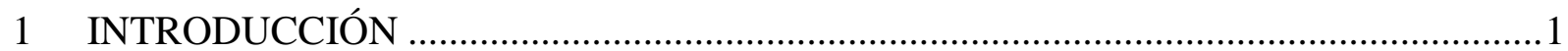

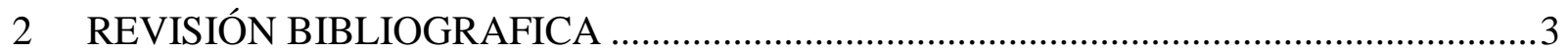

2.1 Biorremediación de sitios contaminados con hidrocarburos ..............................................

2.1.1 Mecanismos para la degradación de hidrocarburos ...................................................

2.1.2 Rutas metabólicas en la asimilación de hidrocarburos ...............................................5

2.2 Bioemulsificantes y el género Acinetobacter ............................................................... 8

2.2.1 Rol de las Biopelículas Exopolisacáridas .............................................................11

2.2.2 Análisis y caracterización de biopelículas de EPS.....................................................12

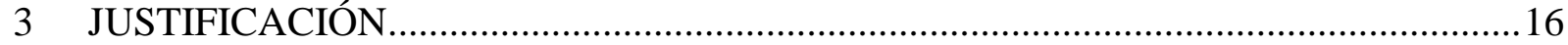

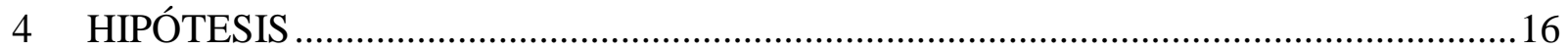

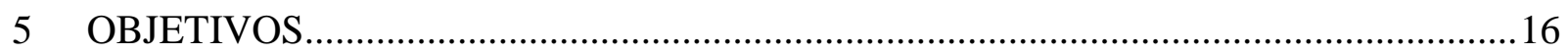

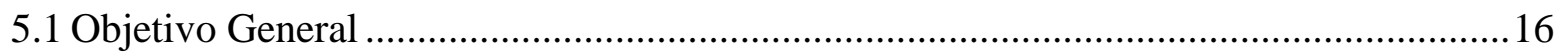

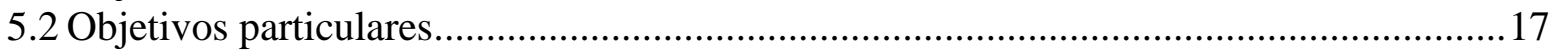

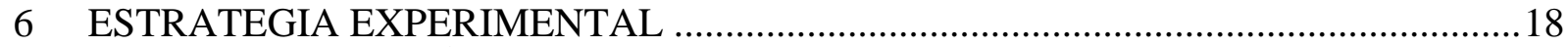

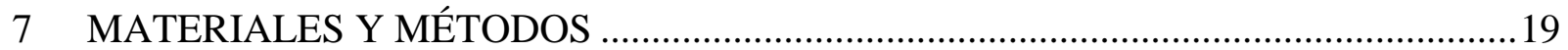

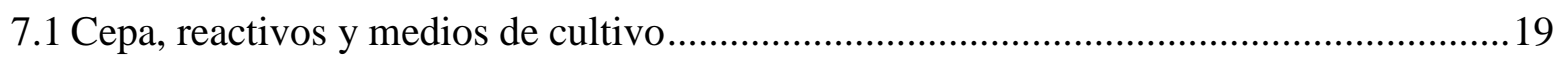

7.2 Identificación bioquímica y molecular del microorganismo ...........................................19

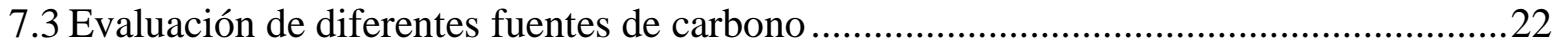

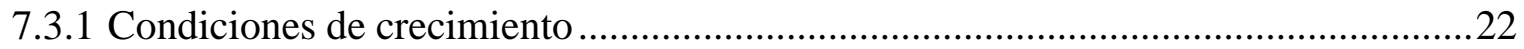

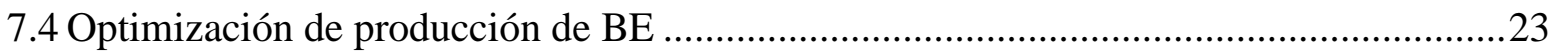

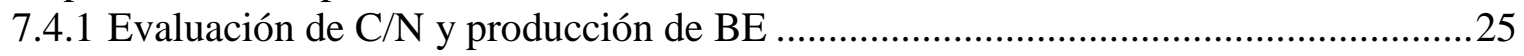

7.4.2 Cinéticas de HXD residual en airlift .................................................................25

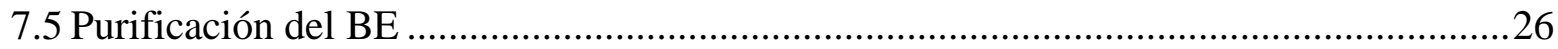

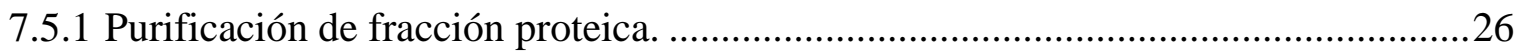

7.5.2 Purificación de fracción carbohidrato .........................................................................2

7.5.3 Determinación del peso molecular del BE por cromatografía de permeación en gel/exclusión de tamaño (SEC).................................................................................29

7.5.4 Análisis por resonancia magnética nuclear $\left({ }^{1} \mathrm{H}\right.$ y ${ }^{13} \mathrm{C}, \mathrm{COSY}$ y NOESY $)$..................30

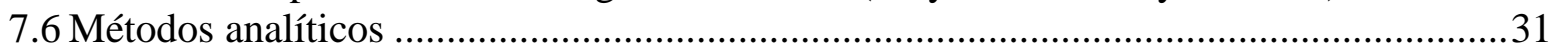

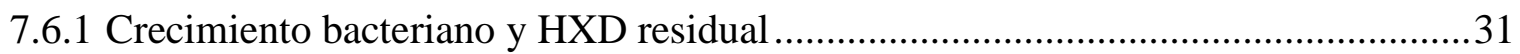

7.6.2 Concentración de carbohidratos y proteínas .................................................................32

7.6.3 Actividad y capacidad emulsificante con HPAs y potencial Z ................................32

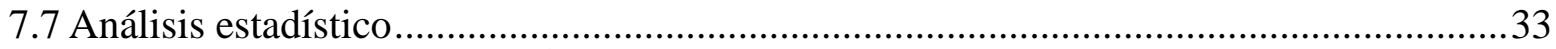

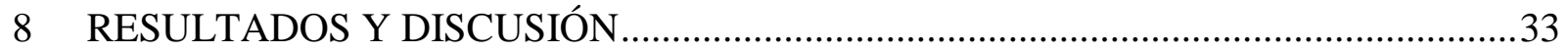

8.1 Identificación bioquímica y molecular del microorganismo .................................................3

8.1.1 Perfil bioquímico de Acinetobacter bouvetii UAM25 ...............................................34

8.1.2 Análisis de secuencias de rDNA 16S ....................................................................36

8.2 Evaluación de diferentes fuentes de carbono y la AE resultante ......................................38

8.3 Optimización de las condiciones de producción del BE................................................42

8.4 Consumo de HXD y capacidad BE en biorreactor airlift.................................................49 
8.4.1 Evaluación del efecto de $\mathrm{Ug}$ en las variables de respuesta ....................................50

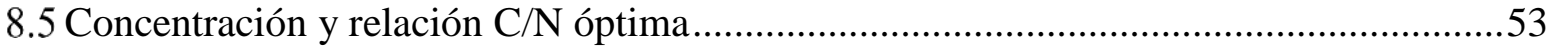

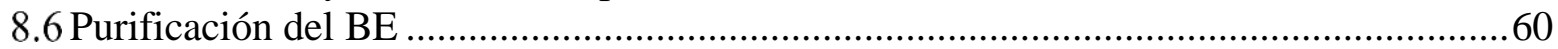

8.6.1 Evaluación de las proteínas del extracto crudo .................................................61

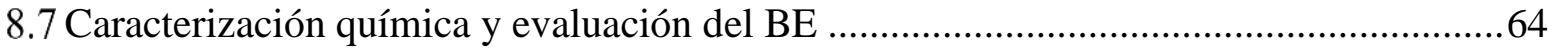

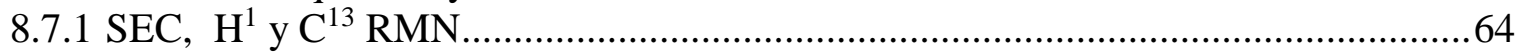

8.7.2 Emulsificación de HPAs y estabilidad cinética de emulsiones .............................71

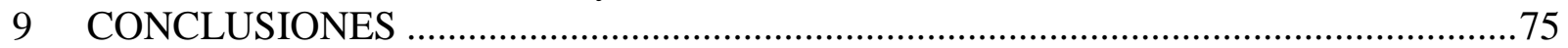

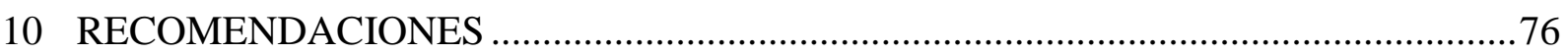

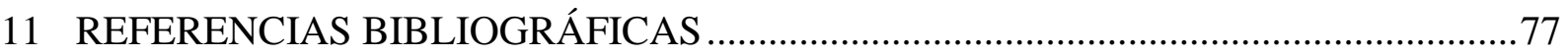

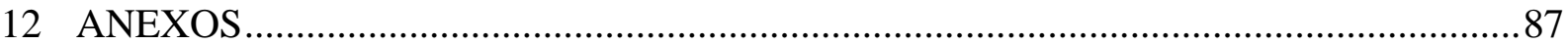

Anexo A. Secuencias de DNA (FASTA) utilizadas para los análisis filogenéticos .............87

Anexo B. Análisis de varianza y efectos principales del diseño central compuesto. ............88

Anexo C Espectro NOESY del BE purificado, la interacción (int) entre componentes anoméricos y alifáticos, señalada en un círculo.........................................................91

Anexo D. Artículo de investigación. ...........................................92

\section{Índice de Figuras}

Figura 1 Especies comunes de hidrocarburos policíclicos aromáticos presentes como contaminantes ....6

Figura 2 Rutas metabólicas de biodegradación de a) alcanos y de b) HPAs ......................................7

Figura 3 Modelo estructural de EPS en bicapa, propuesto por Nielsen \& Jahn (1999); UF, unión fuerte y

UD unión débil de EPS ............................................................................................ 12

Figura 4 Ejemplo de una biopelícula producida sobre una superficie de acero inoxidable de un biorreactor. Tinción con 4,6-diamidino-2-fenilindol para visualizar por microscopia de epifluorescencia. Bar, $20 \mu$,

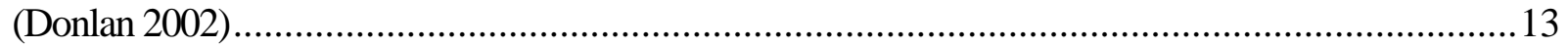

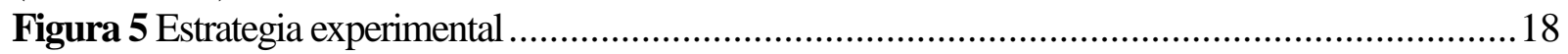

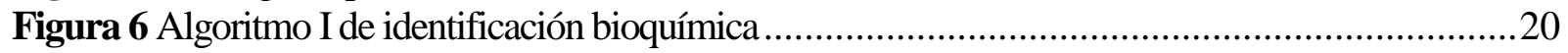

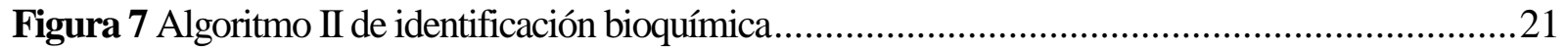

Figura 8 Algoritmo para la optimización del medio de cultivo..................................................24

Figura 9 Biorreactor airlift (BAL) utilizado para la producción de bioemulsificante .........................26

Figura 10 Sistema de diafiltración discontinua y concentración por ultrafiltración .............................29

Figura 11 Equipo HPLC, acoplado a detector RID para el análisis por SEC ..................................30

Figura 12 Morfología macroscópica (a) y microscópica (b) de A. bouvetii UAM25..........................34

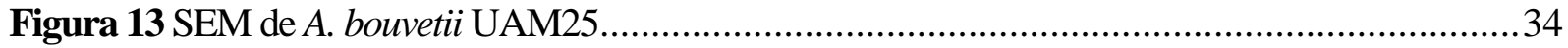

Figura 14 A) A. bouvetii UAM25 en citrato de Simmons; B) control positivo Klebsiella

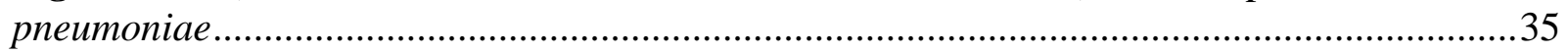

Figura 15 A. bouvetii en prueba de hemólisis en agar sangre ...................................................35

Figura 16 Análisis de correlación absoluta a partir de los perfiles bioquímicos. B. subtilis fue utilizado

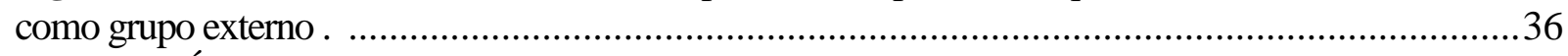

Figura 17 Árbol filogenético, construcción por Neighbor-Joining, Bootstrap: 1000, Kimura 2 modelado gamma = 0.17. Grupo externo; Bacillus sp........................................................................ 37

Figura 18 Árbol filogenético, construcción por Neighbor-Joining, Bootstrap: 1000, Kimura 2 modelado

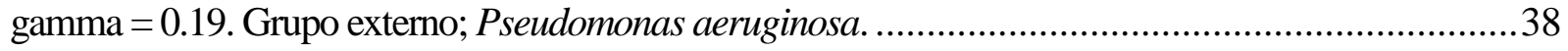

Figura 19 Capacidad de $A$. bouvetii UAM25 para utilizar diferentes fuentes de carbono de naturaleza

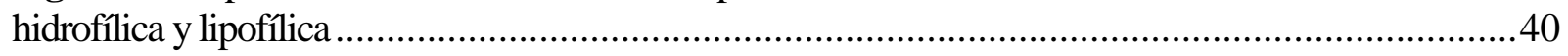


Figura 20 Evaluación de $A$. bouvetii UAM25 en diferentes fuentes de carbono.

Figura 21 Gráfica de contorno (a) y de superficie (b) de la AE vs fuente de nitrógeno y de carbono. c) Diagrama de Pareto de efectos estandarizados $(\alpha=0.05)$..

Figura 22 Resultados experimentales del diseño Path of Steepest Ascent para AE............................45

Figura 23 Superficie de respuesta (a) y gráfica de contorno (b) con respuesta AE............................48

Figura 24 Cinéticas de; degradación de HXD en BAL ..........................................................49

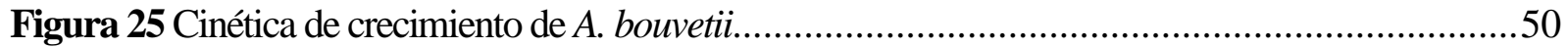

Figura 26 Cinética de crecimiento celular.........................................................................51

Figura 27 Evaluación de los diferentes tratamientos a través de la concentración de los carbohidratos totales (CHOS), de proteína (Prot) y crecimiento celular después de $48 \mathrm{~h}$.

Figura 28 Relación AE con concentración de proteínas. Concentración y unidades de actividad emulsificante indicadas como partes por millón (ppm) y AE respectivamente.

Figura 29 Relación de AE con la concentración de Carbohidratos totales. Concentración y unidades de actividad emulsificante indicadas como partes por millón (ppm) y AE respectivamente.

Figura 30 Crecimiento celular en BAL $\left(\bullet^{\bullet}\right)$, AE $\left({ }^{-}-\Delta^{-}\right)$y HXD residual $\left({ }^{-}-{ }^{-}\right)$. La línea continua corresponde al ajuste del crecimiento por el modelo de Gompertz ..............................................57

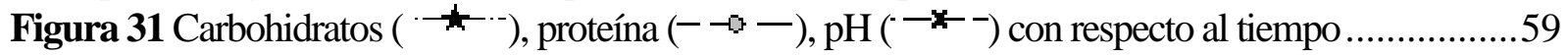
Figura 32 SDS-PAGE de las proteínas obtenidas a 50, 60 y $70 \%$ de saturación con sulfato de amonio62 Figura 33 Cromatograma SEC de BE puro de A. bouvetii UAM25. Se indican los puntos de la curva patrón y la señal del BE puro .....

Figura 34 Señal RID para el BE de A. bouvetii UAM25 aglomerado. ..........................................66

Figura 35 Espectros de RMN de los hidrolizados...................................................................68

Figura 36 Espectros a) 1H RMN y b) 13C RMN de BE puro ...............................................69

Figura 37 Espectro 2D COSY RMN del BE puro con interacciones entre desplazamientos ...............70

Figura 38 AE del BE mezclado con; HXD, HXD: $\beta$-metilnaftaleno (NAP), HXD: pireno (PYR), y HXD:

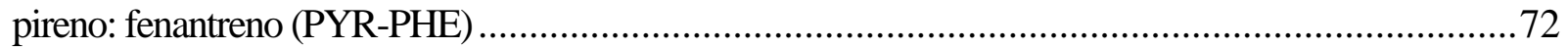

Figura 39 a) Estabilidad cinética de las emulsiones; y b) Potencial $\mathrm{Z}$ a diferentes valores de $\mathrm{pH}$..........74

\section{Índice de Cuadros}

Cuadro I Bioemulsificantes/Biosurfactantes de uso común en la biorremediación ....

Cuadro II Composición general de los polímeros extracelulares (biopelículas) de acuerdo a Nielsen \& Jahn (1999)

Cuadro III Métodos de extracción de EPS (More et al. 2014) ....................................................14

Cuadro IV Diseño factorial $2^{\mathrm{k}}$ para la evaluación del MM ........................................................22

Cuadro V Métodos de hidrólisis aplicados a las muestras de BE, previos al análisis de RMN. ............31

Cuadro VI Diseño Path of Steepest Ascent ........................................................................44

Cuadro VII Diseño Central Compuesto para la optimización de la producción de BE........................47

Cuadro VIII Distribución de BE en el BAL .........................................................................53

Cuadro IX Producción de carbohidratos, proteína y cambio de $\mathrm{pH}$ a las 48 h, utilizando botellas serológicas y BAL

Cuadro X Composición de los extractos obtenidos por las tres diferentes técnicas de purificación

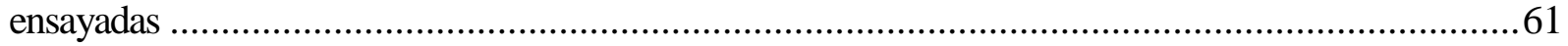

Cuadro XI Purificación de proteínas con carbohidratos asociados y su AE ..................................63

Cuadro XII Resultados de hidrólisis de BE......................................................................67 


\section{Resumen}

Los hidrocarburos aromáticos policíclicos causan contaminación ambiental provocando daño a diversos sistemas ecológicos, por lo que es necesario desarrollar estrategias para la recuperación de estos sitios. Entre las técnicas de restauración actuales, están aquellas que utilizan las propiedades de los microorganismos o de sus metabolitos para la biodegradación de contaminantes, estas técnicas son denominadas como de biorremediación y algunos de los metabolitos relevantes son los bioemulsificantes (BEs). La producción y caracterización de los BEs es de alta relevancia biotecnológica debido a su gran capacidad para mejorar las técnicas de biorremediación. Los objetivos de este trabajo fueron: (i) confirmar la identidad de la cepa productora de BE, UAM25 (ii) producir el BE con la mayor actividad emulsificante bajo condiciones óptimas en botellas serológicas y biorreactores airlift; (iii) purificar y caracterizar parcialmente la biomolécula; y (iv) evaluar la actividad emulsificante del BE utilizando mezclas de $n$-hexadecano, $\beta$-metilnaftaleno, pireno y fenantreno, correlacionando su actividad emulsificante con su estructura química. La identidad a nivel especie de la cepa UAM25 correspondió a la no patógena, bouvetii. Acinetobacter bouvetii UAM25 fue capaz de crecer en fuentes de carbono hidrofílicas e hidrofóbicas, mostrando una dinámica de producción de $\mathrm{BE}$ asociada al crecimiento. Las condiciones de producción de BE con mayor actividad emulsificante se establecieron con una relación Carbono/Nitrógeno de 10.5 en biorreactor airlift, con velocidad superficial de gas $(\mathrm{Ug})$ de $0.6 \mathrm{~cm} \cdot \mathrm{s}^{-1}$ en un medio con fuente de carbono cinco veces más concentrada que las previamente reportadas. El BE producido bajo las mejores condiciones de producción fue purificado, el rendimiento fue de $150 \mathrm{mg} \cdot \mathrm{L}^{-1}$ de $\mathrm{BE}$ puro con peso molecular de 1,010 kDa y con 160 unidades de actividad emulsificante. El BE fue capaz de emulsificar $\mathrm{n}$-hexadecano y $\beta$-metilnaftaleno, así como mezclas de pireno y fenantreno de manera inespecífica. Este nuevo BE muestra una estructura de polisacárido diferente de las previamente reportadas para este mismo género bacteriano. Se observó una alta capacidad del BE para emulsificar hidrocarburos policíclicos aromáticos, al compararlo con emulsificantes comerciales, tales como Tween 80 y Triton X-100. Nuestro trabajo sugiere el potencial de este BE para mejorar técnicas de biorremediación de suelos, sedimentos y agua. 


\section{Abstract}

Polycyclic aromatic hydrocarbons cause environmental pollution, resulting in ecological damages. Therefore, the aim to develop strategies for the recovery of polluted sites recovery. Among the currently used techniques there are those focused on the use of microorganisms or their metabolites in biodegradation. These approaches are commonly known as bioremediation and, some of the relevant metabolites are the bioemulsifiers (BEs). The production and characterization of the BEs have a high biotechnology relevance due to its great capacity for the improvement of bioremediation techniques. The objectives of this work were: (i) to confirm the identity of the BE producer strain, UAM25 (ii) to produce BE in serological flasks and airlift bioreactors, with the highest emulsifying activity under optimum conditions; (iii) to purify and partially characterize the biomolecule; and (iv) to evaluate the emulsifying activity of BE using $\mathrm{n}$-hexadecane, $\beta$-methylnaphthalene, pyrene and phenanthrene blends, then correlating its emulsifying activity with its chemical structure. The identity UAM25 strain was assigned to a non-pathogenic species, of bouvetii. Acinetobacter bouvetii UAM25 was able to grow on hydrophilic and hydrophobic carbon sources, with growth associated BE production. BE production conditions, that results in the highest emulsifying activity, were established as follows: $\mathrm{C} / \mathrm{N}$ ratio of 10.5 in airlift bioreactor, with superficial gas velocity $(\mathrm{Ug})$ of $0.6 \mathrm{~cm} \cdot \mathrm{s}^{-1}$ and carbon source concertation five times higher than previous report. The BE produced under the best production conditions was purified, the yield was $150 \mathrm{mg} \cdot \mathrm{L}^{-1}$ of pure $\mathrm{BE}$ with molecular weight of $1.010 \mathrm{kDa}$ and 160 units of emulsifying activity. The BE was able to emulsify nhexadecane and $\beta$-methylnaphthalene, as well as pyrene and phenanthrene blends in a nonspecific manner. This new $\mathrm{BE}$ shows a polysaccharide structure different from those previously reported for this same bacterial genus. A high BE capacity was observed for emulsifying polycyclic aromatic hydrocarbons compared to commercial emulsifiers such as Tween 80 and Triton X-100. Our work demonstrates the potential of this BE to improve bioremediation techniques of soils, sediments and water. 
$\mathrm{AE}$

AST

BAL

$\mathrm{BE}$

BS

CHOS

COSY

DCC

DGalp

DMSO-d6

EDTA

EPS

$\mathrm{EtOH}$

FID

GalpA

HLB

HPA

HPLC

HXD

Int

$K_{L} a$

LRhap

MM

MW

NAP

NOESY

PDI

PEG
Actividad Emulsificante

Agar soya tripticaseina

Biorreactor airlift

Bioemulsificante

Biosurfactante

Carbohidratos

Espectroscopia de correlación

Diseño central compuesto

$\alpha$-D-galactosa

Dimetilsulfóxido deuterado

Ácido etilendiaminotetraacético

Exopolímero

Etanol

Detector de ionización de flama

$\beta$-D-galactosa

Balance hidrofílico lipofílico

Hidrocarburos policíclicos aromáticos

Cromatografía líquida de alta eficacia

n-Hexadecano

Interacción

Coeficiente de transferencia de oxigeno

$\alpha$-L-ramnosa

Medio mineral

Peso molecular

$\beta$-metilnaftaleno

Espectroscopia de mejoramiento nuclear de Overhauser

Índice de polidispersidad

Polietilenglicol 


$\begin{array}{ll}\text { PHE } & \text { Fenantreno } \\ \text { ppt } & \text { Partes por millón } \\ \text { PTFE } & \text { Politetrafluoroetileno } \\ \text { PYR } & \text { Pireno } \\ \text { RID } & \text { Detector de índice de refracción } \\ \text { RMN } & \text { Resonancia magnética nuclear } \\ \text { SDS-PAGE } & \text { Electroforesis en gel de poliacrilamida con dodecilsulfato sódico } \\ \text { SEC } & \text { Cromatografía de permeación en gel y exclusión de tamaño } \\ \text { SEM } & \text { Microscopia electrónica de barrido } \\ \text { UE } & \text { Unidades de Emulsificación } \\ \text { UFC } & \text { Unidades formadoras de colonias } \\ \text { Ug } & \text { Velocidad de ascenso de aire } \\ X_{\text {max }} & \text { Crecimiento bacteriano máximo } \\ \lambda & \text { Fase lag } \\ \mu_{\max } & \text { Tasa especifica máxima de crecimiento }\end{array}$




\section{INTRODUCCIÓN}

El ambiente es afectado por actividades humanas que liberan contaminantes a los ecosistemas, además, dependiendo de las características físico-químicas de los contaminantes, estos se distribuirán y desplazarán entre los cuerpos receptores finales: agua, aire y suelo. Entre los contaminantes más comunes en el ambiente, destacan los hidrocarburos derivados de actividades petroleras, considerándolos como una mezcla de hidrocarburos de distinta naturaleza, se utilizan ampliamente en la industria, entre otras cosas en forma de combustibles y se constituyen de una mezcla compleja de n-alcanos, aromáticos, resinas, asfaltenos e hidrocarburos policíclicos aromáticos (HPAs), estos últimos pueden ser muy persistentes en sitios contaminados debido a su baja solubilidad en agua, esto restringe su biodisponibilidad para ser degradados (Henry \& Abazinge 2009). El manejo inadecuado de los derivados del petróleo o incluso del crudo mismo se traduce en la contaminación de ambientes. Para evitar la necesidad de la disposición de los sitios contaminados es posible aplicar técnicas de restauración o remediación, con las que se pretende eliminar o disminuir los contaminantes hasta una concentración aceptable con métodos ambientalmente amigables. Entre las técnicas de restauración que se utilizan actualmente, se conocen aquellas que aprovechan las propiedades de los microorganismos o de sus metabolitos para la biodegradación o mineralización del contaminante, estas técnicas se conocen comúnmente como de biorremediación (Ron \& Rosenberg 2001). Estas técnicas utilizan diferentes organismos como hongos, bacterias y plantas que se encuentran de forma natural en el ambiente u organismos genéticamente modificados (Sun et al. 2017). El petróleo y los hidrocarburos que permanecen temporadas prolongadas, actúan como si se encontraran presentes naturalmente en el suelo, lo que ha permitido a muchos microorganismos aclimatarse a su presencia y utilizarlos como fuente de carbono. En el caso de los hidrocarburos, las bacterias Gram negativas parecen encontrarse más adaptadas a estas fuentes de carbono (Wrenn \& Venosa 1996). Entre los organismos más utilizados en estos tipos de restauración se encuentran bacterias del género Acinetobacter que producen enzimas que regulan la degradación de los hidrocarburos y generan compuestos que 
favorecen el contacto con el contaminante hidrofóbico y/o fraccionan este último potencializando su biotransformación (Ron \& Rosenberg 2001).

Un tipo de compuesto producido por Acinetobacter spp., con el que se ha observado una degradación facilitada de hidrocarburos, son los agentes biológicos que modifican la tensión superficial y son capaces de formar emulsiones estables, también conocidos como bioemulsificantes (BEs). En la actualidad se reconocen principalmente como BEs de Acinetobacter spp. al Emulsan de Acinetobacter calcoaceticus, al Alasan de especies como A. radioresistens y en menor medida se han estudiado otros compuestos de especies como A. jonhsonii y A. lwoffii, sin existir hasta ahora un estudio completo del BE producido por $A$. bouvetii. Estos tipos de BEs se distinguen por ser formadores de emulsiones estables que no suelen disminuir sensiblemente la tensión superficial en comparación a los BE de bajo peso molecular (Ivera et al. 2008).

Actualmente, de acuerdo a Web of Science (C 2017 Clarivate Analytics) el término con comodín Bioemulsifier* genera un conjunto de publicaciones responsables de más de 8500 citas, de las cuales más de 2000 corresponden sólo al periodo comprendido entre los años 2015-2017 en donde el interés por este tema demuestra el mayor crecimiento histórico con un $h$-index de 47 y un promedio de 30 publicaciones anuales, con este término para este periodo de tiempo, con un promedio de 5 publicaciones al año relacionadas específicamente con bioemulsificantes de Acinetobacter con un h-index de 30. Es decir, el interés por la temática en general es creciente. Con respecto al interés específico en la emulsificación de hidrocarburos y caracterización de BEs de diferentes microorganismos (términos de búsqueda bioemulsifier characterization hydrocarbons), el máximo interés comenzó a partir del 2014 con un continuo aumento y un $h$ index de 17 y un pico máximo de citas de 138 en el 2016, aumentando en un promedio de 22 citas al año desde el 2013. Todo esto indica un creciente interés por el estudio de las propiedades de los BEs así como de su capacidad en la emulsificación de hidrocarburos, indicando la relevancia del objeto de estudio de la presente tesis para la contribución al conocimiento y desarrollo de tecnología en estos temas específicos.

En el siguiente capítulo se presenta una revisión bibliográfica donde se revisa el estado del arte y se justifica el estudio del BE de A. bouvetii UAM25, sus usos en el campo de la biotecnología, así como la importancia de las características estructurales de estos compuestos con actividad 
emulsificante (AE). Posteriormente se detalla la estrategia experimental con la que se obtuvieron los resultados y se realizaron las discusiones apropiadas. Conclusiones y recomendaciones pertinentes son presentadas en los capítulos 9 y 10. Se ha incorporado una serie de anexos al final del trabajo como soporte a los resultados de análisis estadísticos, químicos y filogenéticos.

\section{REVISIÓN BIBLIOGRAFICA}

\subsection{Biorremediación de sitios contaminados con hidrocarburos}

Uno de los problemas ambientales persistentes, es la contaminación resultante de las actividades relacionadas con el manejo de hidrocarburos, estos pueden contaminar suelo y agua, provocando un importante daño a los sistemas, dado que su acumulación en animales y tejidos vegetales puede causar muerte y mutaciones entre los individuos interrelacionados (Paisio et al. 2016). Los hidrocarburos derivados del petróleo son una mezcla compleja de compuestos químicos, que dependiendo del sistema en que se encuentren su forma de acumulación difiere, por lo que las propiedades de volatilidad, solubilidad y susceptibilidad para ser biodegradados cambian (Speight \& Arjoon 2012). Algunos de los hidrocarburos contaminantes, como los HPAs, tienen características carcinogénicas y mutagénicas, entre estos hidrocarburos se encuentran el pireno (PYR) y el fenantreno (PHE) que son componentes de algunos combustibles de uso automotriz y se han encontrado como parte de mezclas de diésel, contaminando cuerpos acuíferos (Sjögren et al. 1995). Una de las estrategias ambientalmente amigables, que se puede utilizar para recuperar sitios contaminados con hidrocarburos, es aquella que utiliza la capacidad de los microorganismos para degradarlos. Este conjunto de técnicas se denominan biorremediación. Esta se enfoca en la biodegradación, es decir, la mineralización de compuestos orgánicos transformándolos en $\mathrm{CO}_{2}, \mathrm{H}_{2} \mathrm{O}$, compuestos inorgánicos y proteínas celulares, así como a su transformación a complejos orgánicos más sencillos no tóxicos para el ambiente (Gargouri et al. 2014).

Las técnicas de biorremediación pueden ser de tipo aerobio o anaerobio (oxidativo o reductor, respectivamente); sin embargo, los microorganismos capaces de biorremediar el suelo se verán afectados por las características de los sistemas ( $\mathrm{pH}$, salinidad y materia orgánica, entre otros). Por ejemplo, una salinidad extremadamente alta o un $\mathrm{pH}$ muy bajo son capaces de desnaturalizar la estructura terciaria de las proteínas, precipitarlas, modificar los componentes polisacáridos de 
sus metabolitos y deshidratar células, es decir, significa la destrucción de los organismos nativos del sistema y de las enzimas necesarias para el metabolismo de nutrientes (Speight \& Arjoon 2012). La recuperación de un sistema ecológico contaminado utilizando las propiedades de los microorganismos, puede ser debida a la solubilización del contaminante utilizando metabolitos con actividad en superficie o con capacidad de pseudosolubilizar y/o emulsificar hidrocarburos complejos, metabolitos como las moléculas anfipáticas BEs. Con esto los contaminantes podrán estar más susceptibles para ser biodegradados (Barkay et al. 1999). Los BE tienen varias ventajas sobre los emulsificantes sintéticos. Los BEs son biodegradables y no representan riesgo al ambiente, además, existe evidencia que estos no son tóxicos para otros microorganismos y por lo tanto no inhiben la biodegradación de los contaminantes orgánicos (Beltrani et al. 2015). El entendimiento de la forma en que se producen estos BEs y la evaluación de sus capacidades asociadas a sus características fisicoquímicas, es relevante para el diseño de tratamientos de biorremediación.

\subsubsection{Mecanismos para la degradación de hidrocarburos}

Para diseñar técnicas de biorremediación efectivas es necesario entender los mecanismos de biodegradación y cómo son afectados por diversos parámetros fisicoquímicos y biológicos, incluidas la cantidad de microorganismos, la concentración de nutrientes y sales, el pH y la temperatura, la bioaccesibilidad al contaminante, así como las condiciones de la matriz o sitio a remediar (Speight \& Arjoon 2012). Con el objetivo de conocer y controlar estos parámetros, es conveniente simular o producir los metabolitos de manera ex situ en biorreactores que favorezcan su producción y posterior purificación (Guo et al. 2015). Conforme el peso molecular y la complejidad del hidrocarburo incrementa, la biodegradación se dificulta, por esto la mineralización de poliaromáticos es más lenta que la de monoaromáticos (Haritash \& Kaushik 2009). Algunos de los HPAs presentes como contaminantes se muestran en la Figura 1, mientras las principales rutas de biodegradación de hidrocarburos alifáticos y aromáticos se muestran en la Figura 2. Para que los hidrocarburos sean biodegradados debe ocurrir un aumento de la disponibilidad biológica del sustrato hidrófobo a los microorganismos, con la consiguiente emulsificación, pseudosolubilización o en algunos casos reducción de tensión superficial del medio alrededor de la bacteria y la reducción de la tensión interfacial entre la pared celular 
bacteriana y las moléculas de hidrocarburo. Otro mecanismo involucra la interacción entre el BE y la superficie celular, promoviendo modificaciones en la membrana, facilitando la adherencia a los hidrocarburos (aumento de la hidrofobicidad) y reduciendo el índice de lipopolisacáridos de la pared celular sin dañar la membrana (Souza et al. 2014) favoreciendo el contacto directo del microorganismo con el hidrocarburo.

\subsubsection{Rutas metabólicas en la asimilación de hidrocarburos}

Para la degradación de hidrocarburos, es necesario que los microorganismos estén provistos de monooxigenasas, responsables de catalizar la oxidación de alcanos en un metilo terminal, para la consecuente producción de un alcohol primario, el procesamiento posterior transforma este alcohol primario a un ácido graso degradable por la vía clásica de la $\beta$-oxidación. Hidrocarburos como el n-hexadecano (HXD) son ampliamente utilizados como compuesto modelo en el estudio de la biodegradación de alcanos (Whyte et al. 2002), este hidrocarburo también ha sido reportado como fuente de carbono útil en la producción de BEs (Liu et al. 2010). Como resultado de la degradación de hidrocarburos, microorganismos como Acinetobacter spp. pueden producir moléculas con actividad en superficie capaces de emulsificar los contaminantes orgánicos no polares. 


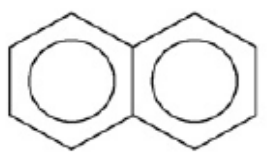

Naftaleno

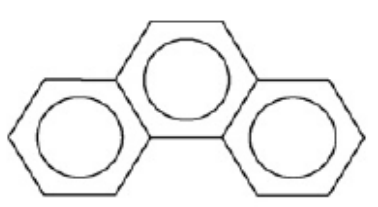

Fenantreno

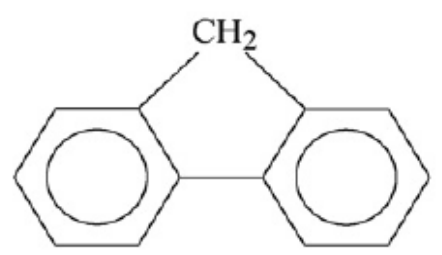

Fluoreno

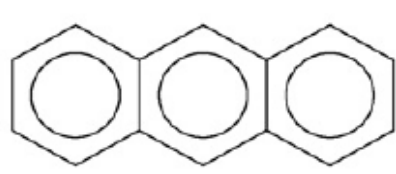

Antraceno

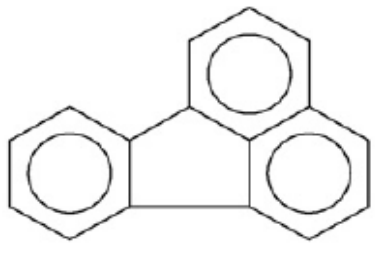

Fluoranteno

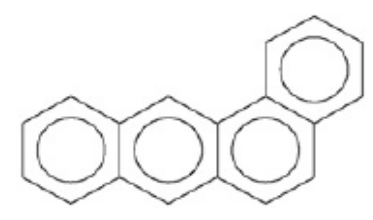

Benzo(a)antraceno<smiles>c1cc2ccc3cccc4ccc(c1)c2c34</smiles>

Pireno

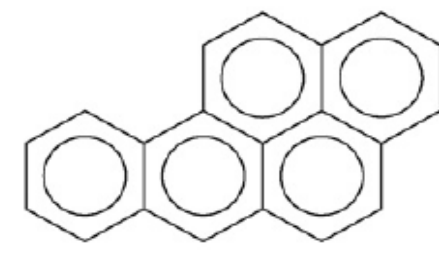

Benzo(a)pireno

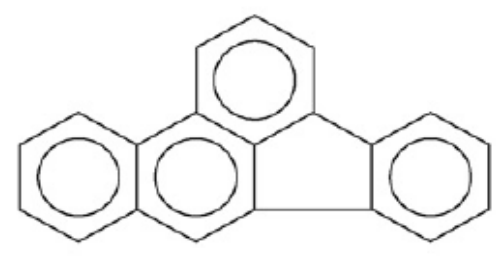

Benzo(a)fluoranteno

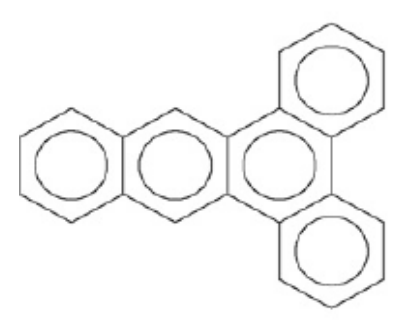

$\operatorname{Dibenz}(\mathbf{a}, \mathbf{c})$ antraceno

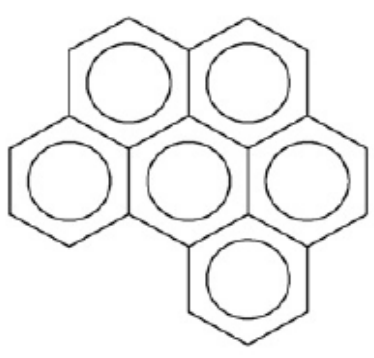

Benzo(g,h,i)perileno

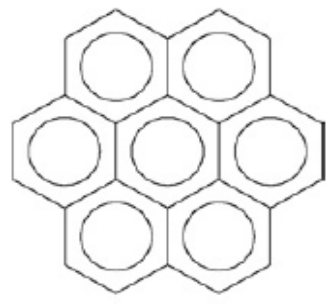

Coroneno

Figura 1 Especies comunes de hidrocarburos policíclicos aromáticos presentes como contaminantes. Fuente: Haritash \& Kaushik, 2009 
b)

a)
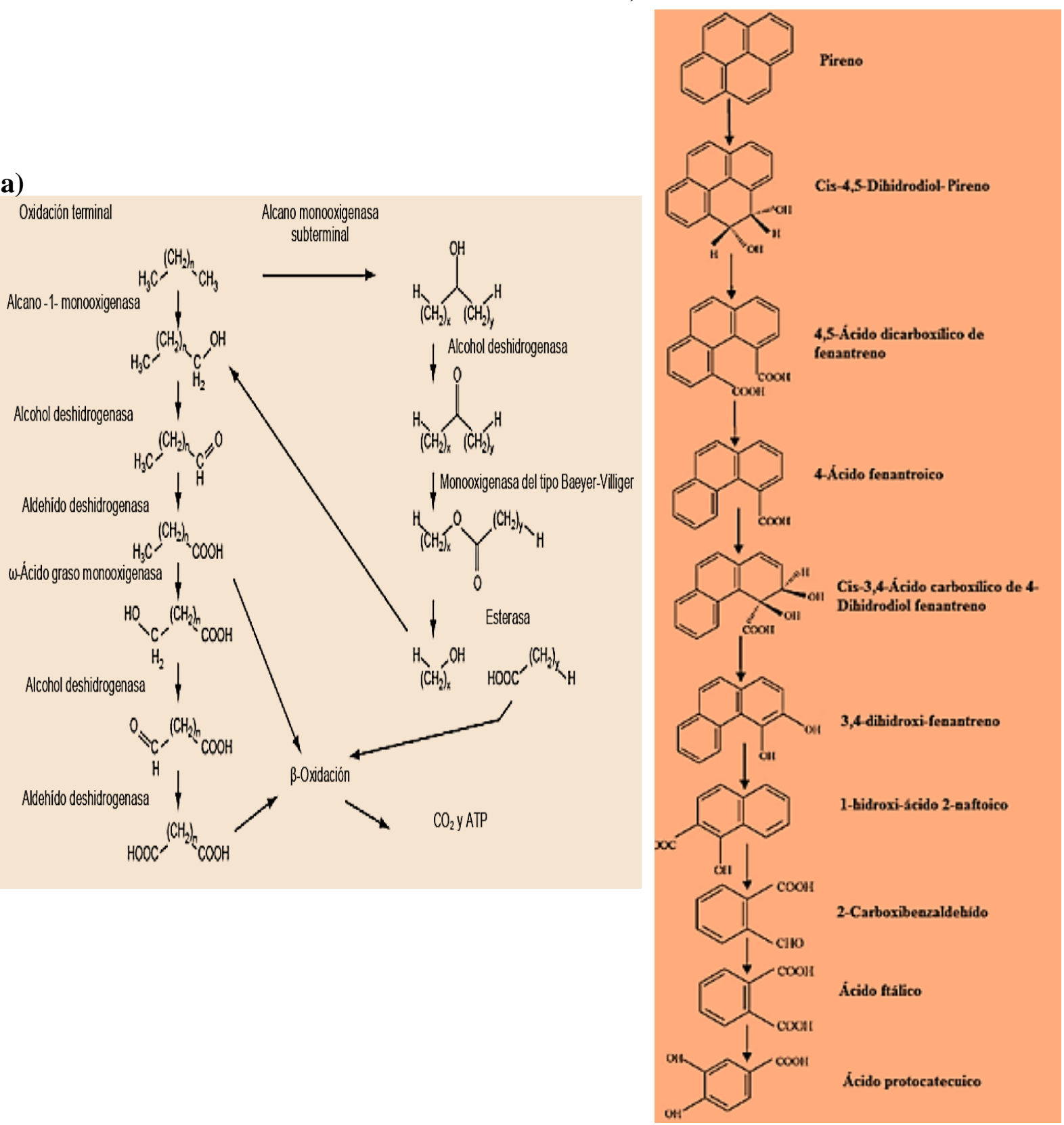

Figura 2 Rutas metabólicas de biodegradación de a) alcanos y de b) HPAs.

Fuente: Ashraf et al. 1994; Haritash \& Kaushik 2009 


\subsection{Bioemulsificantes y el género Acinetobacter}

Se han definido hasta este punto a los BEs como biomoléculas biodegradables auxiliares para remediar sitios contaminados con hidrocarburos. Pero también es necesario entender a estos compuestos como moléculas anfipáticas, con porciones hidrófobas e hidrofílicas que actúan entre fluidos de diferentes polaridades (aceite/agua y agua/aceite), permitiendo el acceso a sustratos hidrófobos y provocando cambios tales como la reducción de la tensión superficial cuando su actividad principal es biosurfactante, y afectando el área de contacto de compuestos insolubles (tales como hidrocarburos), su movilidad, biodisponibilidad y, posteriormente, su biodegradación cuando su actividad principal es bioemulsificante (Souza et al. 2014). Los términos biosurfactantes (BSs) y BEs son utilizados frecuentemente de manera intercambiable; sin embargo, estas moléculas presentan algunas diferencias. Los BEs suelen diferenciarse por tener mayor peso molecular y poca o nula capacidad para disminuir la tensión superficial del agua de manera inmediata (Uzoigwe et al. 2015), parte de la confusión es resultado de la propiedad de algunos BSs, de tener capacidad emulsificante además de surfactante. En el Cuadro I se enlistan algunos de los BS/BE más reportados en la literatura, estos pueden diferenciarse por sus características químicas y por el microorganismo productor. Diferentes factores influyen en el tipo y calidad del BE que los microorganismos producen, por ejemplo, las condiciones del medio y la fuente de carbono disponible, así como su relación con otros componentes como el nitrógeno (Beltrani et al. 2015). 


\section{Cuadro I Bioemulsificantes/Biosurfactantes de uso común en la biorremediación}

\begin{tabular}{|c|c|c|c|}
\hline Clase & $\mathrm{BE} / \mathrm{BS}$ & Microorganismo productor & Referencia \\
\hline \multirow[t]{13}{*}{$\begin{array}{l}\text { Bajo peso } \\
\text { molecular }\end{array}$} & Rhamnolípidos & Pseudomonas aeruginosa & Ghosh \& Mukherji 2016 \\
\hline & Trehalolípidos & $\begin{array}{r}\text { Arthrobacter paraffineus } \\
\text { Rhodococcus erythropolis } \\
\text { Mycobacterium }\end{array}$ & $\begin{array}{r}\text { Franzetti et al. } 2010 \\
\text { Yalçin \& Ergene } 2009 \\
\text { M'rassi et al. } 2015\end{array}$ \\
\hline & Soforolípidos & $\begin{array}{r}\text { Candida lipolytica } \\
\text { Torulopsis bombicola }\end{array}$ & $\begin{array}{r}\text { Monteiro et al. } 2010 \\
\text { Singh } 2012\end{array}$ \\
\hline & Vicosina & Pseudomona libanensis & Saini et al. 2008 \\
\hline & Surfactina & Bacillus subtilis & Sousa et al. 2012 \\
\hline & Polimixinas & Bacillus polymyxa & Ron \& Rosenberg 2001 \\
\hline & Gramicidina $S$ & Bacillus brevis & Singh 2012 \\
\hline & Fosfolípidos & $\begin{array}{r}\text { Acinetobacter spp. } \\
\text { Thiobacillus thiooxidans }\end{array}$ & $\begin{array}{l}\text { Ron \& Rosenberg } 2001 \\
\text { Beebe \& Umbreit } 1971\end{array}$ \\
\hline & Flavolípidos & Flavobacterium sp. & Bodour et al. 2004 \\
\hline & Lipopéptidos & $\begin{array}{r}\text { Bacillus subtilis } \\
\text { Bacillus licheniformis } \\
\text { Pseudomonas fluorescens }\end{array}$ & $\begin{array}{r}\text { Sousa et al. } 2012 \\
\text { Javaheri et al. } 1985 \\
\text { Janek et al. } 2010\end{array}$ \\
\hline & $\begin{array}{l}\text { Péptidos de ornitina y } \\
\text { lisina }\end{array}$ & Streptomyces tendae & Zambry et al. 2017 \\
\hline & Lípidos de polioles & Rhodotorula glutinis & Easterling et al. 2009 \\
\hline & Ácidos grasos & $\begin{array}{l}\text { Nocardia erythropolis } \\
\text { Penicillium spiculisporum }\end{array}$ & $\begin{array}{r}\text { Park et al. } 1998 \\
\text { Pacwa et al. } 2011\end{array}$ \\
\hline \multirow[t]{8}{*}{$\begin{array}{l}\text { Alto peso } \\
\text { molecular }\end{array}$} & Sulfonolípidos & Starmerella bombicola & Konishi et al. 2015 \\
\hline & Diglicosil diglicéridos & Capnocytophaga sp. & Holt et al. 1979 \\
\hline & Alasan & Acinetobacter radioresistens & Toren et al. 2001 \\
\hline & Emulsan & Acinetobacter calcoaceticus RAG-1 & Rosenberg et al. $1979 \mathrm{a}$ \\
\hline & Biodispersan & Acinetobacter calcoaceticus A2 & Elkeles et al. 1994 \\
\hline & Liposan & Candida lipolytica & Cirigliano \& Carman 1985 \\
\hline & Acetil heteropolisacárido & Sphingomonas paucimobilis & Hashimoto \& Murata 1998 \\
\hline & $\begin{array}{l}N \text {-acetil y } O \text {-piruvil } \\
\text { heteropolisacárido }\end{array}$ & Pseudomonas fluorescens & Janek et al. 2010 \\
\hline
\end{tabular}


Los BEs pueden producirse asociados al crecimiento celular y pueden químicamente estar compuestos por mezclas de heteropolisacáridos, lipoproteínas, lipopolisacáridos y/o proteínas, por lo que también se les denomina BE exopolisacáridos (Smyth et al. 2010). En el caso de su aplicación en biorremediación los BEs pueden unirse a los hidrocarburos y dispersarlos en forma de emulsiones que pueden perdurar por varios días, incluso semanas, favoreciendo la biodegradación de los contaminantes (Uzoigwe et al. 2015).

Entre los productores principales de BEs se encuentran varias especies del género Acinetobacter. Este género está compuesto por bacterias Gram-negativas, no formadoras de esporas, no móviles, son microorganismos aerobios estrictos, catalasa positivos y oxidasa negativos y se distribuyen ampliamente en el ambiente, algunas especies pueden encontrarse en ambientes hospitalarios. Los BEs de Acinetobacter spp. más estudiados son; Emulsan, Alasan y Biodispersan. El Emulsan de Acinetobacter RAG-1 es un heteropolisacárido aniónico y proteico cuya actividad superficial se debe a la presencia de ácidos grasos unidos a sus estructuras polisacáridas vía uniones $O$-ester y $N$-acil, presenta una alta especificidad a sustrato, si bien no es altamente efectivo al emulsificar compuestos aromáticos o hidrocarburos cíclicos, estos contaminantes pueden ser eficientemente emulsificados si están presentes en concentraciones relativamente bajas y en mezcla con hidrocarburos alifáticos (Ron \& Rosenberg 2001). A. calcoaceticus BD4 produce una cápsula de polisacáridos, que bajo condiciones apropiadas, se libera al medio junto con proteínas unidas a la misma, generando un emulsificante altamente eficiente, en este caso, la cápsula y las proteínas no tienen actividad emulsificante por si solas, pero juntas funcionan como un BE, esto se puede demostrar al mezclar los polisacáridos purificados de la cápsula con las proteínas, resultando en la reconstitución de la actividad emulsificante (Kaplan \& Rosenberg 1982). El Alasan, es un emulsificante producido por cepas de $A$. radioresistens, tiene un peso molecular de aproximadamente $1 \times 10^{6} \mathrm{Da}$; la diferencias principales que tiene con respecto del Emulsan es que en su parte estructural proteica tiene un enlace covalente con alanina y a estas estructuras proteicas se les atribuye la actividad emulsificante (Toren et al. 2001). Otro BE de Acinetobacter, el Biodispersan, con peso molecular de $52.4 \mathrm{kDa}$, es un EPS que originalmente se ha detectado como un producto extracelular de cepas de A. calcoaceticus A2, es eficiente dispersando dióxido de titanio y piedra caliza pero no es utilizado ampliamente como emulsificante (Rosenberg et al. 1988). 
Las diferencias entre las características estructurales químicas que existen entre los diferentes BEs de Acinetobacter spp. ponen en evidencia que, dependiendo de la especie dentro del género, podría cambiar el tipo de BE que se produce, y este BE puede cumplir una función específica en la degradación de hidrocarburos o puede ser producido como parte de un mecanismo de colonización de superficies y supervivencia en forma de biopelícula.

\subsubsection{Rol de las Biopelículas Exopolisacáridas}

Las biopelículas, son un tipo de agregado celular, el cual es posible por la producción de substancias poliméricas extracelulares. Otros tipos de agregados diferentes a las biopelículas son los flóculos de lodos activados y la nieve marina. En cualquier caso estos compuestos son importantes para la actividad de los microorganismos que requieren superar condiciones hostiles de crecimiento o para aquellas bacterias no motiles - e.g., aquellas dentro del género Acinetobacter - que dependen de esta formación de agregados para lograr lo colonización de superficies (Doughari et al. 2011). Las biopelículas pueden encontrarse en forma de geles y sus propiedades fisicoquímicas están gobernadas por factores como; $\mathrm{pH}$, disponibilidad de iones, intercambio de oxígeno, entre otros. Las biopelículas pueden ser clasificadas dependiendo de su composición química (Cuadro II).

Cuadro II Composición general de los polímeros extracelulares de acuerdo a Nielsen \& Jahn (1999)

\begin{tabular}{|c|c|c|c|c|}
\hline $\begin{array}{l}\text { Polímero } \\
\text { extracelular }\end{array}$ & $\begin{array}{l}\text { Componentes principales } \\
\text { (subunidades, precursores) }\end{array}$ & $\begin{array}{l}\text { Tipo principal de } \\
\text { enlace entre unidades }\end{array}$ & $\begin{array}{l}\text { Estructura del esqueleto } \\
\text { del polímero }\end{array}$ & $\begin{array}{l}\text { Sustituyentes } \\
\text { (ejemplos) }\end{array}$ \\
\hline Exopolisacáridos & $\begin{array}{l}\text { monosacáridos } \\
\text { ácidos urónicos } \\
\text { amino-azúcares }\end{array}$ & enlace glucosídico & lineal, ramificada & $\begin{array}{l}\text { orgánicos: } O \text {-acetilo, } \mathrm{N} \text {-acetilo, } \\
\text { succinilo, piruvilo } \\
\text { inorgánicos: sulfato, fosfato }\end{array}$ \\
\hline $\begin{array}{l}\text { Proteínas } \\
\text { (polipéptidos) }\end{array}$ & aminoácidos & enlace peptídico & lineal & $\begin{array}{l}\text { oligosacáridos (glucoproteínas), } \\
\text { ácidos grasos (lipoproteínas) }\end{array}$ \\
\hline Ácidos nucleicos & nucleótidos & enlaces fosfodiéster & lineal & - \\
\hline \multirow[t]{2}{*}{ (Fosfo)lípidos } & $\begin{array}{l}\text { ácidos grasos } \\
\text { glicerol }\end{array}$ & enlaces éster & cadenas laterales & - \\
\hline & $\begin{array}{l}\text { fosfato } \\
\text { etanolamina } \\
\text { serina } \\
\text { colina } \\
\text { azúcares }\end{array}$ & & & \\
\hline Compuestos húmicos & $\begin{array}{l}\text { compuestos fenólicos } \\
\text { azúcares simples } \\
\text { aminoácidos }\end{array}$ & $\begin{array}{l}\text { enlaces éter, C-C y } \\
\text { peptídicos }\end{array}$ & de enlace cruzado & - \\
\hline
\end{tabular}


Dentro de esta clasificación de exopolímeros (EPS) se encuentran las biopelículas de naturaleza exopolisacárida, de aquí se puede generalizar a este tipo de biopelículas como, de EPS unido y de EPS soluble (Fig 3). Las biopelículas con EPS unido a células resultan de la producción de polímeros capsulares y sustancias gelosas que favorecen la unión a compuestos orgánicos, es decir tienen tanto funciones infectivas y de protección como de ajuste de hidrofobicidad de pared celular. Las biopelículas con EPS soluble, corresponden principalmente a coloides y macromoléculas solubles - e.g., los BEs - que pueden provenir de la despolimerización del EPS unido a células (Nielsen \& Jahn 1999).

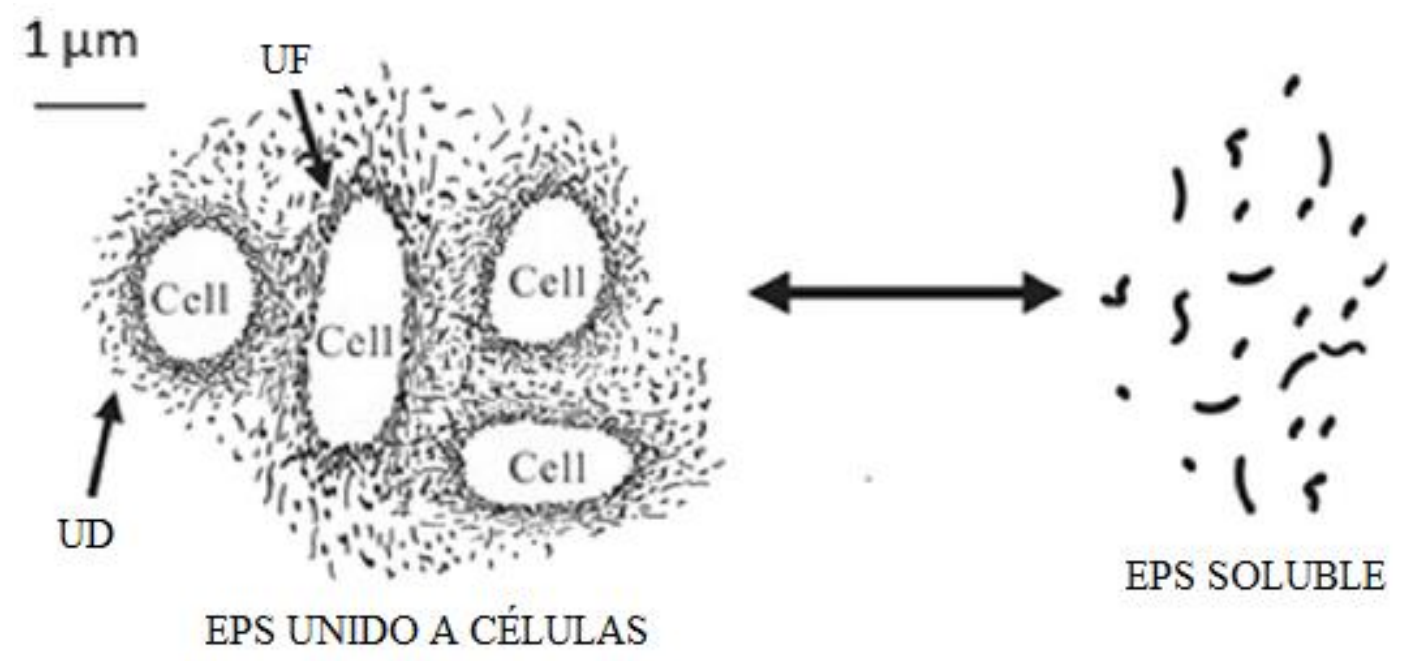

Figura 3 Modelo estructural de EPS en bicapa, propuesto por Nielsen \& Jahn (1999); UF, unión fuerte y UD unión débil de EPS

En general, una de las funciones más importantes de los EPS es conferir estabilidad estructural a la matriz de las biopelículas mediante interacciones no covalentes entre las cadenas de polisacáridos o indirectamente vía puentes catiónicos multivalentes (Marin et al. 1996).

\subsubsection{Análisis y caracterización de biopelículas de EPS}

Dado que la mayoría de los EPS son de consistencia gelosa, para poder analizar y caracterizarlos, es necesario utilizar técnicas apropiadas para solubilizarlos, por medio del rompimiento de las interacciones entre las cadenas laterales de los polisacáridos que los componen (Meisen et al. 
2008). Se describe a continuación una secuencia típica para el análisis y caracterización de biopelículas de EPS:

\section{Muestreo y pretratamiento}

Obtención de la muestra proveniente del ambiente o de biorreactores (Fig 4), los pretratamientos incluyen el lavado, homogenización de la muestra y en algunos casos ajuste de $\mathrm{pH}$ (Satpute et al. 2010):

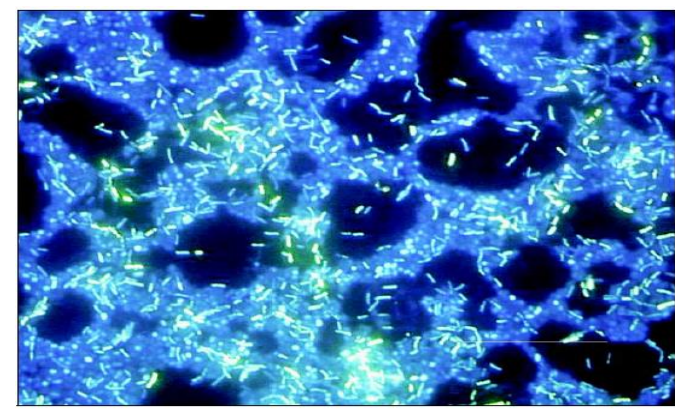

Figura 4 Ejemplo de una biopelícula producida sobre una superficie de acero inoxidable de un biorreactor. Tinción con 4,6-diamidino-2-fenilindol para visualizar por microscopia de epifluorescencia. Bar, $20 \mu$, (Donlan 2002)

\section{Extracción y purificación}

Los EPS se extraen por el método apropiado de acuerdo al tipo de polímero y al medio de cultivo donde se producen, en el cuadro III se muestran los principales métodos de extracción de EPS de acuerdo a More et al. 2014. 


\section{Cuadro III Métodos de extracción de EPS (More et al. 2014)}

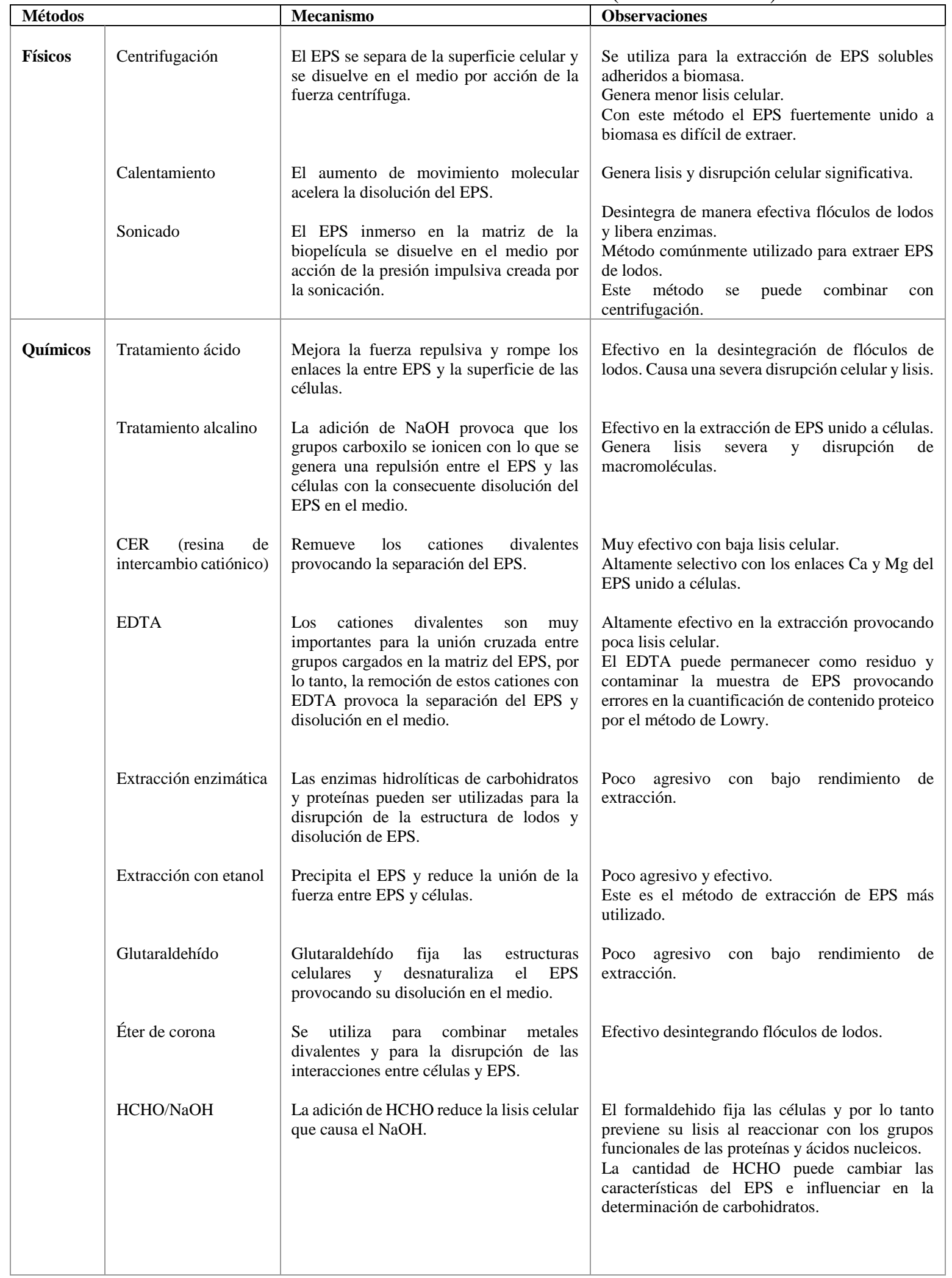




\begin{tabular}{|l|l|l|l|}
\hline $\mathrm{NaCl}$ & $\begin{array}{l}\text { La adición de altas concentraciones de } \\
\mathrm{NaCl} \text { favorece el intercambio catiónico. }\end{array}$ & Método no agresivo y de bajo costo. \\
& $\mathrm{NH}_{4} \mathrm{OH} /$ EDTA & $\begin{array}{l}\text { Este método combina al ajuste de pH y a } \\
\text { los métodos de intercambio iónico para } \\
\text { mejorar la eficiencia de extracción. } \\
\text { Utilizar un álcali fuerte como el } \mathrm{NH}_{4} \mathrm{OH} \\
\text { reduce la lisis celular. }\end{array}$ & Desintegra de manera efectiva flóculos de lodos. \\
\hline
\end{tabular}

Algunos métodos son lo suficientemente efectivos para extraer BEs EPS con alta pureza, pero algunos métodos requieren de un posterior paso de remoción de impurezas como sales y residuos de fuente de carbono. La ultrafiltración es un método de remoción de impurezas que por sí solo puede funcionar como método de extracción cuando los volúmenes de muestra son pequeños. Este método permite el paso de pequeñas moléculas del caldo de cultivo, como sales, aminoácidos, ácidos orgánicos, alcoholes y otros metabolitos al tiempo que las macromoléculas de EPS se concentran en una membrana de corte específico (Satpute et al. 2010).

\section{Análisis}

Si bien los BE son analizados funcionalmente a través de la determinación de su actividad emulsificante y estructuralmente por su tamaño molecular por cromatografía de permeación en gel y exclusión de tamaño (SEC). Los BE como EPS son usualmente analizados para la identificación de componentes macromoleculares (e.g., polisacáridos y proteínas), en algunos casos es necesario utilizar técnicas analíticas de mayor resolución como la resonancia magnética nuclear (RMN) para determinación de las estructuras químicas, su interrelación y su efecto en la actividad bioemulsificante. La combinación de diversidades estructurales y la limitada dispersión de señales en los espectros de RMN de carbohidratos de EPS hacen relativamente difícil la interpretación de estos. Esta técnica permite analizar el tipo de azúcares que componen los EPS. En conjunto con el análisis de compuestos marcados en ${ }^{13} \mathrm{C}$ la sensibilidad de la técnica aumenta y con esto el espacio conformacional ocupado por los carbohidratos y las interacciones entre grupos funcionales pueden ser definidas a través del análisis de espectros en 1- y 2-D (Bubb 2003). 


\section{JUSTIFICACIÓN}

Se conocen diferentes sitios contaminados con altas concentraciones de hidrocarburos, incluyendo HPAs poco solubles en agua, que demandan atención y remedio. Se sabe que los BEs de las cepas del género Acinetobacter spp. son eficientes facilitadores de la degradación de hidrocarburos y son capaces de solubilizar HPAs; sin embargo, la manera en la que el BE es producido depende de la especie de Acinetobacter, el tipo de ambiente y la naturaleza del hidrocarburo contaminante; a su vez, la naturaleza del BE que se produce determina el mecanismo por el cual los hidrocarburos pueden llegar a ser biodegradados. La purificación, caracterización química y evaluación de la capacidad para emulsificar hidrocarburos del BE producido por A. bouvetii UAM25 son relevantes porque permitirán contribuir: (i) al diseño de tratamientos novedosos altamente efectivos en la recuperación de sitos contaminados por hidrocarburos, (ii) al entendimiento de la naturaleza físico-química del BE y la estabilidad de las emulsiones producidas y (iii) a entender la forma en la que emulsifica compuestos orgánicos en medios acuosos.

\section{HIPÓTESIS}

El bioemulsificante que produce Acinetobacter bouvetii UAM25 presenta una estructura química novedosa y es competente para emulsificar hidrocarburos policíclicos aromáticos.

\section{OBJETIVOS}

\subsection{Objetivo General}

Producir, purificar y caracterizar parcialmente el bioemulsificante de Acinetobacter bouvetii UAM25 y evaluar su funcionalidad en la emulsifación de hidrocarburos policíclicos aromáticos. 


\subsection{Objetivos particulares}

- Comprobar la especie de la cepa UAM25.

- Encontrar las condiciones de operación a nivel de laboratorio de mayor producción del bioemulsificante por la cepa UAM25.

- Purificar el bioemulsificante a partir de extractos libres de células.

- Caracterizar parcialmente la estructura química del bioemulsificante producido e identificar los componentes que le confieren la actividad emulsificante.

- Determinar la capacidad bioemulsificante en mezclas con hidrocarburos policíclicos aromáticos, así como la estabilidad de las emulsiones. 


\section{ESTRATEGIA EXPERIMENTAL}

En la Figura 5 se presenta la estrategia experimental. El primer paso fue la identificación de la especie de Acinetobacter, que permitió tener certeza de que la especie no pertenecía a alguna con propiedades patógenas, dado que hallazgos a partir del análisis molecular de secuencias de DNA indicaron que UAM25 podría tener la identidad haemolyticus y no la previamente reportada por Tzintzun-Camacho et al. (2012). La siguiente etapa fue la producción de BE en cantidad suficiente para facilitar su purificación a partir del sobrenadante libre de células. Si bien la caracterización química se llevó a cabo a partir del BE puro, el análisis preliminar del sobrenadante proporcionó información sobre la naturaleza química del BE. La evaluación de capacidad emulsificante se realizó correlacionando con las características químicas y estructurales del BE.

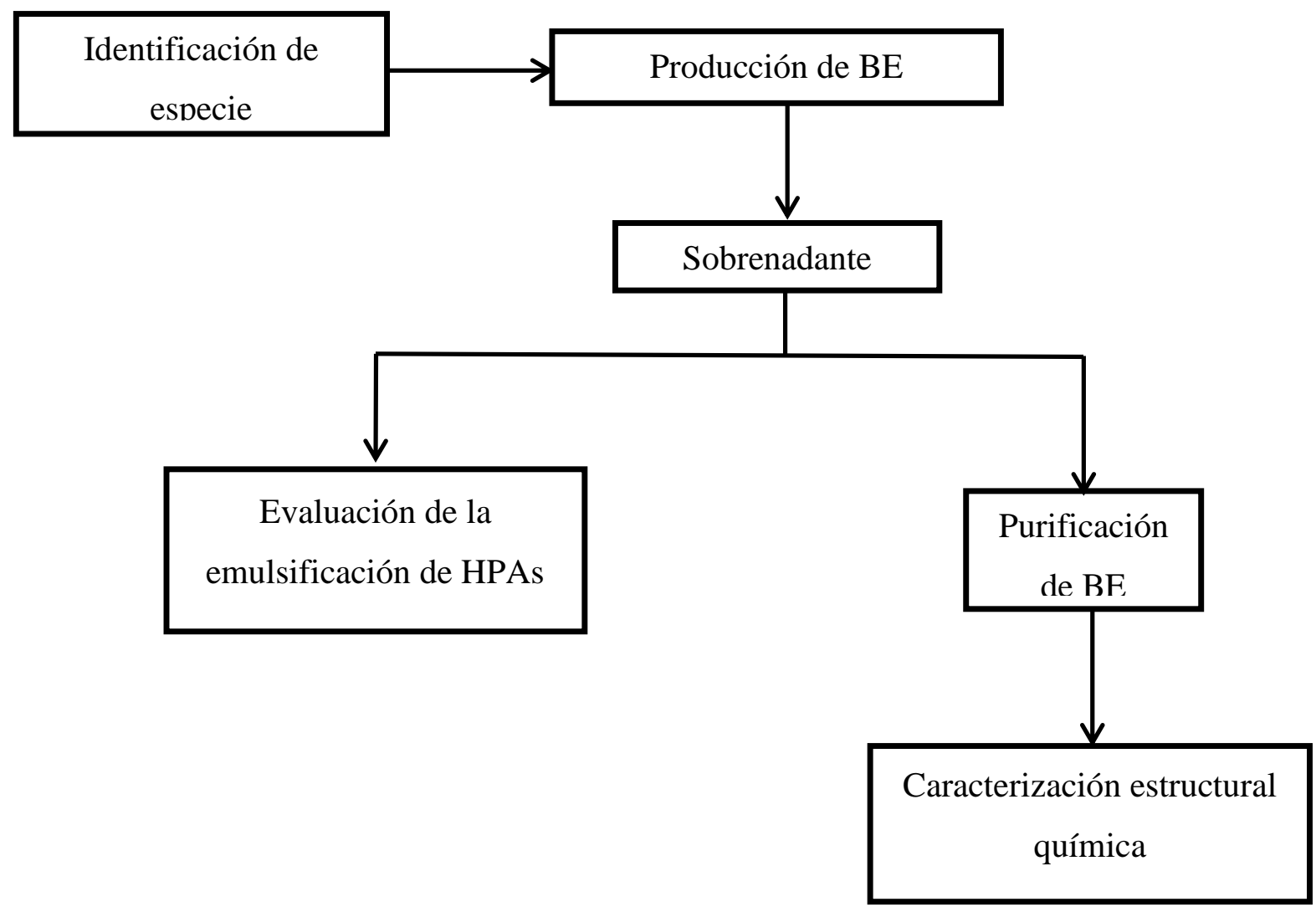

Figura 5 Estrategia experimental 


\section{MATERIALES Y MÉTODOS}

\subsection{Cepa, reactivos y medios de cultivo}

La cepa de Acinetobacter bouvetii UAM25 (número GenBank HQ424441) está disponible en la colección de cultivos WDCM449 del Instituto Politécnico Nacional (IPN) bajo el código ENCB-MG-076. Se utilizaron solventes con pureza de 99\% (Sigma-Aldrich, USA). Se utilizaron medios de propagación microbiológica (Becton Dickinson, México) y sales (J.T. Baker, México) grado reactivo. La composición del medio mineral (MM) fue $\left(\mathrm{g} \cdot \mathrm{L}^{-1}\right): \mathrm{K}_{2} \mathrm{HPO}_{4}$ $0.215, \mathrm{KCl} 0.113, \mathrm{MgSO}_{4} \cdot 7 \mathrm{H}_{2} \mathrm{O} 0.11, \mathrm{NaNO}_{3} 0.775$.

\subsection{Identificación bioquímica y molecular del microorganismo}

El análisis bioquímico preliminar se realizó de acuerdo con los algoritmos I y II (Figuras 6 y 7) diseñados a partir de los perfiles bioquímicos de las especies relacionas con A. bouvetii. Los perfiles metabólicos se utilizaron para la construcción de un dendograma con una matriz compuesta de las siguientes pruebas; crecimiento a 37 y $44{ }^{\circ} \mathrm{C}$ en medio nutritivo, hemólisis en agar sangre, crecimiento en medio citrato de Simmons, producción de ácido a partir de D- Glucosa, L-Arabinosa, L-Ramnosa, D-Xilosa, D-Manosa y D-Celobiosa. Además se realizaron las pruebas de $\mathrm{KOH} 3 \%$, catalasa y oxidasa.

La identificación molecular se realizó a partir de la alineación y análisis filogenético de la secuencia HQ424441 respecto secuencias de DNA ribosomal de subunidad 16S (16S DNAr) altamente relacionadas con la cepa UAM25 utilizando el software MEGA 5 (Tamura et al. 2011). Se realizó además un análisis morfológico macroscópico y microscópico utilizando microscopia electrónica de barrido (SEM) con el equipo Zeiss modelo dsm-940. 


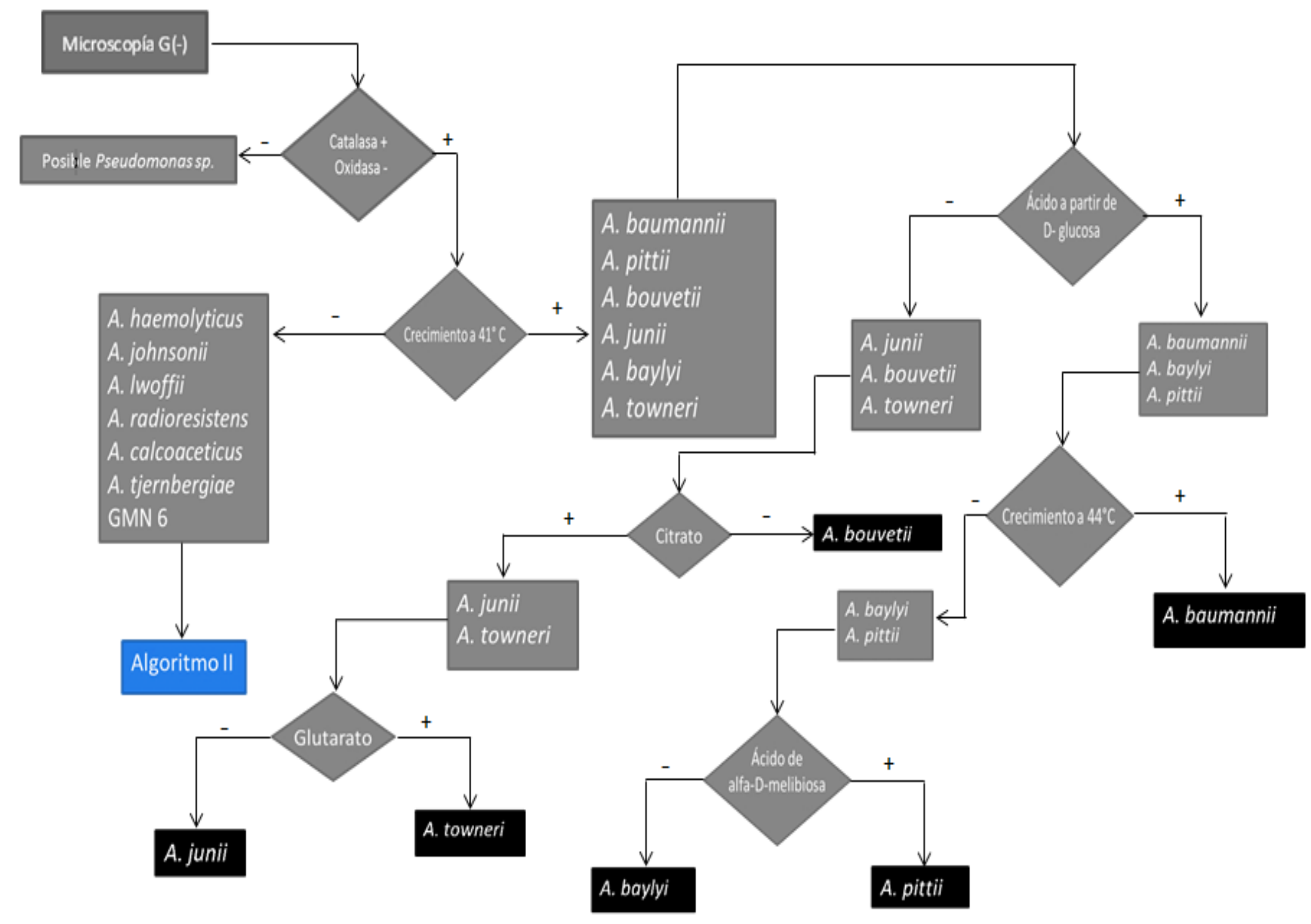

Figura 6 Algoritmo I de identificación bioquímica 


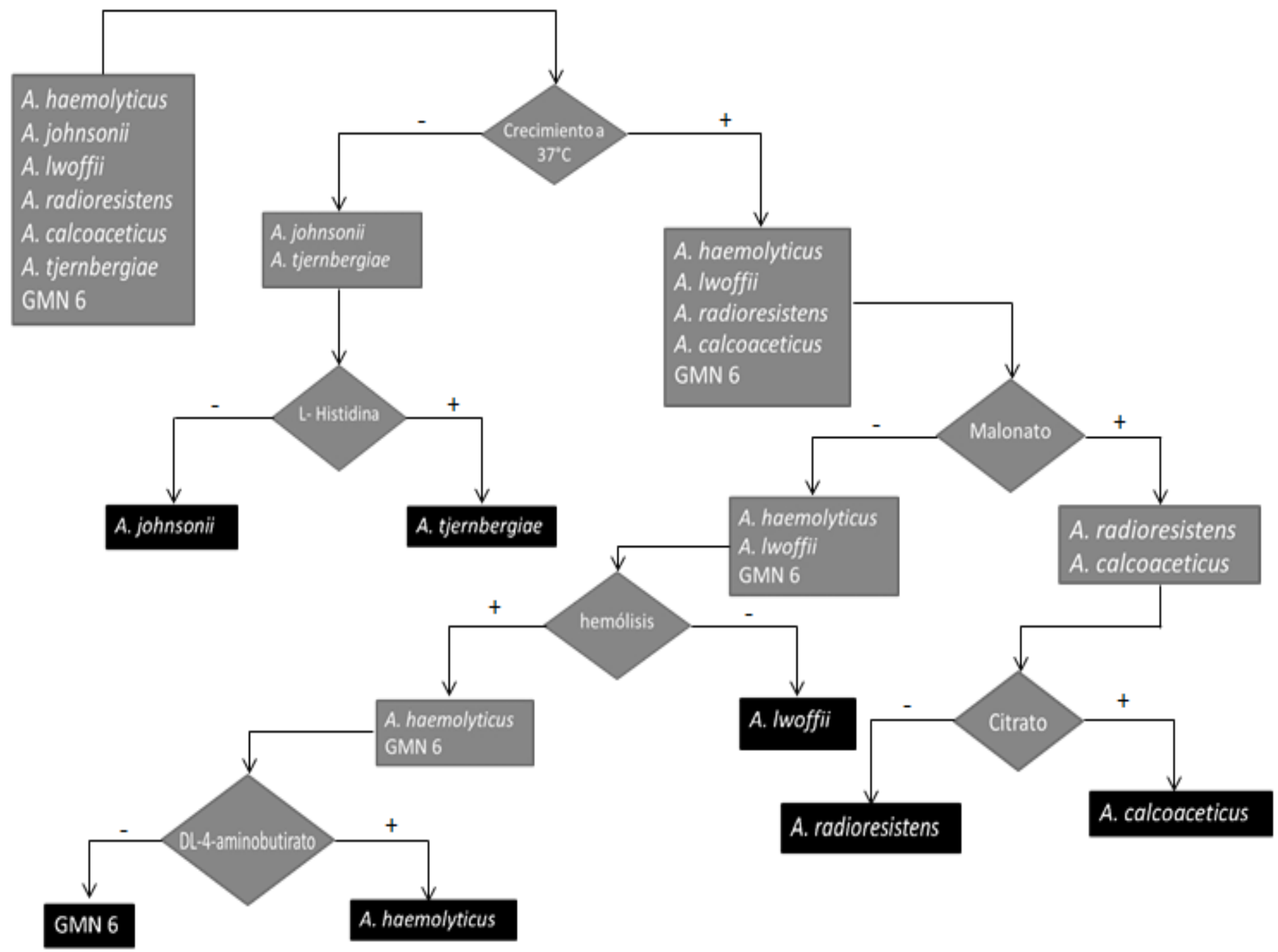

Figura 7 Algoritmo II de identificación bioquímica 


\subsection{Evaluación de diferentes fuentes de carbono}

Se evaluó la capacidad de A. bouvetii UAM25 para crecer en diferentes sustratos utilizando fuentes de carbono hidrofílicas e hidrofóbicas. Se utilizó una $\mathrm{C} / \mathrm{N}=10$ con $\mathrm{NaNO}_{3}$ como fuente de nitrógeno para todos los casos. Las fuentes de carbono evaluadas fueron: HXD, diésel, etanol, glucosa y acetato de sodio. Se evaluó además el efecto en las variables de respuesta de esta misma proporción de $\mathrm{C} / \mathrm{N}$, pero con concentración inicial 10 veces superior (10X). Para todos los tratamientos se cuantificó la concentración carbohidratos y proteínas en MM libre de células.

\subsubsection{Condiciones de crecimiento}

Se prepararon inóculos de A. bouvetii UAM25 en caldo nutritivo, llevándolos a fase $\log$, con este fin frascos serológicos con $50 \mathrm{~mL}$ de $\mathrm{MM}$ fueron inoculados con $1 \times 10^{6}$ unidades formadoras de colonias por mililitro (UFC. $\mathrm{mL}^{-1}$ ). El pH inicial se fijó en 6.5, los frascos serológicos se agitaron a $200 \mathrm{rpm}$ a $30^{\circ} \mathrm{C}$. La composición del MM se evaluó de acuerdo con el diseño factorial de dos niveles como se muestra en el Cuadro IV, en el que las fuentes de carbono y nitrógeno se tomaron como variables independientes. La AE, concentración de carbohidratos y proteínas fueron evaluadas después de $48 \mathrm{~h}$ de crecimiento.

Cuadro IV Diseño factorial $2^{\mathrm{k}}$ para la evaluación del MM

\begin{tabular}{rrrrr} 
& \multicolumn{4}{c}{ Combinaciones codificadas } \\
\hline Variable & $\mathbf{- 1 , - 1}$ & $\mathbf{+ 1 , + 1}$ & $\mathbf{+ 1 , - 1}$ & $\mathbf{- 1 , + 1}$ \\
\hline $\mathbf{H X D}$ & 1 & 3 & 3 & 1 \\
$\mathbf{N a N O}_{3}$ & 0.7352 & 1.103 & 0.7352 & 1.103 \\
$\mathbf{K}_{\mathbf{2}} \mathbf{H P O}_{4}$ & 0.215 & 0.215 & 0.215 & 0.215 \\
$\mathbf{K C l}$ & .113 & 0.113 & 0.113 & 0.113 \\
$\mathbf{M g S O}_{4}$ & 0.11 & 0.11 & 0.11 & 0.11 \\
\hline $\mathbf{C} / \mathbf{N}$ & 7 & 14 & 21 & 4.66 \\
\hline
\end{tabular}




\subsection{Optimización de producción de BE}

El método de acenso pronunciado (path of steepest ascent) se estructuró a partir de la regresión del diseño factorial de dos niveles descrito en el Cuadro IV. El tamaño de paso en el método (step size) para la fuente de carbono se codificó de acuerdo con la Eq 1:

$$
\Delta x c=\frac{\Delta X c}{\text { mitad de rango }}
$$

Donde $\Delta x c$ es el valor adimensional (codificado) del tamaño de paso y, $\Delta X c$ es el valor real. El tamaño de paso de la fuente de nitrógeno se determinó de acuerdo con la Eq. 2:

$$
\Delta x n=\frac{\beta c}{\beta n} \cdot \Delta x c
$$

Donde $\beta c$ y $\beta n$ son las pendientes de la regresión lineal para la fuente de carbono y nitrógeno respectivamente, los valores se utilizaron en términos de variables codificadas. La decodificación de este último tamaño de paso $(\Delta X n)$ se calculó con la Eq. 3:

$$
\Delta X n=\Delta x n \cdot \text { mitad de rango }
$$

Los resultados de la primera corrida de experimentos se utilizaron para obtener la ecuación de primer orden. El método de ascenso pronunciado permitió el diseño central compuesto (DCC) y posterior determinación de la ecuación cuadrática con la que se determinó el máximo de producción de $\mathrm{BE}$, tomando la Actividad Emulsificante (AE) como medida indirecta de producción. En caso de falta de ajuste $(\alpha<0.05)$ se procedió de acuerdo con el algoritmo de la Figura 8, hasta obtener un valor máximo teórico calculado a partir del DCC. Éste se validó con un valor experimental bajo las condiciones obtenidas en el modelo cuadrático correspondiente. Los experimentos de optimización se realizaron en frascos con $50 \mathrm{~mL}$ de $\mathrm{MM}$ a pH 6.5 y 200 rpm a $30^{\circ} \mathrm{C}$ en una agitadora New Brunswick I 26. 


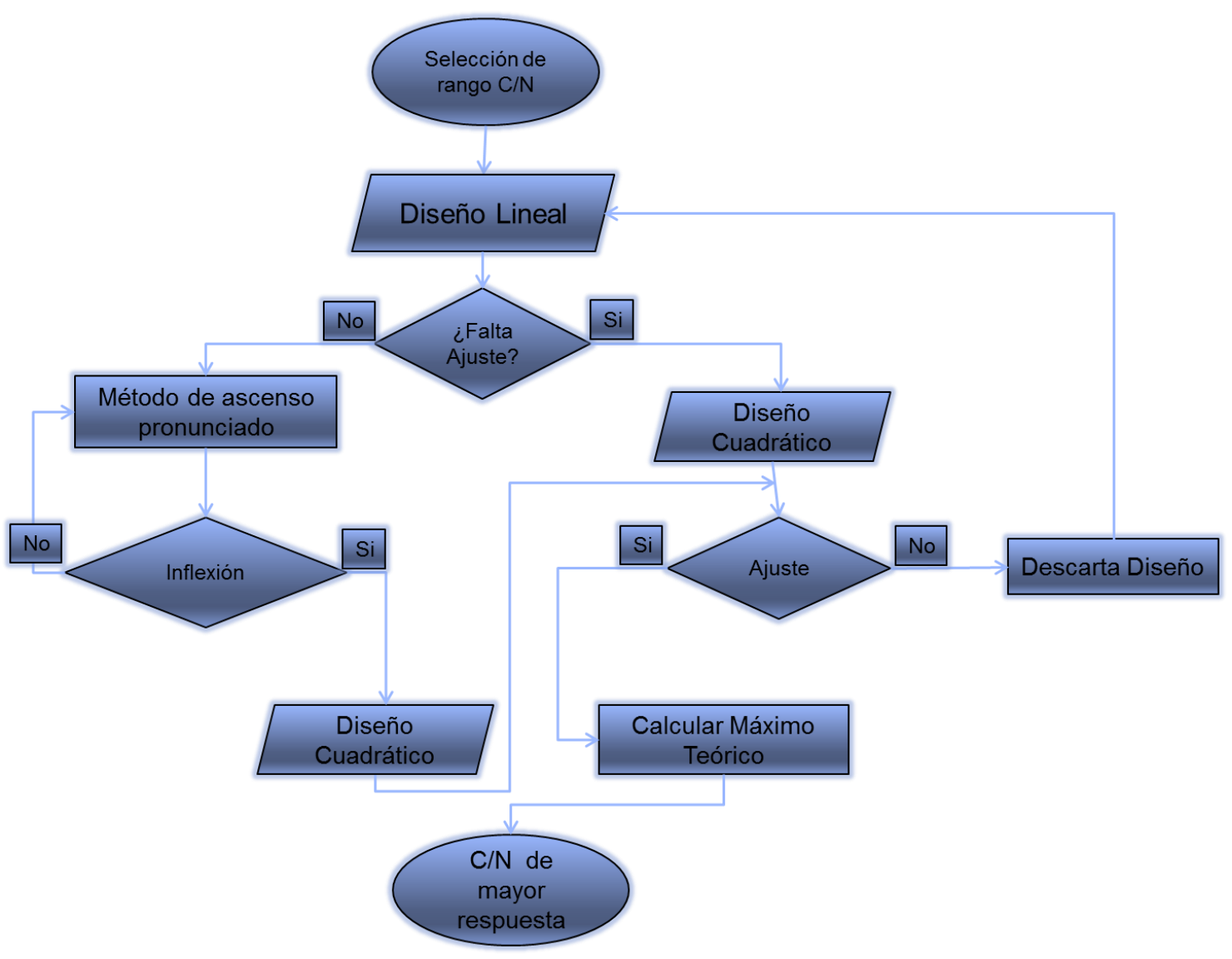

Figura 8 Algoritmo para la optimización del medio de cultivo 


\subsubsection{Evaluación de $\mathrm{C} / \mathrm{N}$ y producción de $\mathrm{BE}$}

Se evaluó la proporción $\mathrm{C} / \mathrm{N}=10.5$ en diferentes concentraciones, con HXD como fuente de carbono. Se evaluó además la concentración de inóculo. Los tratamientos fueron los siguientes:

A [5x, 6]: 5 veces (5x) la concentración del MM y de HXD, con un inóculo de $1 \cdot 10^{6} \mathrm{UFC} \cdot \mathrm{mL}^{-1}$. $B[10 x, 6]: 10 x$ la concentración de MM y HXD, con un inóculo de $1 \cdot 10^{6} \mathrm{UFC} \cdot \mathrm{mL}^{-1}$. $C[10 x, 7]: 10 x$ la concentración de MM y HXD, con un inóculo de $1 \cdot 10^{7} \mathrm{UFC} \cdot \mathrm{mL}^{-1}$. $D[1 x, 7]: 1 \mathrm{x}$ la concentración de MM y HXD, con un inóculo de $1 \cdot 10^{7} \mathrm{UFC} \cdot \mathrm{mL}^{-1}$. $E$ [1x, 6]: 1x la concentración de MM y HXD, con un inóculo de $1 \cdot 10^{6} \mathrm{UFC} \cdot \mathrm{mL}^{-1}$, este tratamiento se consideró como control.

Cada unidad experimental consistió en un frasco serológico con $50 \mathrm{~mL}$ de $\mathrm{MM}$, todos los frascos se incubaron a $30{ }^{\circ} \mathrm{C}$ por $48 \mathrm{~h}$ a $200 \mathrm{rpm}$. Después de $48 \mathrm{~h}$ de crecimiento las variables de respuestas (proteína, carbohidratos y AE) fueron evaluadas.

\subsubsection{Cinéticas de HXD residual en airlift}

Con el fin de obtener un lote de sobrenadante de mayor cantidad y homogeneidad que el que se obtendría a partir de las botellas serológicas, la producción de BE se realizó en un biorreactor airlift (BAL) (Fig 9) con capacidad de trabajo de $1 \mathrm{~L}$, los proporciones geométricas del BAL correspondieron a las reportadas por Lizardi-Jiménez et al. (2014). Se utilizó la C/N calculada con el diseño experimental anterior. Se midió además la concentración de carbohidratos totales, AE, HXD residual y cambio de $\mathrm{pH}$ durante un periodo de $72 \mathrm{~h}$ a $30{ }^{\circ} \mathrm{C}$, con la finalidad de validar que la $\mathrm{AE}$ máxima se encuentra dentro del periodo pre-estimando. Además de las condiciones antes mencionadas, la producción de BE en BAL se realizó a dos diferentes velocidades superficiales de gas; $\mathrm{Ug}=0.6 \mathrm{~cm} \cdot \mathrm{s}^{-1} \mathrm{y} \mathrm{Ug}=2.7 \mathrm{~cm} \cdot \mathrm{s}^{-1}$, con esto se analizó si existió algún efecto sobre las variables de respuestas analizadas al cambiar dicho parámetro. Además se evaluó el $k_{L} a$ utilizando la técnica dinámica acoplada a un electrodo de oxígeno disuelto (ADI dO2, Applisens, The Netherlands) de acuerdo a Lizardi-Jiménez et al. (2012). 


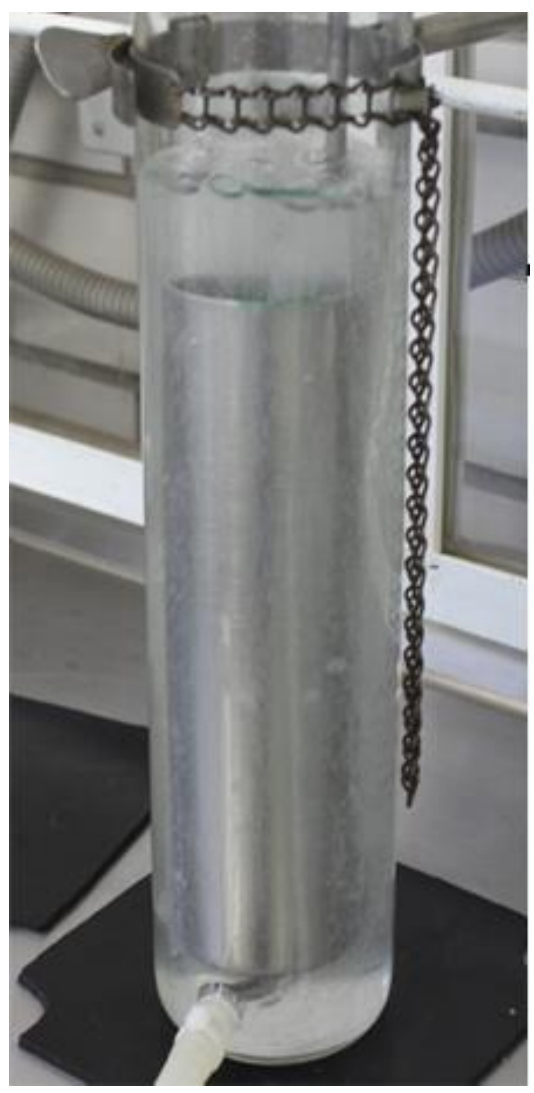

Figura 9 Biorreactor airlift (BAL) utilizado para la producción de bioemulsificante

\subsection{Purificación del BE}

Se tomaron alícuotas de $100 \mathrm{~mL}$ de cultivo del BAL después de $48 \mathrm{~h}$. Las células fueron separadas a través de dos pasos secuenciales de centrifugación: (i) $8000 \times \mathrm{g}$ por $30 \mathrm{~min}$ a $4{ }^{\circ} \mathrm{C}$; se recolectó el sobrenadante y (ii) se centrifugó una vez más a $10000 \times \mathrm{g}$ por $20 \mathrm{~min}$ a $4{ }^{\circ} \mathrm{C}$. El sobrenadante fue filtrado por membranas de acetato de celulosa $(0.45 \mu \mathrm{m})$. Varias técnicas de purificación de BE fueron evaluadas.

\subsubsection{Purificación de fracción proteica.}

Para la purificación de la fracción proteica, el sobrenadante libre de células se trató con diferentes porcentajes de sulfato de amonio (30, 40, 50, 60, y $70 \%$ ) a $4{ }^{\circ} \mathrm{C}$. Se obtuvo el precipitado después de reposar los tratamientos $12 \mathrm{~h} \mathrm{a} 4{ }^{\circ} \mathrm{C}$ y centrifugar a $8000 \times \mathrm{g}$ por $30 \mathrm{~min}$, después se dializaron los sobrenadantes y precipitados re-suspendidos para la remoción de partículas a través de una membrana con un corte de $10 \mathrm{kDa}$ (Rosenberg et al. 1979b), a las 
fracciones obtenidas de cada tratamiento de precipitación se les midieron las variables; proteína, carbohidrato y AE, las proteínas del extracto obtenido fueron evaluadas también por 1D SDSPAGE. Se utilizó el método de electroforesis de Laemmli (1970). El gel de corrida al $10 \%$ de acrilamida se preparó mezclando; $12.3 \mathrm{~mL}$ de agua miliQ; $7.5 \mathrm{~mL}$ de buffer de gel preparado con $1.5 \mathrm{~mL}$ Tris- $\mathrm{HCl}$ a pH 6.6; $9.9 \mathrm{~mL}$ acrilamida/Bis- acrilamida $\left(30 \% / 0.8 \% \mathrm{p} / \mathrm{v} \mathrm{H}_{2} \mathrm{O}\right) ; 0.3$ $\mathrm{mL}$ de $\mathrm{SDS}$ al $10 \%\left(\mathrm{p} / \mathrm{v} \mathrm{H}_{2} \mathrm{O}\right) ; 0.15 \mathrm{~mL}$ de persulfato de amonio (APS) al $10 \% \mathrm{p} / \mathrm{v} \mathrm{H}_{2} \mathrm{O}$ y 5 $\mu L$ TEMED (N',N',N',N', tetrametiletilendiamida).

Para el gel concentrador se realizó la siguiente mezcla; $3.05 \mathrm{~mL}$ de agua miliQ; $1.35 \mathrm{~mL}$ de buffer concentrador (Tris- $\mathrm{HCl} 0.5 \mathrm{M}$ a pH 6.8); $0.665 \mathrm{~mL}$ de acrilamida/Bis-acrilamida (30 $\% / 0.8 \%$ p/v $\left.\mathrm{H}_{2} \mathrm{O}\right) ; 50 \mu \mathrm{L}$ de SDS al $10 \% ; 50 \mu \mathrm{L}$ de APS y $5 \mu \mathrm{L}$ de TEMED. El buffer de corrida se preparó con la siguiente composición; Glycina 200 Mm; Tris-HCl 0.5 M a pH 6.8 y $0.1 \%\left(\mathrm{p} / \mathrm{v} \mathrm{H}_{2} \mathrm{O}\right)$ de SDS. El buffer de muestra se preparó mezclando $0.02 \mathrm{~g}\left(\mathrm{p} / \mathrm{v} \mathrm{H}_{2} \mathrm{O}\right)$ de azul de bromofenol; $0.313 \mathrm{~mL}$ de buffer concentrador (0.5 M Tris- $\mathrm{HCl}$ a $\mathrm{pH}$ 6.8); $0.5 \mathrm{~mL}$ de SDS al $10 \%$; $0.25 \mathrm{~mL}$ (v/v) de glicerol, todo se llevó a $2.5 \mathrm{~mL}$ con agua miliQ. La polimerización y corrida de los geles se realizó en un sistema MINI-PROTEAN tetra-cell de BIO-RAD. Las muestras se ajustaron a una concentración de $30 \mathrm{ng}$ de proteína y se trataron con buffer de muestra y (1:1) y $1 \mu \mathrm{L}$ de $\beta$-mercapto-etanol, se incubaron a $90{ }^{\circ} \mathrm{C}$ por $10 \mathrm{~min}$, después se cargaron $20 \mu \mathrm{L}$ de muestra por pozo y $5 \mu \mathrm{L}$ de marcador de peso molecular (broad range \#1610318 BIO-RAD), como control positivo se utilizó albumina sérica bovina (ABS Protein Standard II BIO-RAD). Los geles se corrieron a 180 volts por $1 \mathrm{~h}$ y se tiñeron con plata utilizando el kit Silver Stain Plus BIO-RAD siguiendo el protocolo del fabricante.

\subsubsection{Purificación de fracción carbohidrato}

Para obtener el BE en su forma pura y para su posterior caracterización química, se realizaron diferentes técnicas de purificación, que se describen a continuación.

1. Precipitación con iso-propanol: El sobrenadante libre de células se mezcló con 1.5 volúmenes de iso-propanol a $-20{ }^{\circ} \mathrm{C}$, se dejó reposar durante $12 \mathrm{~h}$ a $4{ }^{\circ} \mathrm{C}$, después se centrifugó a $8000 \times \mathrm{g}$ durante $30 \mathrm{~min}$ para obtener un precipitado, este último se resuspendió en $5 \mathrm{~mL}$ de $\mathrm{H}_{2} \mathrm{O}$ destilada y se dializó a $4{ }^{\circ} \mathrm{C}$ frente $\mathrm{H}_{2} \mathrm{O}$ destilada (cuatro cambios de $1 \mathrm{~L}$ durante en un lapso de $48 \mathrm{~h}$ ) con una membrana de celulosa regenerada 
(CR) con corte de 12000 MW, la re-suspensión dializada se filtró a través de una membrana CR de $0.45 \mu \mathrm{m}$. Por último, la suspensión se liofilizó y se determinó el rendimiento de la extracción.

2. Tratamiento con Formaldehido- $\mathrm{NaOH}$ : Se realizó de acuerdo a la técnica reportada por Pan et al. (2010), con las siguientes modificaciones: a $70 \mathrm{~mL}$ de medio de cultivo se le agregaron $0.42 \mathrm{~mL}$ de formaldehido al $36.5 \%$ a $4{ }^{\circ} \mathrm{C}$ y se dejó reposar durante $1 \mathrm{~h}$, después se le añadieron $28 \mathrm{~mL}$ de $\mathrm{NaOH} 1 \mathrm{M}$ a $4{ }^{\circ} \mathrm{C}$ y se dejó reposar por $3 \mathrm{~h}$, después se centrifugó a $8000 \times g$ durante 30 min para obtener el sobrenadante libre de células, el HXD residual fue retirado manualmente después de su congelación. El sobrenadante se dializó a $4{ }^{\circ} \mathrm{C}$ frente $\mathrm{H}_{2} \mathrm{O}$ destilada (cuatro cambios de $1 \mathrm{~L}$ durante en un lapso de 48 h) con una membrana CR con corte de 12000 MW, la re-suspensión dializada se filtró con una membrana $\mathrm{CR}$ de $0.45 \mu \mathrm{m}$. Por último, la suspensión se liofilizó y se determinó el rendimiento de la extracción.

3. Ultrafiltración: El sobrenadante libre de células fue dializado y concentrado por ultrafiltración utilizando una celda agitada (Fig 10) con membrana Omega de poliétersulfona de $30 \mathrm{kDa}$ de cut-off (PALL, EUA). El aire inyectado fue filtrado a través de una membrana de politetrafluoroetileno (PTFE) a una presión de 20 PSI. La diafiltración se realizó de manera discontinua, de tal forma que después de concentrar 100 veces $100 \mathrm{~mL}$ de sobrenadante, el retenato se diluyó a su volumen original varias veces hasta que la conductividad del filtrado fuera $0.01 \mathrm{mS} \cdot \mathrm{cm}^{-1} \mathrm{o}$ inferior, tomando como referencia la conductividad del agua destilada. Por último, el concentrado desalado se liofilizó y se determinó el rendimiento de la extracción. El extracto obtenido fue evaluado para la determinación de peso molecular del BE por cromatografía de permeación en gel y exclusión de tamaño (SEC); además, el BE así purificado se analizó para su caracterización química por RMN. 


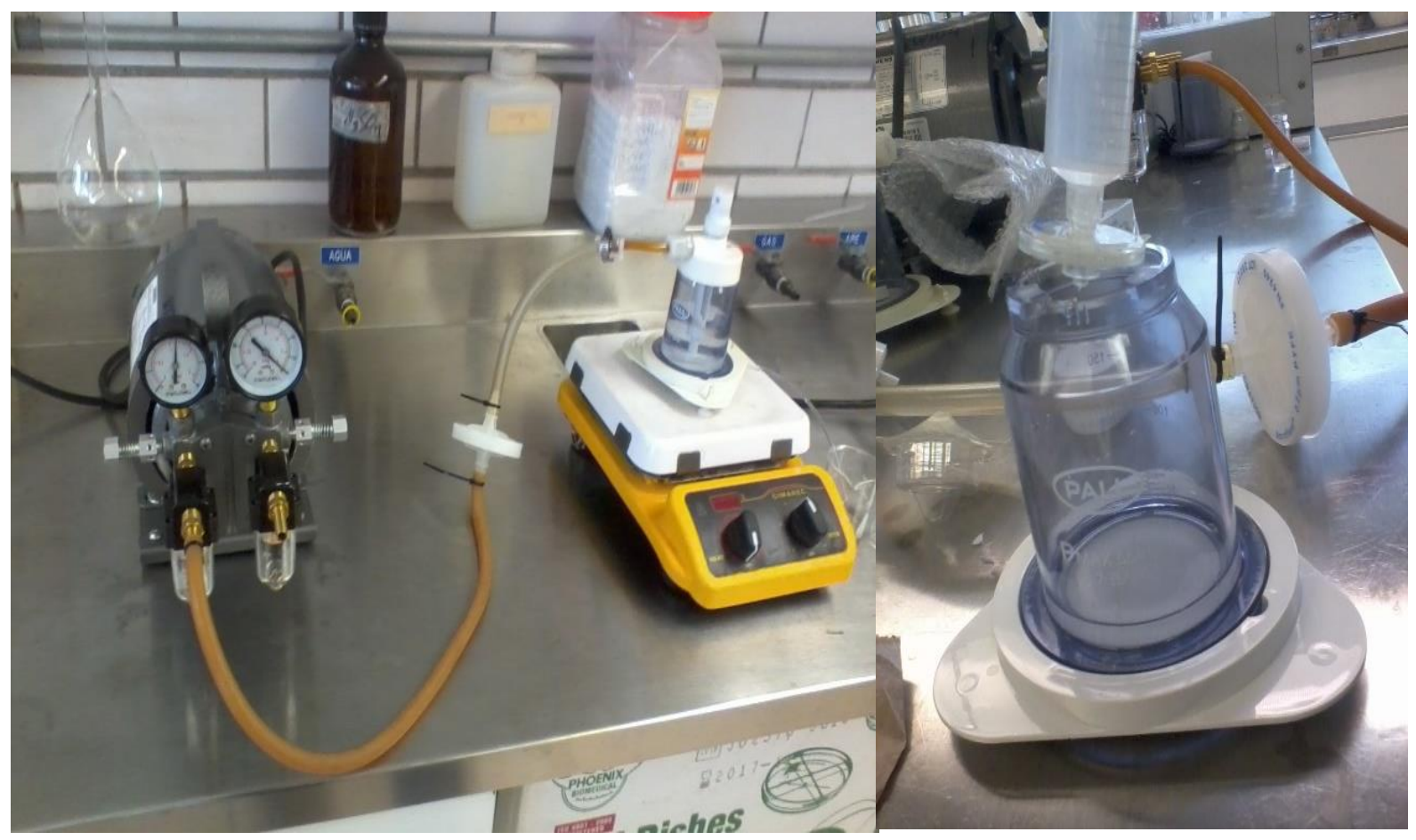

Figura 10 Sistema de diafiltración discontinua y concentración por ultrafiltración

\subsubsection{Determinación del peso molecular del BE por cromatografía de permeación en gel/exclusión de tamaño (SEC).}

Para el análisis SEC, muestras de $3 \mathrm{mg}$ de BE liofilizado fueron re-suspendidas en $1.5 \mathrm{~mL}$ de $\mathrm{H}_{2} \mathrm{O}$ miliQ y posteriormente filtradas a través de una membrana de $0.45 \mu \mathrm{m}$ antes de ser inyectadas. Se utilizó el equipo de HPLC de la serie Agilent (EUA) 1260 Infinity LC, acoplado a un detector de índice de refracción (RID) (1260 Infinity Refractive Index Detector) (Fig 11) equipado con dos columnas PL aquagel-OH 50 (Waters, EUA) en serie (15 $\mu \mathrm{m}, 300 \times 7.5 \mathrm{~mm}$ ) instaladas en un termostato a $25{ }^{\circ} \mathrm{C}$. Las muestras se inyectaron a un flujo constante de 0.8 $\mathrm{mL} \cdot \mathrm{min}^{-1}$ a 18 bar utilizando $\mathrm{H}_{2} \mathrm{O}$ desionizada como fase móvil. Para determinar el peso molecular se construyó una curva patrón utilizando estándares polietilenglicol (PEG) en un 
rango de peso molecular de aproximadamente $30 \mathrm{kDa}$ a $1000 \mathrm{kDa}$, los datos fueron procesados con ayuda del software Cirrus SEC (Agilent, USA).

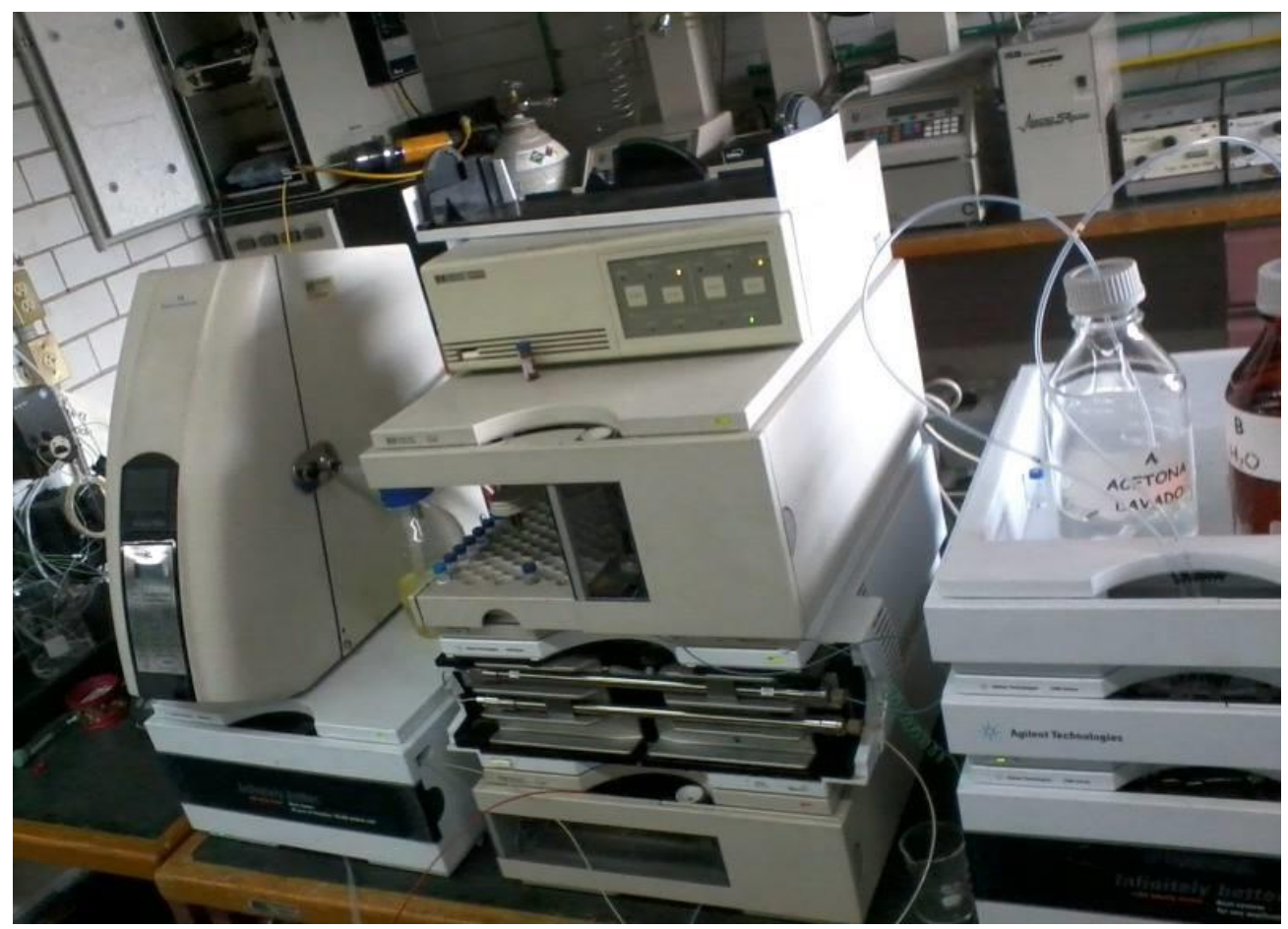

Figura 11 Equipo HPLC, acoplado a detector RID para el análisis por SEC

\subsubsection{Análisis por resonancia magnética nuclear $\left({ }^{1} \mathrm{H}\right.$ y ${ }^{13} \mathrm{C}, \mathrm{COSY}$ y NOESY)}

Los análisis de RMN se realizaron en un espectrómetro Unity (Varian, USA) a 400 y $100 \mathrm{MHz}$ para la obtención de los espectros de ${ }^{1} \mathrm{H}$ y ${ }^{13} \mathrm{C}$, respectivamente. Se utilizaron agua deuterada y DMSO-d6 como solventes para la obtención de los diferentes espectros. Las muestras prior análisis de resonancia fueron hidrolizadas por diferentes métodos para seleccionar las mejores condiciones de hidrólisis (Cuadro V). El método de hidrólisis para los análisis bidimensionales fue el siguiente; el BE liofilizado se mezcló con $\mathrm{HCl} 2.0 \mathrm{~N}$ en proporción 1:1 (v/v), esta mezcla se calentó en baño de agua por 15 min. El hidrolizado se liofilizó resultando una película fina translucida. La asignación de las señales se realizó de acuerdo con la Bacterial Carbohydrate Structure Database (Egorova \& Toukach 2014). 
Cuadro V Métodos de hidrólisis aplicados a las muestras de BE, previos al análisis de RMN

\begin{tabular}{|lcc|}
\hline \multicolumn{1}{|c}{$\begin{array}{c}\text { aMétodo } \\
\text { Agitación Vortex }\end{array}$} & $\begin{array}{c}\text { Tiempo } \\
\text { (10 min }\end{array}$ \\
\hline$\Delta$ & $10 \mathrm{~min}$ & \\
\hline EDTA 2\% & $20 \mathrm{~min}$ & $\Delta$ \\
\hline EDTA 2\% & $12 \mathrm{~h}$ & $\Delta$ \\
\hline EDTA 2\% & $10 \mathrm{~min}$ & \\
\hline NaOH 1N & $20 \mathrm{~min}$ & $\Delta$ \\
\hline NaOH 1N & $12 \mathrm{~h}$ & $\Delta$ \\
\hline NaOH 1N & $20 \mathrm{~min}$ & \\
\hline EDTA 2\% + NaOH 1N & $10 \mathrm{~min}$ & \\
\hline HCl 2N & $12 \mathrm{~h}$ & $\Delta$ \\
\hline HCl 2N & $12 \mathrm{~h}$ & $\Delta$ \\
\hline HCl 2N & $2 \mathrm{~h}$ & $\Delta$ \\
\hline HCl 2N & $20 \mathrm{~min}$ & \\
\hline
\end{tabular}

$\Delta:$ Tratamiento en agua en ebullición

${ }^{a}$ Los tratamientos fueron diseñados de acuerdo a métodos clásicos de hidrólisis de biopelículas (More et al. 2014)

\subsection{Métodos analíticos}

Para la medición de las diferentes variables fue necesario separar las células del medio de cultivo, centrifugando por los pasos secuenciales descritos en el numeral 7.5. Al extracto libre de células se le realizó una extracción líquido-líquido del HDX residual utilizando hexanoacetona $(1: 1 \mathrm{v} / \mathrm{v})$ en relación $1: 1$ con respecto al sobrenadante.

\subsubsection{Crecimiento bacteriano y HXD residual}

Para la determinación de crecimiento bacteriano se utilizó la técnica de cuenta viable en placa. Se muestrearon $100 \mu \mathrm{L}$ del medio de cultivo y se realizaron las diluciones necesarias con solución isotónica de $\mathrm{NaCl}$ al $0.85 \%$ p/v. Se inocularon $100 \mu \mathrm{L}$ de cada dilución en cajas Petri 
con $30 \mathrm{~mL}$ de agar soya tripticaseína (AST, Bioxon), las cajas Petri fueron incubadas a $30^{\circ} \mathrm{C}$ durante $48 \mathrm{~h}$. Pasado el tiempo de incubación se contaron por triplicado las unidades formadoras de colonias (UFC) y con el factor de dilución correspondiente, se calculó el crecimiento de $A$. bouvetii UAM 25 en UFC. $\mathrm{mL}^{-1}$. El HXD recuperado fue cuantificado por cromatografía de gases (CG) de acuerdo con Velasco-Alvarez et al. (2011) en un cromatógrafo Varian modelo Star 3900 GC con detector de ionización de flama (FID), auto-muestreador Varian 8410 y columna AT-1HT de $15 \mathrm{~m}$ x $0.25 \mathrm{~mm}$ x $0.10 \mu \mathrm{m}$ de Alltech Heliflex. Se utilizó helio como gas acarreador con un flujo de $30 \mathrm{~mL} \cdot \mathrm{min}^{-1}$ a $40 \mathrm{psi}$. El programa de temperaturas fue: $120^{\circ} \mathrm{C}\left(30^{\circ} \mathrm{C} \cdot \mathrm{min}^{-1}\right)$ para el horno hasta una temperatura de $150{ }^{\circ} \mathrm{C}\left(10^{\circ} \mathrm{C} \cdot \mathrm{min}^{-1}\right)$ luego $170^{\circ} \mathrm{C}\left(15^{\circ} \mathrm{C} \cdot \mathrm{min}^{-1}\right)$ con FID a $300{ }^{\circ} \mathrm{C}$ e inyectando volúmenes de $2 \mu \mathrm{L}$.

\subsubsection{Concentración de carbohidratos y proteínas}

Para la determinación de la concentración de carbohidratos se utilizó la técnica modificada de ácido sulfúrico y fenol de DuBois et al. (1956) como sigue: se agregaron $0.5 \mathrm{~mL}$ de fenol al 5 $\%$ y $2.5 \mathrm{~mL}$ de ácido sulfúrico concentrado a $1 \mathrm{~mL}$ de medio libre de células, la mezcla se dejó reposar por 20 min y después se registró su absorbancia a $480 \mathrm{~nm}$. Para el cálculo de la concentración en las muestras se utilizó una curva patrón de glucosa. Se determinó además la concentración de proteínas por la técnica de Bradford (1976) utilizando albumina sérica bovina para la elaboración de la curva patrón. Para ambas determinaciones se utilizó medio mineral sin inocular como blanco.

\subsubsection{Actividad y capacidad emulsificante con HPAs y potencial $Z$}

Para determinación de la AE se siguió la metodología descrita por Toren et al. (2001) y Rosenberg et al. (1979); a $0.4 \mathrm{~mL}$ de sobrenadante libre de células se le añadieron $40 \mu \mathrm{L}$ de una mezcla HXD y $\beta$-metilnaftaleno (1:1), se agitó en Vórtex durante 2 min y se midió su actividad emulsificante a partir de la densidad óptica registrada a una longitud de onda de $600 \mathrm{~nm}\left(A_{600}\right)$. La respuesta $\mathrm{AE}$ se definió como la capacidad que tiene $1 \mathrm{~mL}$ de sobrenadante libre de células para elevar en 0.1 unidades la absorbancia medida a $600 \mathrm{~nm}$.

La capacidad emulsificante además fue evaluada con las siguientes mezclas de HPAs: HXD:PYR al $1 \%$ (v/p), HXD:ß-metilnaftaleno 1:1 (v/v) y HXD mezclado con PYR y PHE 
ambos al $1 \%$. Los HPAs emulsificados se detectaron a $276 \mathrm{~nm}$, esta longitud es el pico máximo detectado a partir de un barrido espectrofotométrico. Se analizaron además como controles, los emulsificantes sintéticos Tween 80 y Triton X-100, utilizados comercialmente en la emulsificación, con balances hidrofílicos lipofílicos (HLB) de 13.4 y 15 respectivamente. La concentración ensayada para las muestras fue de $150 \mathrm{mg} \cdot \mathrm{L}^{-1}$ tanto para el BE como para los emulsificantes sintéticos. El sobrenadante libre de células $(1 \mathrm{~mL})$ diluido 1:10 con agua desionizada fue analizado para su potencial zeta en un rango de $\mathrm{pH}$ de 2-10 usando el equipo Zetasizer Nano ZS ZEM3500 (Malvern Instruments, RU).

\subsection{Análisis estadístico}

Se utilizó la prueba de ANOVA $(\alpha=0.05)$ de una vía con post hoc Tukey para las comparaciones por pares utilizando el software SPSS v.15.0 (IBM, EUA). El software MINITAB 16 (State College PA, EUA) fue utilizado para los análisis; optimización de MM, método de coeficiente de correlación absoluta y para el perfilado bioquímico.

\section{RESULTADOS Y DISCUSIÓN}

\subsection{Identificación bioquímica y molecular del microorganismo}

Acinetobacter agrupa especies tanto inocuas como patógenas, por medio del análisis molecular, bioquímico, macroscópico y microscópico es posible determinar la especie y por tanto tener un primer indicio de su impacto potencial en el ambiente. La morfología macroscópica y microscópica consistió en colonias circulares, convexas, ligeramente opacas en medio AST, como las que se muestran en la Fig 12. Por SEM se observaron bacilos cortos de aproximadamente $1 \mu \mathrm{m}$ (Fig 13), todas estas características son propias del género Acinetobacter (Carr et al. 2003). 


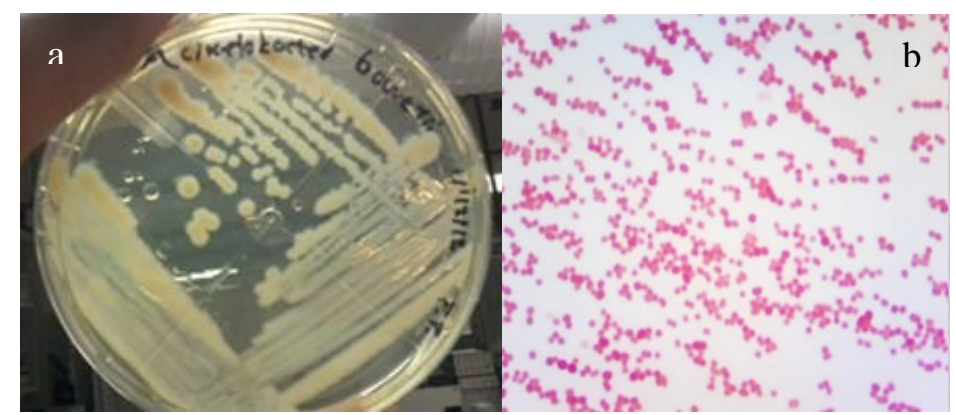

Figura 12 Morfología macroscópica (a) y microscópica (b) de A. bouvetii UAM25

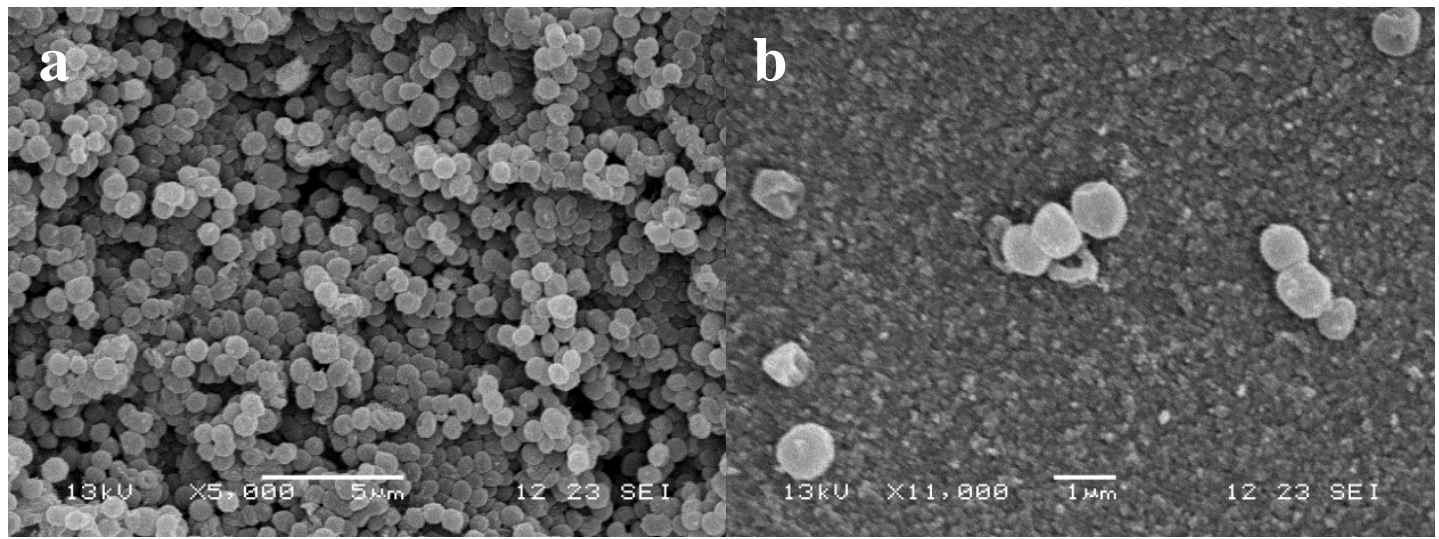

Figura 13 SEM de A. bouvetii UAM25: las líneas de escala corresponden a longitudes de 5 (a) y $1 \mu \mathrm{m}(b)$

\subsubsection{Perfil bioquímico de Acinetobacter bouvetii UAM25}

Para diferenciar de las especies más relacionadas con $A$. bouvetii se seleccionaron pruebas bioquímicas diferenciales para estas especies. La prueba de citrato de Simmons (Fig 14) diferenció $A$. bouvetii de $A$. johnsonii y de A. haemolyticus, dado que estas últimas dos son positivas para la producción de citrato permeasa, virando el color del medio citrato de verde a azul. Como prueba confirmatoria y diferencial de A. bouvetii contra A. haemolyticus, se realizó la prueba de hemólisis en agar sangre, la cepa UAM25 no generó hemólisis por lo que se descartó la especie haemolyticus como la identidad de la cepa (Fig 15). Por último, a través de análisis de correlación absoluta con una matriz de pruebas bioquímicas diferenciales, se confirmó el perfil bioquímico específico para A. bouvetii UAM25 (Fig 16). 


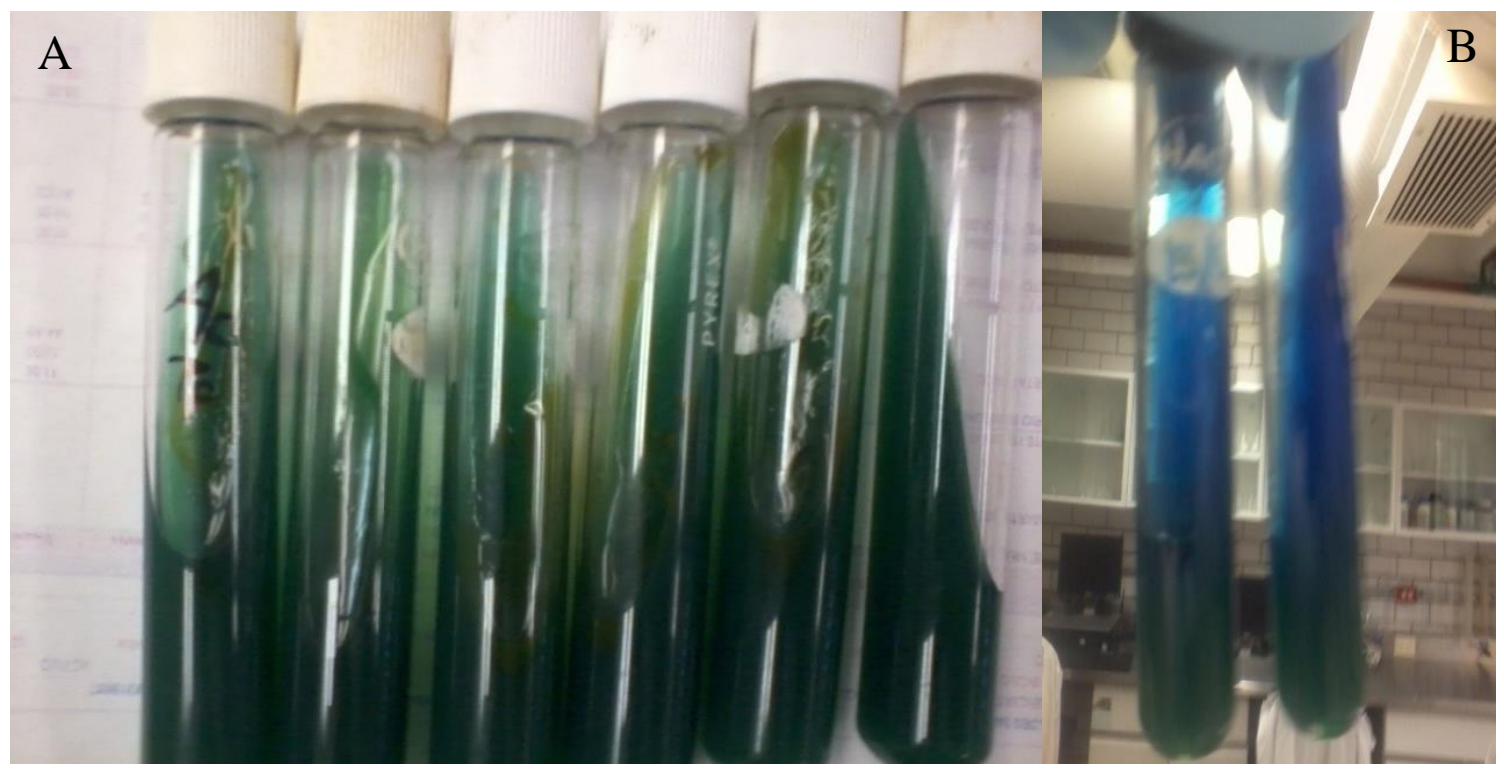

Figura 14 A) A. bouvetii UAM25 en citrato de Simmons; B) control positivo Klebsiella pneumoniae

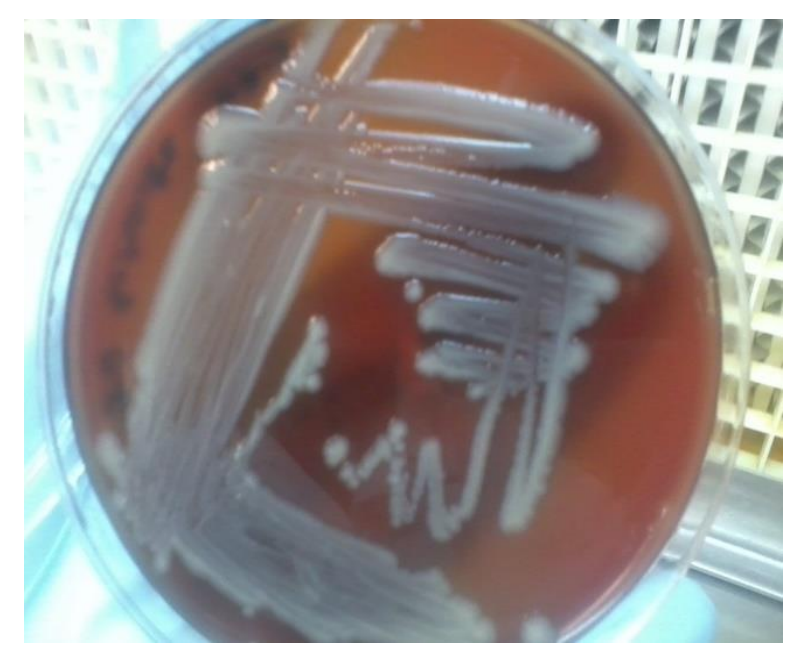

Figura 15 A. bouvetii en prueba de hemólisis en agar sangre, resultado negativo 


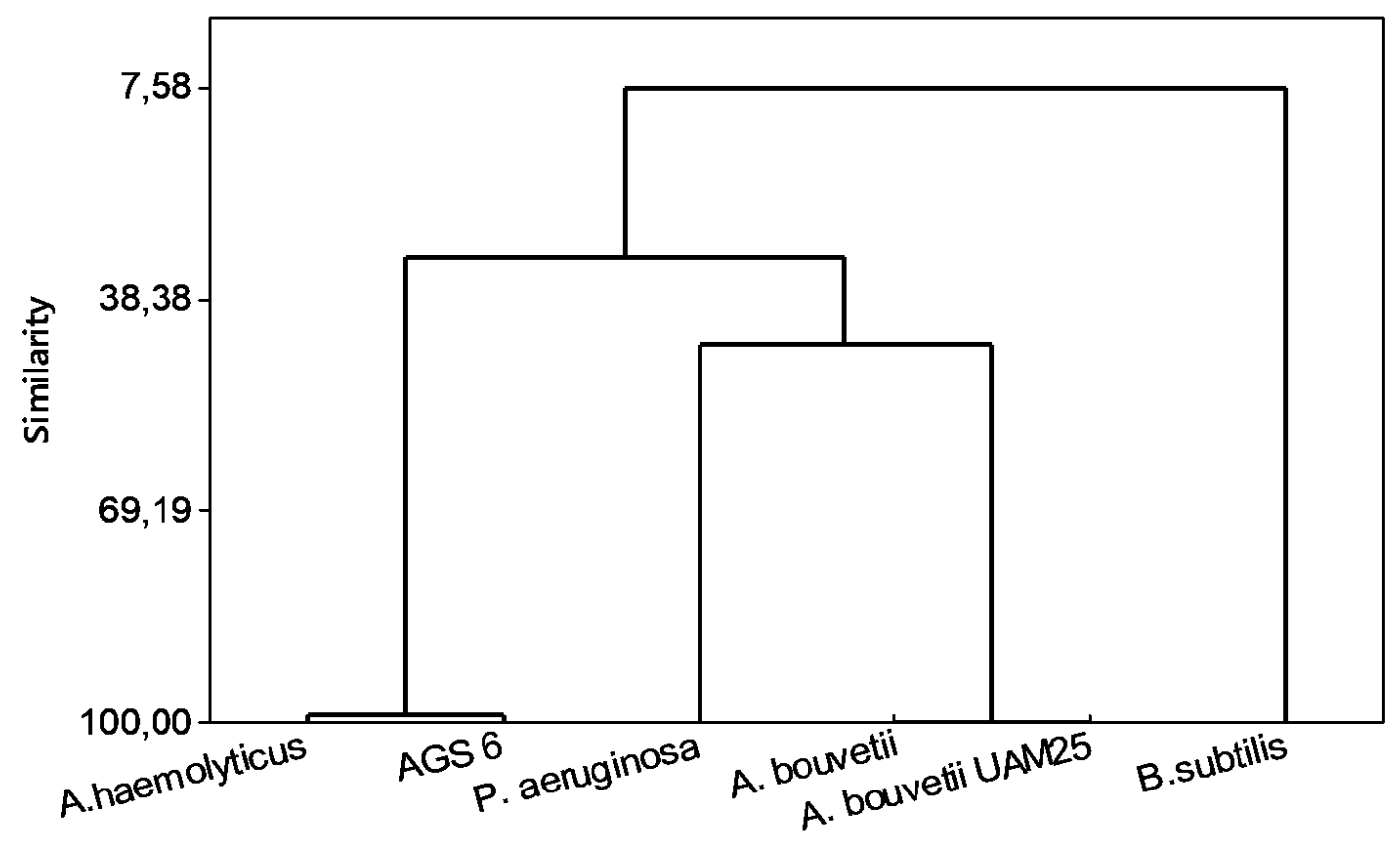

Figura 16 Análisis de correlación absoluta a partir de los perfiles bioquímicos. B. subtilis fue utilizado como grupo externo

\subsubsection{Análisis de secuencias de rDNA 16S}

La cepa UAM25 anteriormente fue clasificada como A. bouvetii (Tzintzun-Camacho et al. 2012); sin embargo, un nuevo análisis de la secuencia (Genbank HQ424441) en diferentes bases de datos demostró una alta similitud filogenética con A. haemolyticus, esta especie representa un riesgo en el sector de salud pública por su capacidad hemolítica. Para asegurar la correspondencia de la especie, dicha secuencia se comparó con otras 45 secuencias del género Acinetobacter mas una secuencia como grupo externo (Fig 17). A partir de este primer análisis se seleccionaron sólo las especies más cercanas a A. bouvetii (Fig 18). El análisis de secuencias demostró una alta relación de la cepa UAM25 con $A$. haemolyticus seguida de las especies $A$. johnsonii y A. bouvetii. Una relación de clusters similar ocurre en otros estudios, como en el reportado por Yuan et al. (2014), esto debido a la cercanía de las genomoespecies que normalmente habitan en suelos y océanos, las cuales además comúnmente son productoras de BEs. La especie $A$. bouvetii fue confirmada entonces como la identidad de la cepa UAM25. La 
cepa no presentó propiedades potencialmente patógenas, como la capacidad de crecimiento a temperaturas superiores a $37^{\circ} \mathrm{C}$, ni capacidad hemolítica (Carr et al. 2003).

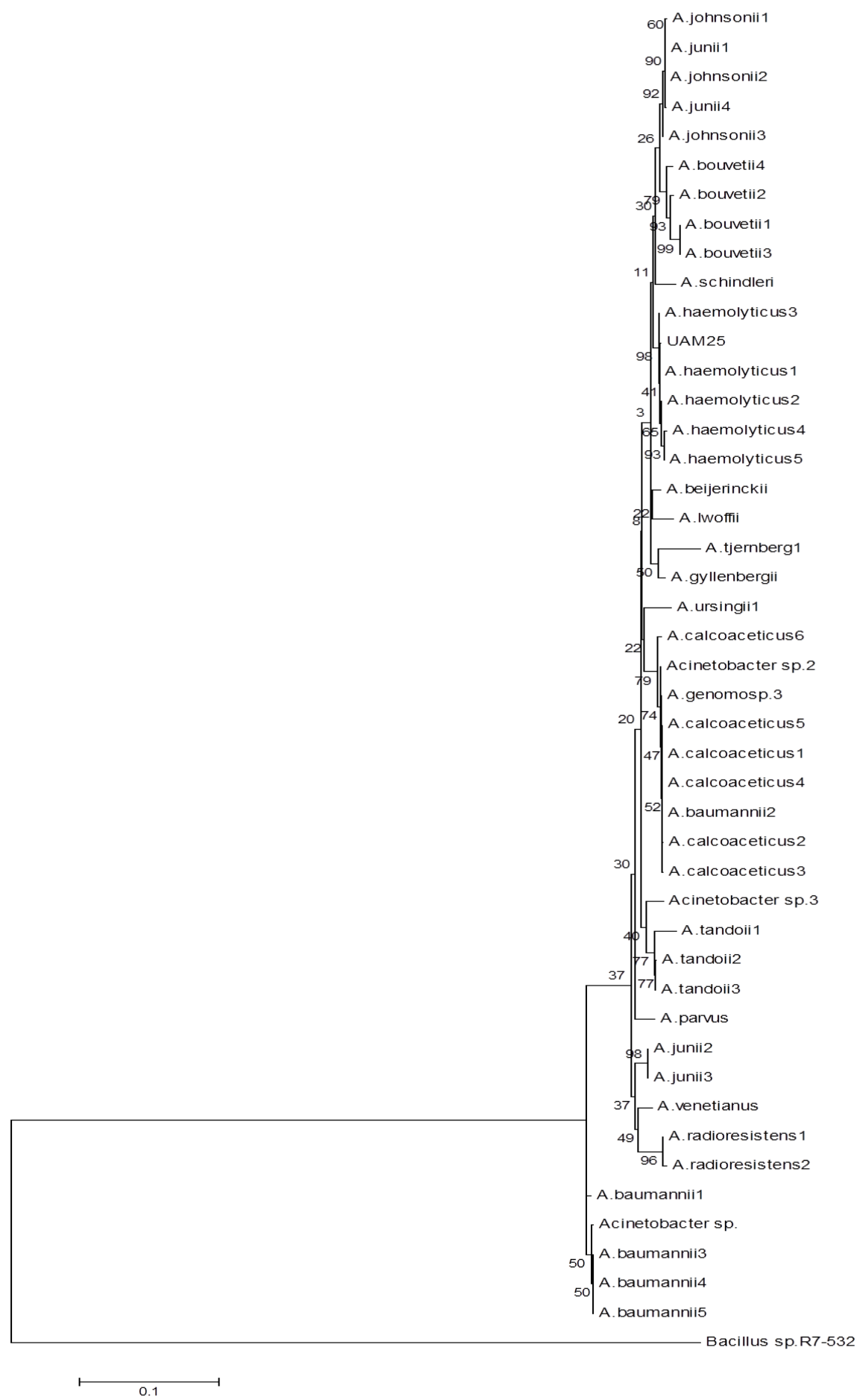

Figura 17 Árbol filogenético, construcción por Neighbor-Joining, Bootstrap: 1000, Kimura 2 modelado gamma $=0.17$. Grupo externo; Bacillus sp. 


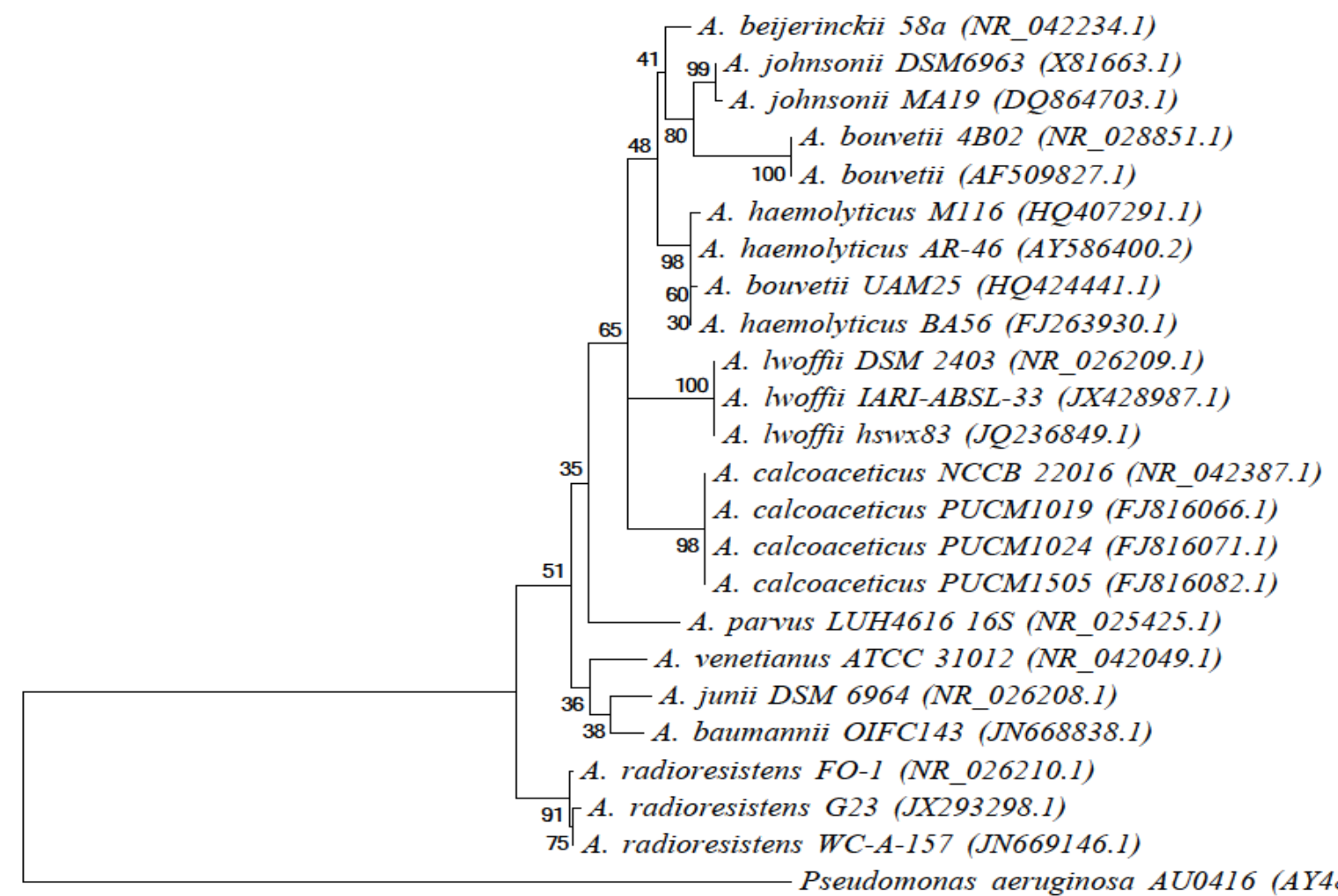

(Y486350.1)

Figura 18 Árbol filogenético, construcción por Neighbor-Joining, Bootstrap: 1000, Kimura 2 modelado gamma = 0.19. Grupo externo; Pseudomonas aeruginosa.

\subsection{Evaluación de diferentes fuentes de carbono y la $\mathrm{AE}$ resultante}

Para conocer la capacidad metabólica de la cepa identificada, se decidió crecerla en diferentes fuentes de carbono y evaluar su AE. La cepa fue capaz de crecer en las diferentes fuentes de carbono ensayadas después de 48 h. Como se muestra en la Figura 19, las fuentes evaluadas fueron de naturaleza hidrofílica y otras hidrofóbicas. No se observó crecimiento con diferencia significativa entre el tratamiento con HXD y etanol $(\alpha=0.05)$. Al evaluar en concentración 10X, el crecimiento con diésel fue ligeramente inferior sin alejarse más de un orden de magnitud del crecimiento en HXD y etanol. El crecimiento con acetato de sodio solo ocurrió a 1X, mientras $10 \mathrm{X}$ resultó ser una concentración inhibitoria. Un resultado relevante es que no se observó crecimiento en glucosa para ningún nivel del tratamiento. 
La producción de moléculas con actividad en superficie y/o emulsificante utilizando microorganismos del género Acinetobacter comúnmente se reporta tanto para tratamientos con fuentes de carbono hidrofílicas como para hidrofóbicas. Por ejemplo, Chen et al. (2012) produjeron biosurfactantes de Acinetobacter sp. en sistemas de optimización con HXD, a su vez Kim et al. (1997) produjeron emulsificante a partir etanol utilizando la cepa Acinetobacter calcoaceticus RAG-1. Aun cuando el HXD se utiliza en un amplio rango de concentración, el etanol puede inhibir cuando está por encima de los $16 \mathrm{~g} \cdot \mathrm{L}^{-1}$. Su et al. (2009) observaron un efecto inhibitorio cuando la concentración de etanol fue superior a los $24 \mathrm{~g} \cdot \mathrm{L}^{-1}$, el tratamiento diseñado para A. bouvetii UAM25 en etanol (EtOH) 10X con $\mathrm{C} / \mathrm{N}=10$ no superó los $13 \mathrm{~g} \cdot \mathrm{L}^{-1}$, dicha concentración está por debajo del nivel inhibitorio. A partir del análisis bioquímico se sabe que A. bouvetii UAM25 no es capaz de producir ácido a partir de glucosa, en la Figura 19 esto se observa como ausencia de crecimiento cuando la glucosa fue la fuente de carbono, esta es una característica de la mayoría de las especies de este género (Carr et al. 2003). Esta incapacidad podría deberse a que la cepa no posee varias enzimas de la glucólisis (glucoquinasa, hexoquinasa); incluso algunas especies de Acinetobacter capaces de utilizar glucosa como fuente de carbono carecen de estas enzimas, tal es el caso de A. baylyi, que utiliza glucosa a través de la oxidación peri-plasmática por la vía Entner-Doudoroff, ya que carece del gen que codifica para la piruvato quinasa, necesaria para el nodo fosfoenolpiruvato-piruvato-oxalacetato (Kannisto et al. 2014). La cepa UAM25 pertenece entonces a la mayoría de las especies del género no oxidantes de glucosa, con capacidad para metabolizar acetato de sodio. El ciclo glioxilato y la gluconeogénesis ocurren cuando acetatos y n-alcanos (HXD) son utilizados como fuentes de carbono (Choi et al. 1996), por tanto se genera la síntesis de azúcares como metabolitos secundarios por estas vías, mientras la obtención de energía ocurre a través de la $\beta$ oxidación (Jung et al. 2011). 


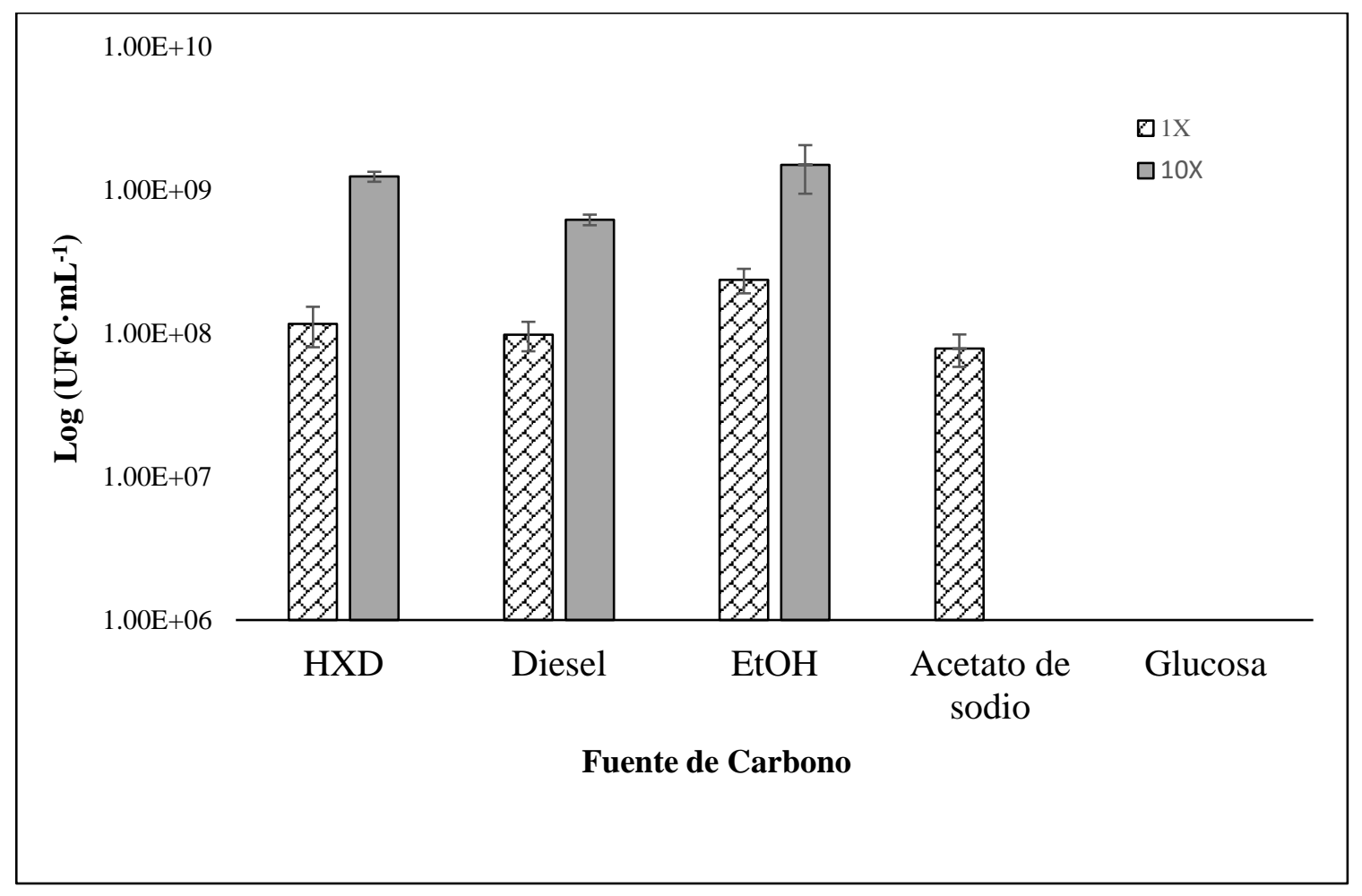

Figura 19 Capacidad de A. bouvetii UAM25 para utilizar diferentes fuentes de carbono de naturaleza hidrofílica y lipofílica

En la Figura 20 se muestra la AE de los sobrenadantes libres de células obtenidos a partir de los diferentes tratamientos (se incluye la composición de proteínas y carbohidratos), la mayor AE se observó cuando HXD y etanol fueron utilizados como fuente de carbono en concentración 10X, la respuesta entonces podría ser optimizada analizando un rango de concentración del MM más amplio. La concentración de carbohidratos y de proteína fue cuantificada considerando a estos como componentes principales de los BE del género. La fuente de carbono puede además tener efecto en la estructura química del BE (Uzoigwe et al. 2015), de forma tal que el crecimiento en etanol resulta en un proporción diferente de carbohidratos/proteína a la proporción cuando HXD es la fuente de carbono.

No se observó efecto proporcional directo de la concentración de fuente de carbono en la respuesta $\mathrm{AE}$, aun cuando esta última es superior a concentraciones más elevadas (10X). Las

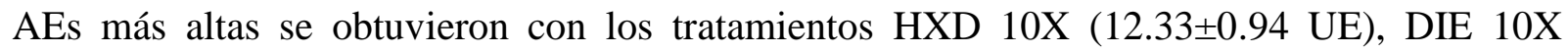
(7.1 $\pm 0.34 \mathrm{UE})$ y etanol $(\mathrm{EtOH}) 10 \mathrm{X}(12.75 \pm 1.38 \mathrm{UE})$, donde la AE del diésel (DIE 10X) fue significativamente inferior $(\alpha=0.05)$ a la de HXD y etanol en $10 \mathrm{X}$, mientras estos últimos no 
presentaron diferencias significativas en $\mathrm{AE}(\alpha=0.05)$ sin embargo entre HXD 10X y EtOH 10X se observaron diferentes proporciones carbohidrato/proteínas, lo que sugiere diferencias en la naturaleza química de los metabolitos presentes en el medio.

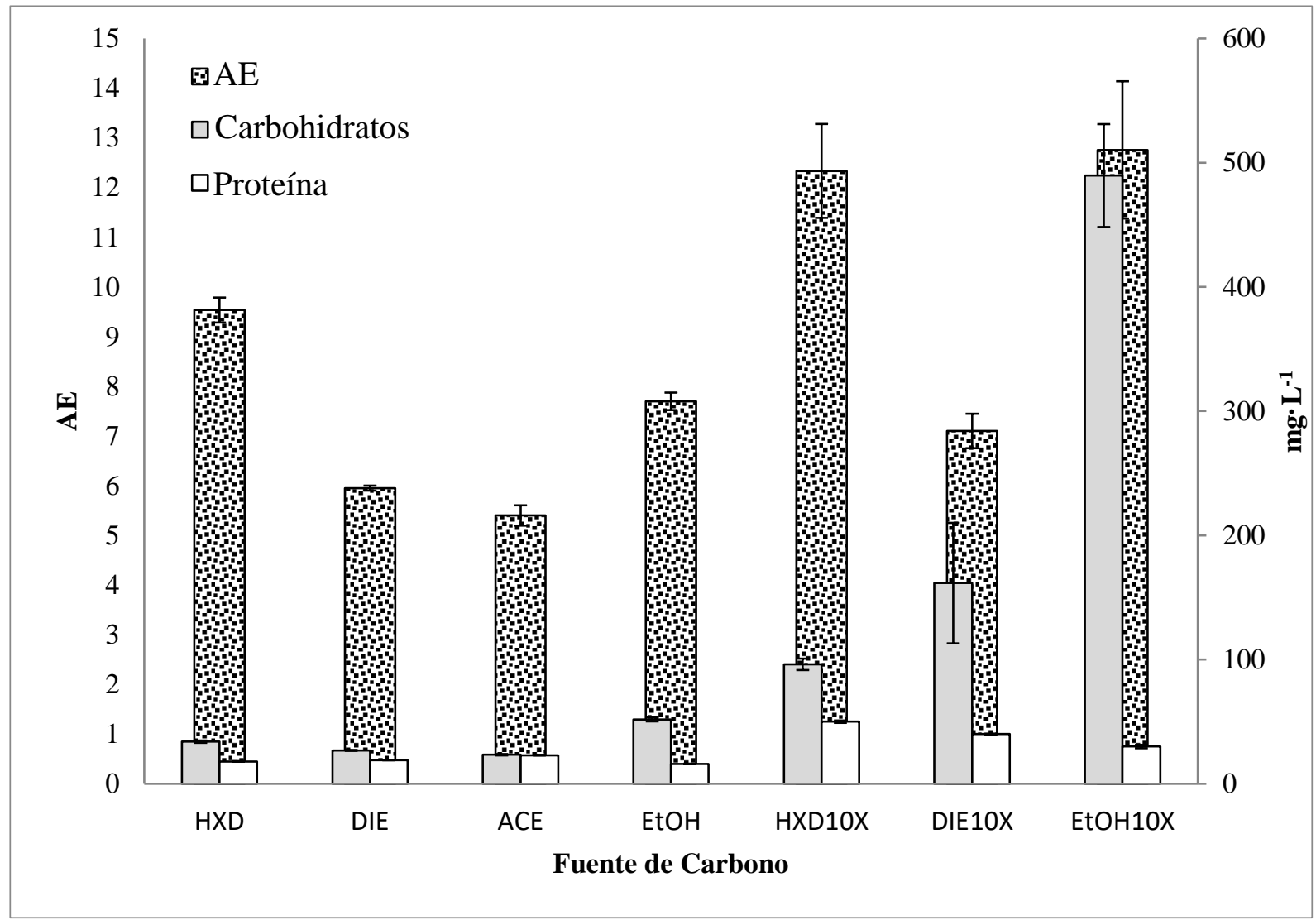

Figura 20 Evaluación de AE, concentración de carbohidratos y proteínas producidas por A. bouvetii UAM25 con diferentes fuentes de carbono, donde HXD; n-hexadecano, DIE; diésel, ACE; acetato de sodio, EtOH; etanol. 10X indica 10 veces la concentración de los componentes del medio

Para todos los tratamientos la concentración de proteína no superó los $50 \mathrm{mg} \cdot \mathrm{L}^{-1}$, la concentración del medio no tuvo un efecto altamente significativo para esta variable, y a su vez no se observó correlación directa de la concentración de proteína con el cambio en AE, por lo que la proteína podría no ser parte de la estructura del BE. Para comprobar la naturaleza de estos componentes fue necesario optimizar la producción de BE y analizar los componentes del mismo. 


\subsection{Optimización de las condiciones de producción del BE}

A partir de los resultados experimentales del diseño factorial $2^{\mathrm{k}}$ se obtuvo la siguiente ecuación lineal en función de la AE:

$$
y=9.6-2 X_{C}-1.06 X_{N}+1.41 X_{C} \cdot X_{N}
$$

Donde los subíndices $C, N$ corresponden a los factores dentro de la regresión, con $X_{C} \cdot X_{N}$ como el coeficiente de la interacción de ambos factores. De acuerdo con la ecuación (4) una reducción proporcional de la concentración de carbono $\left(X_{C}\right)$ cercana al doble con respecto a la concentración de nitrógeno $\left(X_{N}\right)$ favoreció la respuesta de $\mathrm{AE}$. En términos de relación $\mathrm{C} / \mathrm{N}$ se observó que conforme esta relación se aproximó a 10, la respuesta aumentó (Figuras 21 a, b), con el carbono como el factor principal sobre el nitrógeno y con la interacción entre factores (Fig 21 c) no significativa $(\alpha=0.05)$. A partir de los resultados anteriores, con la ecuación (4) (coeficientes codificados), se diseñó el experimento Path of Steepest Ascent (de ascenso pronunciado) descrito en el Cuadro VI, con éste se encontró el rango de $\mathrm{C} / \mathrm{N}$ en la que podría encontrarse el punto de inflexión y, por tanto la máxima respuesta de AE. Los resultados demuestran que existe punto de inflexión y por lo tanto un máximo para la $\mathrm{AE}$ en la región de $\mathrm{C} / \mathrm{N}$ comprendida entre $\mathrm{C} / \mathrm{N}=9.6$ y $\mathrm{C} / \mathrm{N}=11$ (Fig 22). 

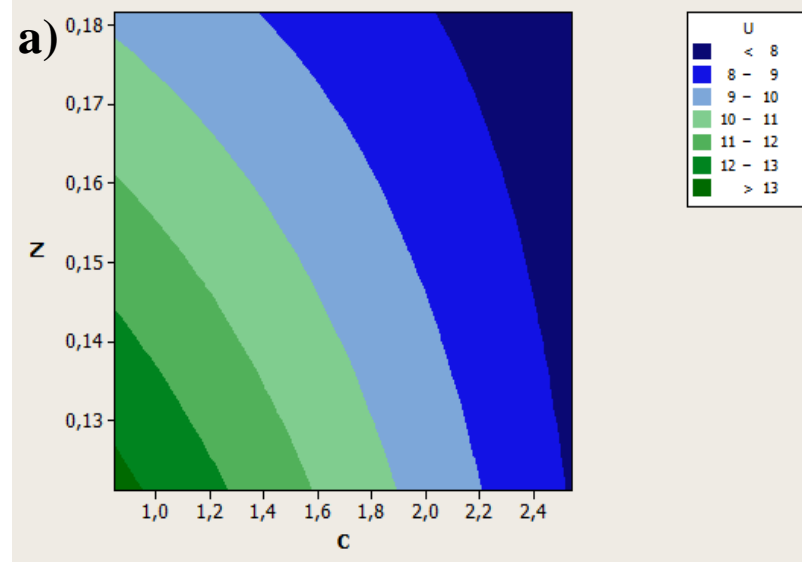

b)
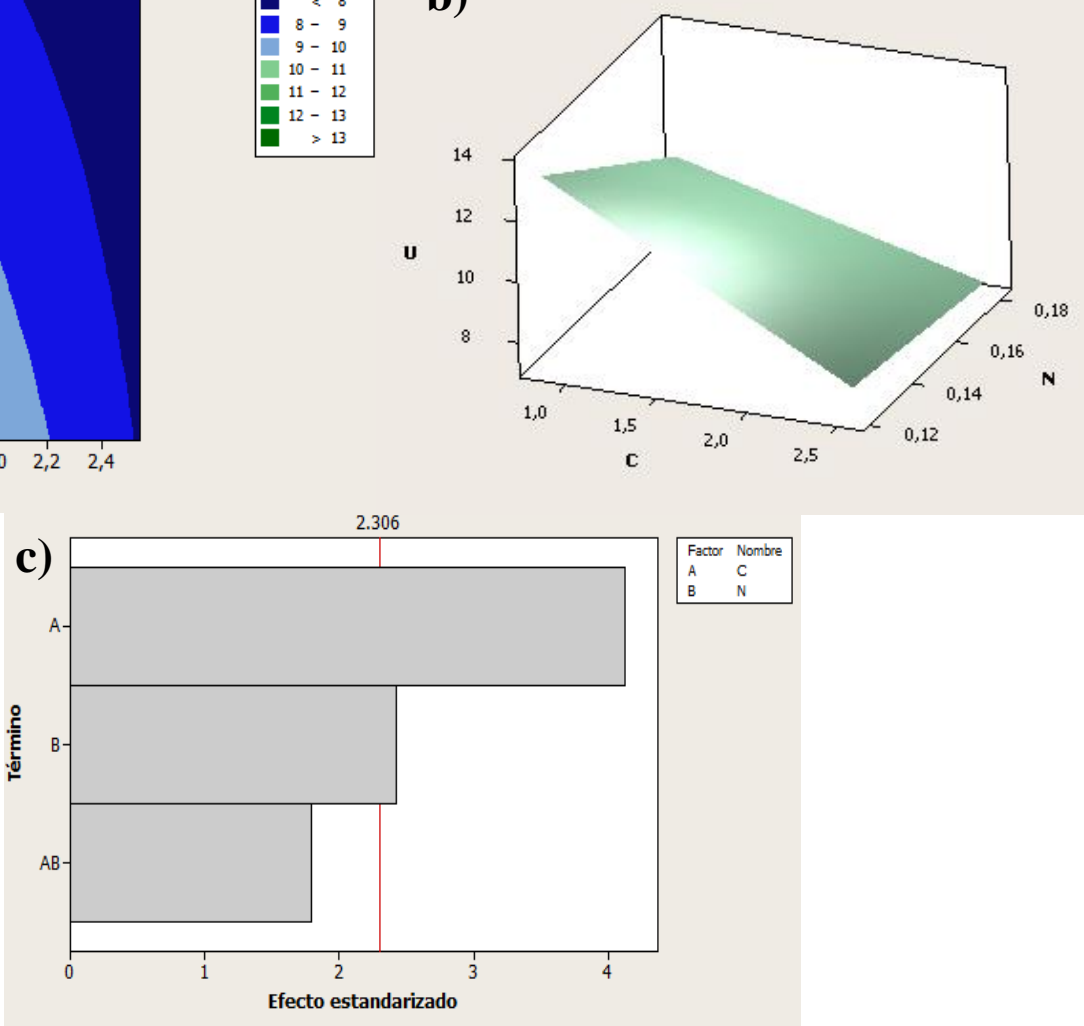

Figura 21 Gráfica de contorno (a) y de superficie (b) de la AE vs fuente de nitrógeno y de carbono. c) Diagrama de Pareto de efectos estandarizados $(\alpha=0.05)$. 
Cuadro VI Diseño Path of Steepest Ascent

\begin{tabular}{cccccc}
\hline \multirow{2}{*}{ Pasos } & \multicolumn{4}{c}{ Niveles de Factor } & \multirow{2}{*}{ C/N } \\
\cline { 2 - 4 } & \multicolumn{2}{c}{ Codificados } & \multicolumn{2}{c}{ Real $\left(\mathbf{g} \cdot \mathbf{L}^{-1}\right)$} & \\
\cline { 2 - 4 } & Carbono & Nitrógeno & Carbono & Nitrógeno & \\
\hline \hline Punto & 0 & 0 & 1.7 & 0.15 & 11.33 \\
base & -0.236 & -0.446 & -0.2 & -0.013 & \\
$\boldsymbol{\Delta}$ & -0.236 & -0.446 & 1.5 & 0.137 & 10.95 \\
$\mathbf{1}$ & -0.472 & -0.892 & 1.3 & 0.124 & 10.48 \\
$\mathbf{2}$ & -0.708 & -1.338 & 1.1 & 0.111 & 9.91 \\
$\mathbf{3}$ & -0.944 & -1.784 & 0.9 & 0.098 & 9.18 \\
$\mathbf{4}$ & -1.18 & -2.23 & 0.7 & 0.085 & 8.24 \\
$\mathbf{5}$ & -1.416 & -2.676 & 0.5 & 0.072 & 6.94 \\
$\mathbf{6}$ & -1.652 & -3.122 & 0.3 & 0.059 & 5.08 \\
$\mathbf{7}$ & -1.888 & -3.568 & 0.1 & 0.046 & 2.17 \\
$\mathbf{8}$ & & & & & \\
\hline
\end{tabular}




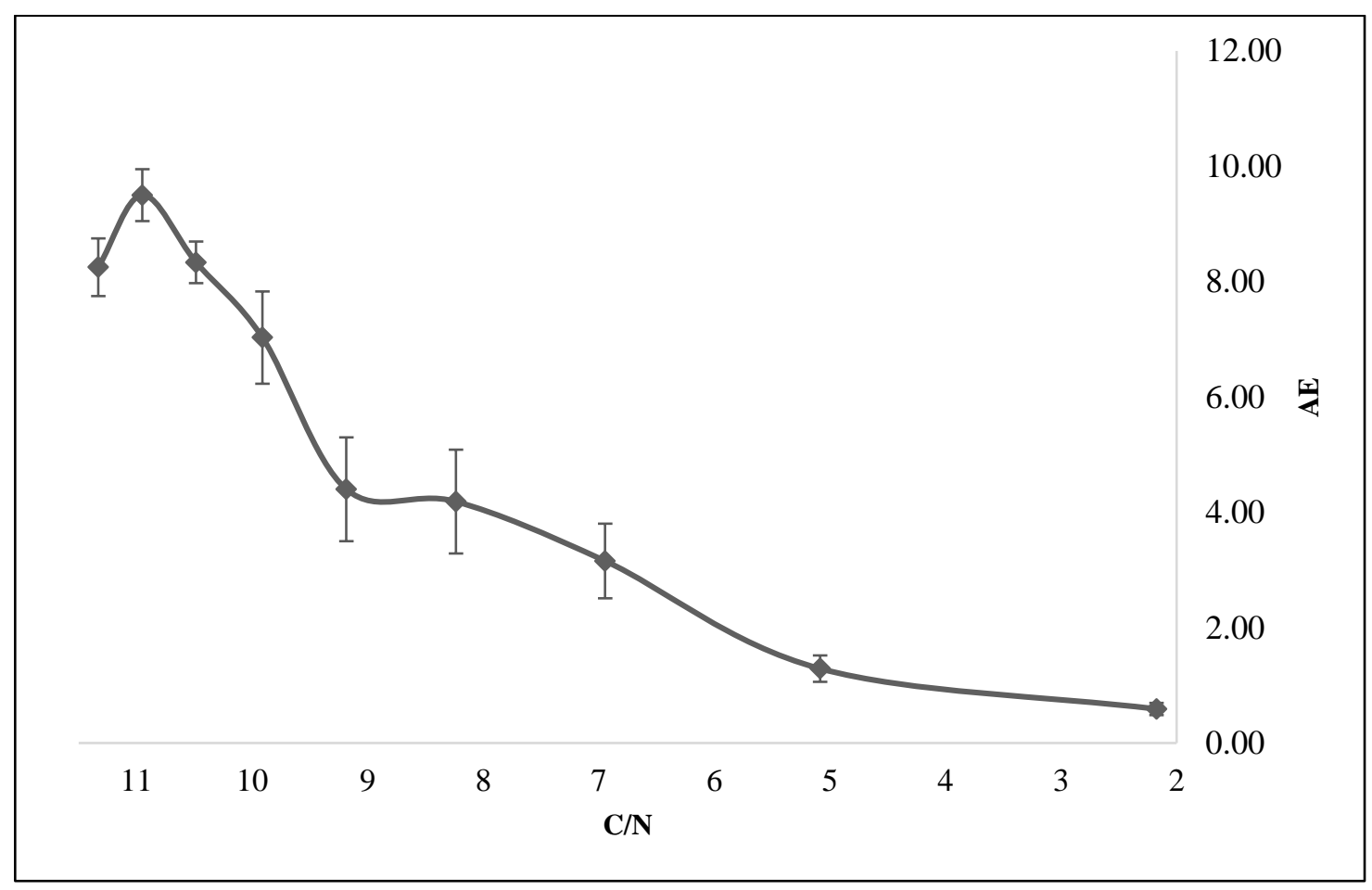

Figura 22 Resultados experimentales del diseño Path of Steepest Ascent para AE

Utilizando el rango de $\mathrm{C} / \mathrm{N}$ que contiene el punto de inflexión (primeros 5 pasos) se realizó un DCC (Cuadro VII) con el cual se determinó que, con una relación $\mathrm{C} / \mathrm{N}=10.48$ con $1.52 \mathrm{~g} \cdot \mathrm{L}^{-1} \mathrm{de}$ HXD y $0.775 \mathrm{~g} \cdot \mathrm{L}^{-}{ }^{1}$ de $\mathrm{NaNO}_{3}$ (Fig. $23 \mathrm{a}$, b) se obtiene la mayor respuesta en AE, con poca variación en el rango de $\mathrm{C} / \mathrm{N}$ de 10 a 11. Esto descrito por la siguiente ecuación de segundo orden:

$$
y=5.36-0.30 X_{C}+0.11 X_{N}-0.75 X_{C} \cdot X_{C}-0.56 X_{N} \cdot X_{N}+0.68 X_{C} \cdot X_{N}
$$

Los coeficientes en la ecuación (5) están codificados y dicho modelo ajustó con $\mathrm{R}^{2}=0.91$. El método de DCC diseñado a partir de un diseño previo de Path of Steepest Ascent fue utilizado por Su et al., (2009) para optimizar los constituyentes del medio de cultivo para la producción 
de Emulsan por Acinetobacter venetianus RAG-1, utilizaron etanol como fuente de carbono, observaron una máxima producción cuando la $\mathrm{C} / \mathrm{N}$ fue de 4 con la concentración de carbohidratos como variable de respuesta. Chen et al., (2012) utilizaron una relación indefinida de $\mathrm{C} / \mathrm{N}$ con extracto de carne y peptona como fuentes de nitrógeno, HXD como fuente de carbono, y Acinetobacter sp. YC-X2 como productora de emulsificante, observaron que la hidrofobicidad de la pared celular del microorganismo tiene un rol fundamental en el consumo de HXD, resultados similares fueron obtenidos por Tzintzun-Camacho et al., (2012) cuando utilizaron una relación $\mathrm{C} / \mathrm{N}=10$ con HXD como fuente de carbono, con A. bouvetii UAM25 como productora, por lo que el consumo de HXD puede atribuirse al contacto directo del microorganismo con el sustrato. Es posible que la relación $\mathrm{C} / \mathrm{N}$ necesaria cambie dependiendo de la hidrofobicidad de la fuente de carbono, mientras que cuando se utilizan sustratos hidrofílicos, como el etanol, la concentración de fosfatos sea más relevante para la promoción de su consumo (Choi et al. 1996). 
Cuadro VII Diseño Central Compuesto para la optimización de la producción de BE

\begin{tabular}{|c|c|c|c|c|c|c|}
\hline \multicolumn{7}{|c|}{ Variable $\left(g \cdot L^{-1}\right)$} \\
\hline Combinación & HXD & $\mathbf{C}$ & $\mathrm{NaNO}_{3}$ & $\mathbf{N}$ & $\mathbf{C} / \mathbf{N}$ & $\mathbf{A E}$ \\
\hline $\mathbf{1}$ & 1.43 & 1.10 & 0.67 & 0.11 & 10.00 & 5.28 \\
\hline 2 & 2.20 & 1.70 & 0.67 & 0.11 & 15.45 & 3.06 \\
\hline 3 & 1.43 & 1.10 & 0.91 & 0.15 & 7.33 & 3.29 \\
\hline 4 & 2.20 & 1.70 & 0.91 & 0.15 & 11.33 & 3.78 \\
\hline 5 & 1.23 & 0.97 & 0.80 & 0.13 & 7.46 & 4.28 \\
\hline 6 & 2.36 & 1.82 & 0.80 & 0.13 & 14.00 & 3.78 \\
\hline 7 & 1.82 & 1.40 & 0.61 & 0.10 & 13.86 & 4.28 \\
\hline 8 & 1.82 & 1.40 & 0.96 & 0.16 & 8.86 & 4.57 \\
\hline 9 & 1.82 & 1.40 & 0.79 & 0.13 & 10.77 & 5.36 \\
\hline 10 & 1.82 & 1.40 & 0.79 & 0.13 & 10.77 & 5.26 \\
\hline 11 & 1.82 & 1.40 & 0.79 & 0.13 & 10.77 & 5.11 \\
\hline 12 & 1.82 & 1.40 & 0.79 & 0.13 & 10.77 & 5.37 \\
\hline 13 & 1.82 & 1.40 & 0.79 & 0.13 & 10.77 & 5.40 \\
\hline
\end{tabular}


a)

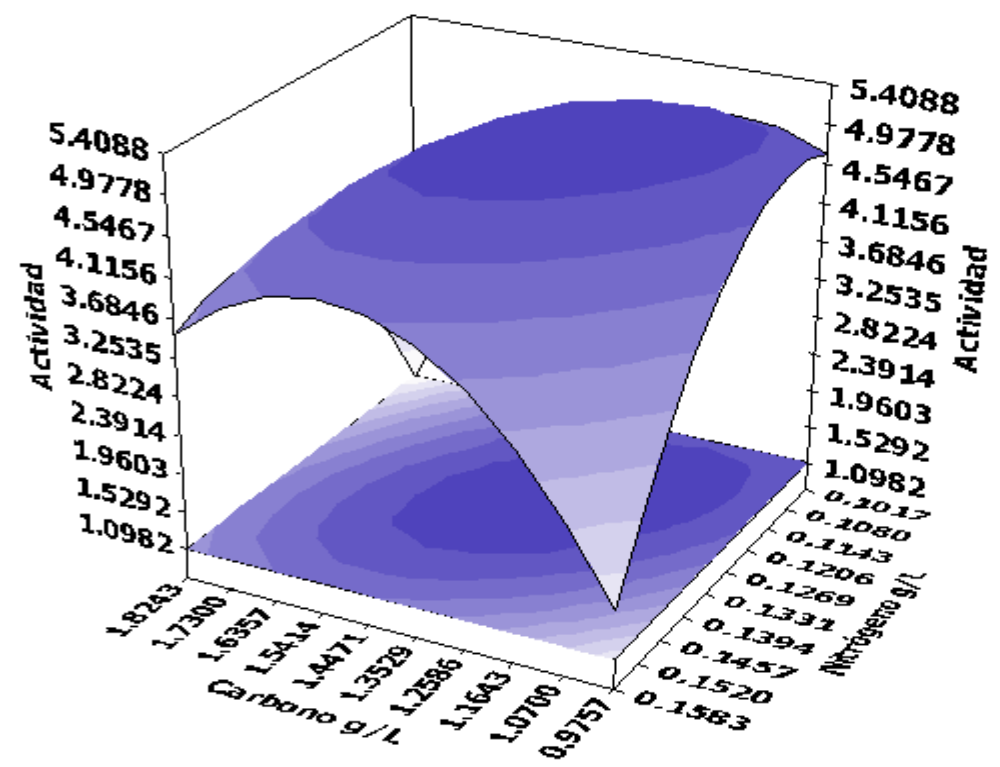

4.9778

4.5467

4.1156

3.6846

3.2535

2.8224

2.3914

1.9603

1.5292

b)

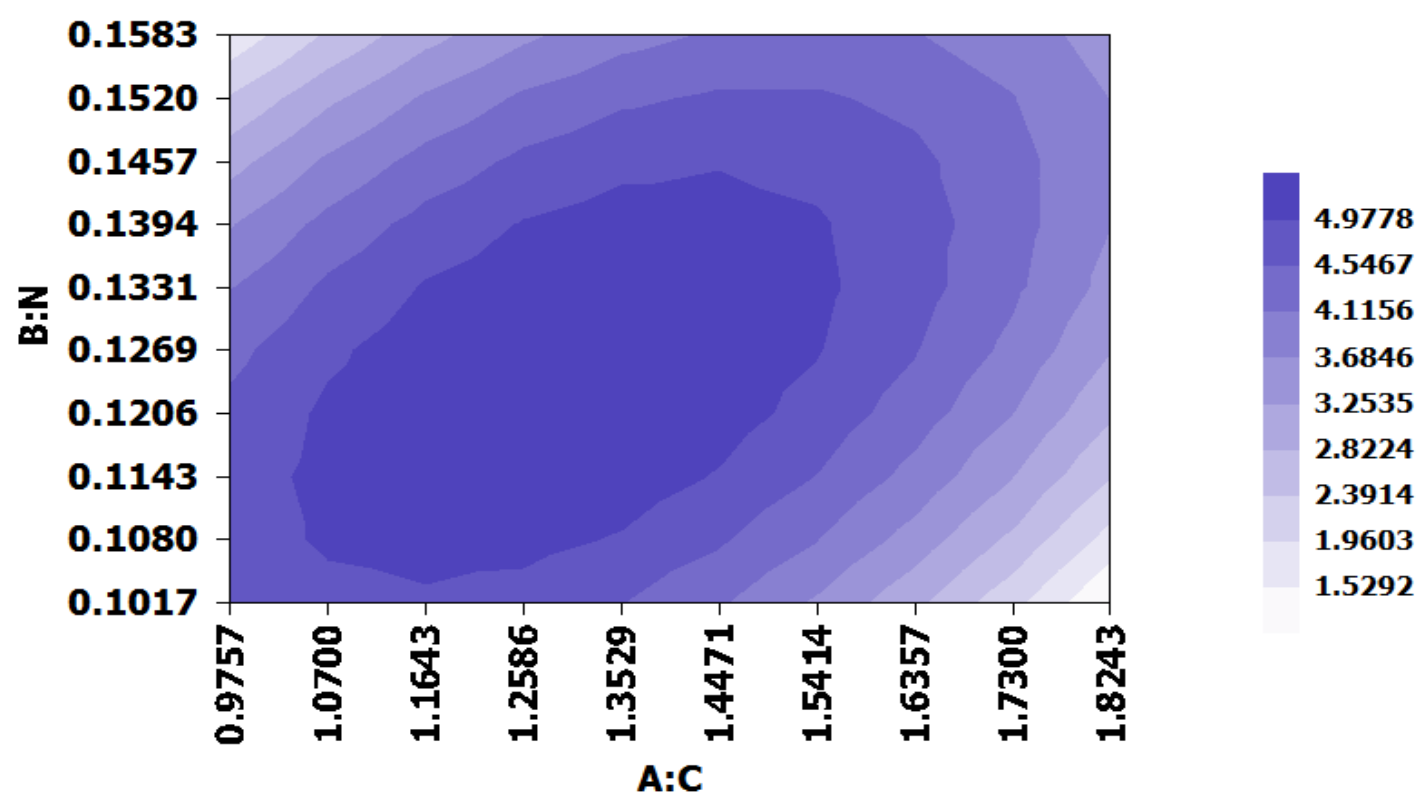

Figura 23 Superficie de respuesta (a) y gráfica de contorno (b) con respuesta AE 
La optimización del medio y condiciones de cultivo para A. bouvetii UAM25, pueden aportar ventajas para el proceso de escalamiento de la producción de BE. En nuestro trabajo se ensayó con un biorreactor airlift con la consecuente modificación de las condiciones de operación, particularmente las hidrodinámicas, con la hipótesis de que estas modificaciones podrían alterar nuestros resultados de capacidad bioemulsificante ya que la modificación del estrés hidrodinámico puede afectar al crecimiento bacteriano y la manera en la que el BE se produce y libera al medio.

\subsection{Consumo de HXD y capacidad BE en biorreactor airlift}

En la Figura 24 se observa que para BAL con Ug de $0.6 \mathrm{~cm} \cdot \mathrm{s}^{-1}$ la degradación de HXD es superior al 90\%. Se observó además un máximo en la concentración de azúcares totales (CHO’s) cercano a los $20 \mathrm{mg} \cdot \mathrm{L}^{-1}$ (Fig 25) y no se detectaron proteínas. Esta concentración es cercana a la mitad de la reportada por $\mathrm{Su}$ et al., (2009) para una cepa de A. venetianus RAG-1 que creció en medio con etanol $\left(16 \mathrm{~g} \cdot \mathrm{L}^{-1}\right)$ como fuente de carbono. Con el fin de mejorar la producción de carbohidratos y con ello mejorar la producción de BE, se ensayaron diferentes condiciones en el reactor airlift.

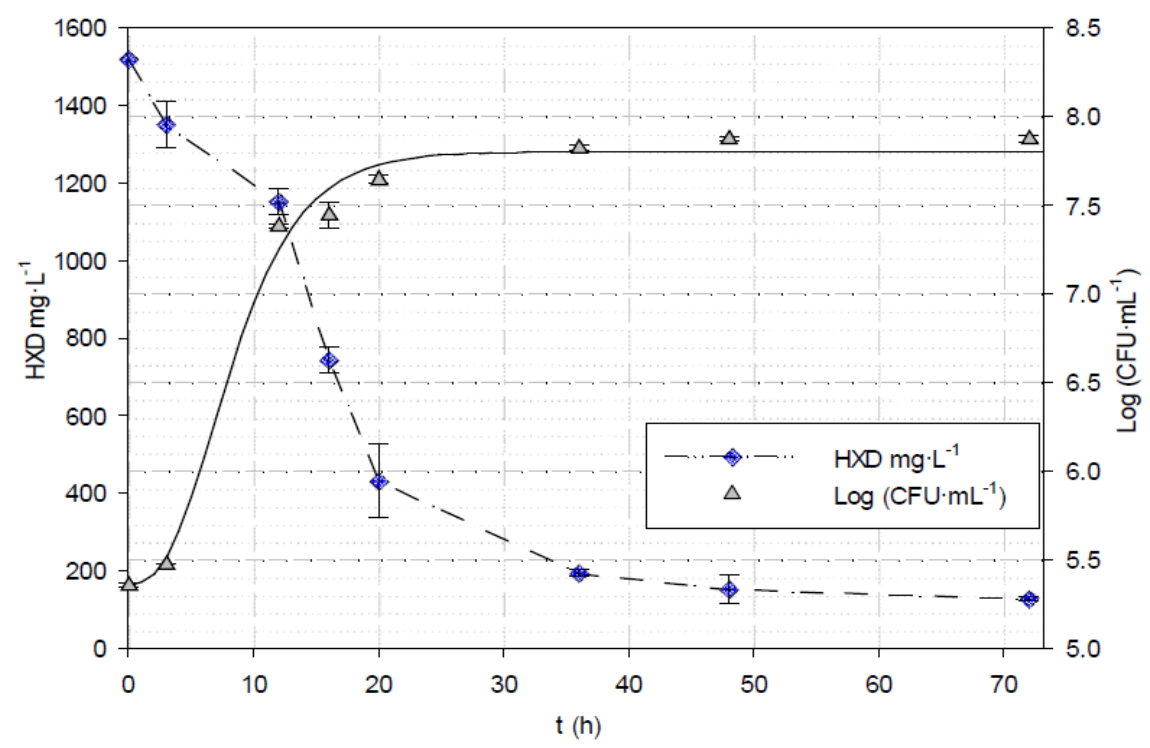

Figura 24 Cinéticas de; degradación de HXD en BAL, crecimiento de $A$. bouvetii con $\mathrm{Ug}=0.6 \mathrm{~cm} \cdot \mathrm{s}^{-1}$. $\mathrm{La}$ línea continua representa el ajuste de los datos experimentales por el modelo de Gompertz 


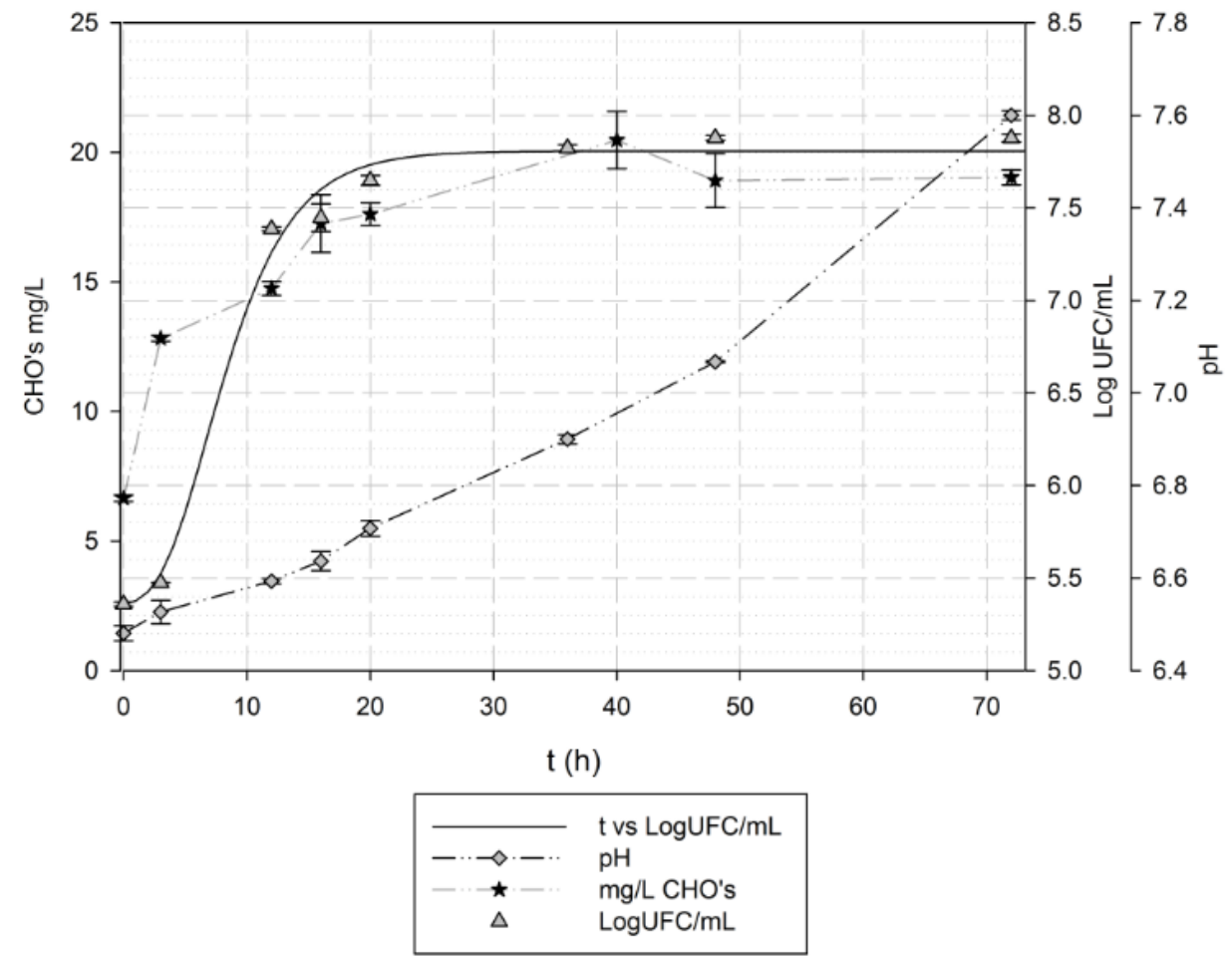

Figura 25 Cinética de crecimiento de A. bouvetii, concentración de carbohidratos totales (CHO's) y cambio de $\mathrm{pH}$, con $\mathrm{Ug}=0.6 \mathrm{~cm} \cdot \mathrm{s}^{-1}$. La línea continua representa el ajuste de los datos experimentales por el modelo de Gompertz

\subsubsection{Evaluación del efecto de Ug en las variables de respuesta}

La Figura 26a muestra el crecimiento celular y la producción de BE bajo diferentes condiciones de Ug, con la composición mineral reportada por Tzintzun-Camacho et al., (2012). Se observó que la Ug y el coeficiente de transferencia de oxígeno $\left(k_{L} a\right)$ no tuvieron efecto significativo sobre la AE del sobrenadante, con valores máximos después de 72 h, de 7.5 y 5.4 unidades de $\mathrm{AE}$ con $\mathrm{X}_{\max }=7.8$ y $7.73 \mathrm{Log} \mathrm{UFC} \cdot \mathrm{mL}^{-1}$ para las $\mathrm{Ug} 0.6$ y $2.7 \mathrm{~cm} \cdot \mathrm{s}^{-1}$ respectivamente (Fig $26 \mathrm{~b}$ ). Se observaron diferencias en los parámetros cinéticos en la etapa inicial de crecimiento, antes de la fase estacionaria. Se observó además producción de una sustancia de consistencia gelosa en forma de biopelícula en las superficies del BAL, esta biopelícula fue separada de las paredes y se evaluó su actividad emulsificante local (Cuadro VIII). 

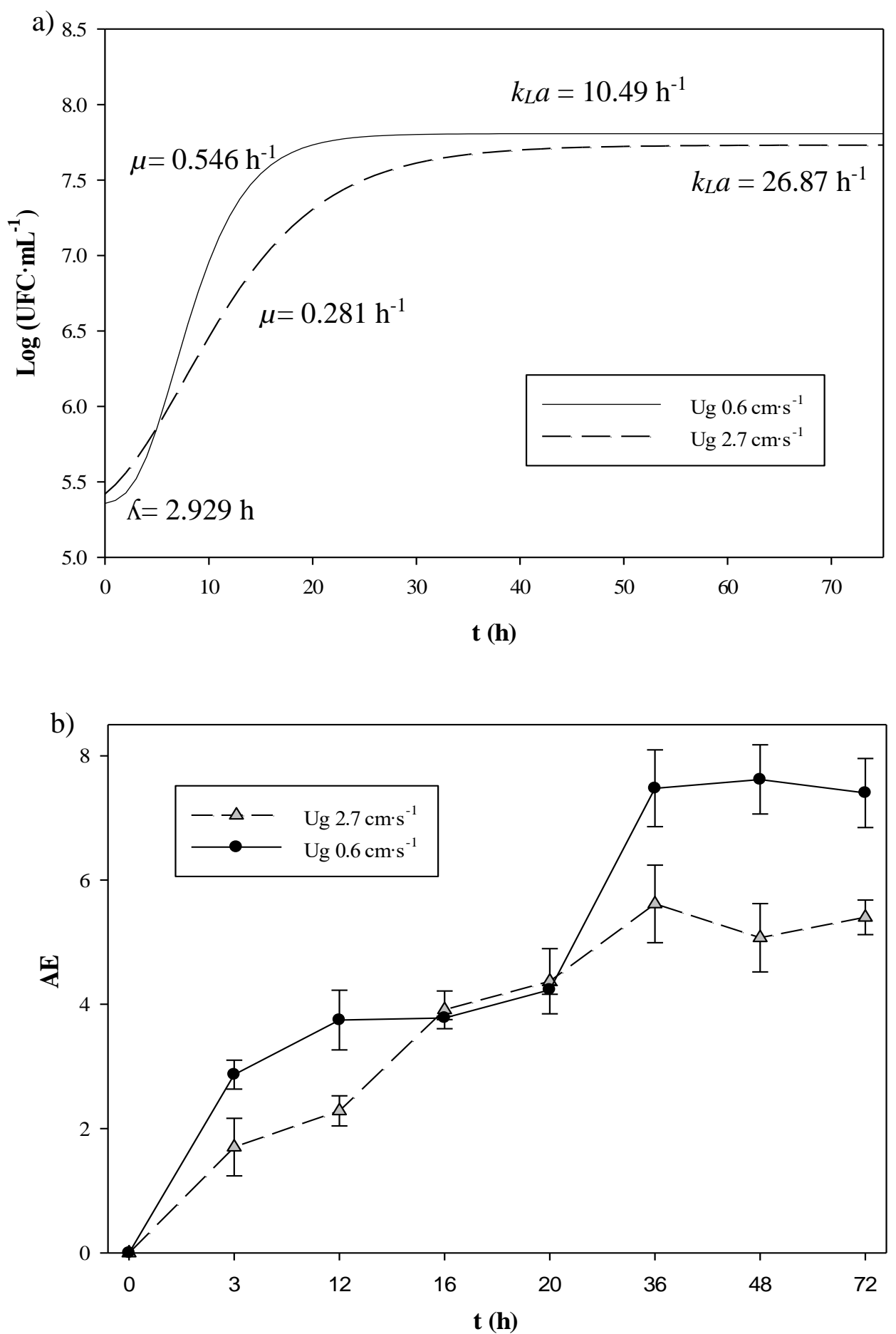

Figura 26 Cinética de crecimiento celular (ajuste por modelo de Gompertz) y parámetros cinéticos calculados (a) y AE (b) en BAL con diferentes Ug 
El patrón de crecimiento en BAL (Fig 26a) se ajustó al modelo re-parametrizado de Gompertz (Zwietering et al. 1990) con $\mathrm{R}^{2}=0.99$. El $k_{L} a$ fue evaluado para buscar diferenciar a UAM25 de las bacterias no productoras de biopelícula, dado que los microorganismos que no producen biopelícula son altamente dependientes de este parámetro, mientras que los microorganismos no móviles productores de biopelícula dependen de parámetros como; la distribución de la biopelícula, depleción, desprendimiento por hidrodinámica y esfuerzo cortante en el sistema, de estos parámetros dependerá la colonización de las superficies del BAL por la cepa.

Tsai (2005), observó que al incrementar la velocidad de flujo, se genera una mejor penetración de los nutrientes y oxígeno a la parte interna de las biopelículas con un incremento consecuente en la densidad de la mismas, pero si el incremento en la velocidad de flujo es demasiado elevado, implica turbulencia en la vecindad de la superficie de la biopelícula, este exceso de esfuerzo genera desprendimiento de biomasa al medio en forma de placas grandes, este desprendimiento se conoce como sloughing y las placas grandes desprendidas así tendrán poca o nula AE, mientras que un desprendimiento menos agresivo por efecto de menor esfuerzo cortante puede generar desprendimiento de porciones pequeñas y solubles, este desprendimiento se conoce como de abrasión y estas porciones desprendidas tendrán mayor AE.

La presencia de biopelícula pudo conferir a la cepa capacidad para resistir el esfuerzo cortante en el reactor, sin embargo la concentración y propiedades de la biopelícula pueden ser afectadas, dependiendo de la cantidad de esfuerzo cortante que soportan (Ras et al. 2013). En nuestro caso la producción de biopelícula pudo verse favorecida a $2.7 \mathrm{~cm} \cdot \mathrm{s}^{-1}$ cuando los valores de $k_{L} a$ son altos. De acuerdo Donlan, (2002) velocidades lineares pueden generar una asociación rápida de biopelícula a las superficies, hasta que la velocidad sea lo suficientemente alta para generar un esfuerzo cortante que promueva el desprendimiento celular de las superficies. (Picioreanu et al. 2001), por lo tanto, con una $\mathrm{Ug}=2.7 \mathrm{~cm} \cdot \mathrm{s}^{-1}$ se observó menor desprendimiento en forma de $\mathrm{BE}$ como una menor AE del medio y menor concentración de UFC en el medio.

Cuando el medio de cultivo en BAL se mantuvo lejos de un flujo turbulento $\left(\mathrm{Ug}=0.6 \mathrm{~cm} \cdot \mathrm{s}^{-1}\right)$, el desprendimiento del exopolisacárido por abrasión (en porciones uniformes de menor tamaño de biomasa) pudo ocurrir, evitando el desprendimiento en placas grandes de biopelícula, y en consecuencia se favoreció la emulsificación de la fuente de carbono, es decir, el desprendimiento gradual de exopolisacárido correspondió a un aumento de BE en el medio, por 
esto, la mayor distribución de las variables de respuesta (carbohidratos, proteína y AE) se encontró en el sobrenadante. Por lo tanto, la biopelícula, es el BE polimérico adherido a las paredes y al distribuidor del BAL.

Se observaron diferencias en la tasa específica de crecimiento y fase $l a g$, las cuales se pueden atribuir a la baja producción de biopelícula, con alta dependencia al mezclado y a los cambios de hidrofobicidad de las paredes celulares para realizar el contacto con el HXD (TzintzunCamacho et al. 2012).

Cuadro VIII Distribución de BE en el BAL

$\%$

Carbohidratos Proteína AE Volumen

\begin{tabular}{lcccc}
\hline Sobrenadante & 95.1 & 100 & 76.5 & 93 \\
\hline Biopelícula sobre la superficie de acero & 4.26 & 0 & 19.34 & 5.9 \\
\hline Biopelícula sobre la superficie de vidrio & 0.64 & 0 & 4.16 & 1.1 \\
\hline
\end{tabular}

Como se muestra en Cuadro VIII, la biopelícula por si sola tiene baja AE y esta variable de respuesta disminuyó cuando una $U g=2.7 \mathrm{~cm} \cdot \mathrm{s}^{-1}$ fue utilizada, por lo tanto, el desprendimiento de biopelícula por sloughing en contra de desprendimiento por abrasión y erosión ocurrió a esta $\mathrm{Ug}$, indicando desprendimiento de $\mathrm{BE}$ soluble con $\mathrm{Ug}$ y $k_{L} a$ inferiores, reflejado con valores de AE y $\mu$ superiores (Fig 26a y b). Por lo tanto, la $U g=0.6 \mathrm{~cm} \cdot \mathrm{s}^{-1}$ fue seleccionada para las siguientes etapas experimentales, ya que la hidrodinámica bajo estas condiciones favorece al aumento de la $\mathrm{AE}$ en el medio por acción del desprendimiento de BE por abrasión. Se observó entonces que la producción de BE en BAL es gobernada por el comportamiento dinámico de la producción de biopelícula.

\subsection{Concentración y relación $\mathrm{C} / \mathrm{N}$ óptima}

Con el fin de mejorar la producción de BE, además de los experimentos de optimización anteriores, donde la $\mathrm{C} / \mathrm{N}=10.5$ fue seleccionada, se evaluó el efecto que tienen en el crecimiento y AE; la concentración de componentes en el medio mineral, concentración de fuente de carbono y biomasa inicial inoculada. Al igual que en la estrategia de optimización por DCC el 
experimento se realizó en dos etapas; (i) evaluación de las variables en botellas serológicas y, con el fin de obtener mayor producción con mayor homogeneidad, (ii) evaluación en BAL del mejor tratamiento.

Analizando los resultados de la primera etapa, no se encontraron diferencias significativas $(\alpha=0.05)$ entre los tratamientos para la variable "crecimiento celular" cuando se utilizó la misma concentración en MM (tratamiento D, E). La concentración de carbohidratos y el crecimiento bacteriano incrementaron de manera proporcional a la concentración de MM y HXD. Las máximas respuestas para las variables; crecimiento, concentración de carbohidratos y proteínas se encontraron en el tratamiento $\mathrm{C}$ con, $1.22 \cdot 10^{9} \mathrm{UFC} \cdot \mathrm{mL}^{-1}, 207 \mathrm{mg} \cdot \mathrm{mL}^{-1}$ y $57 \mathrm{mg} \cdot \mathrm{mL}^{-1}$ respectivamente (Fig 27).

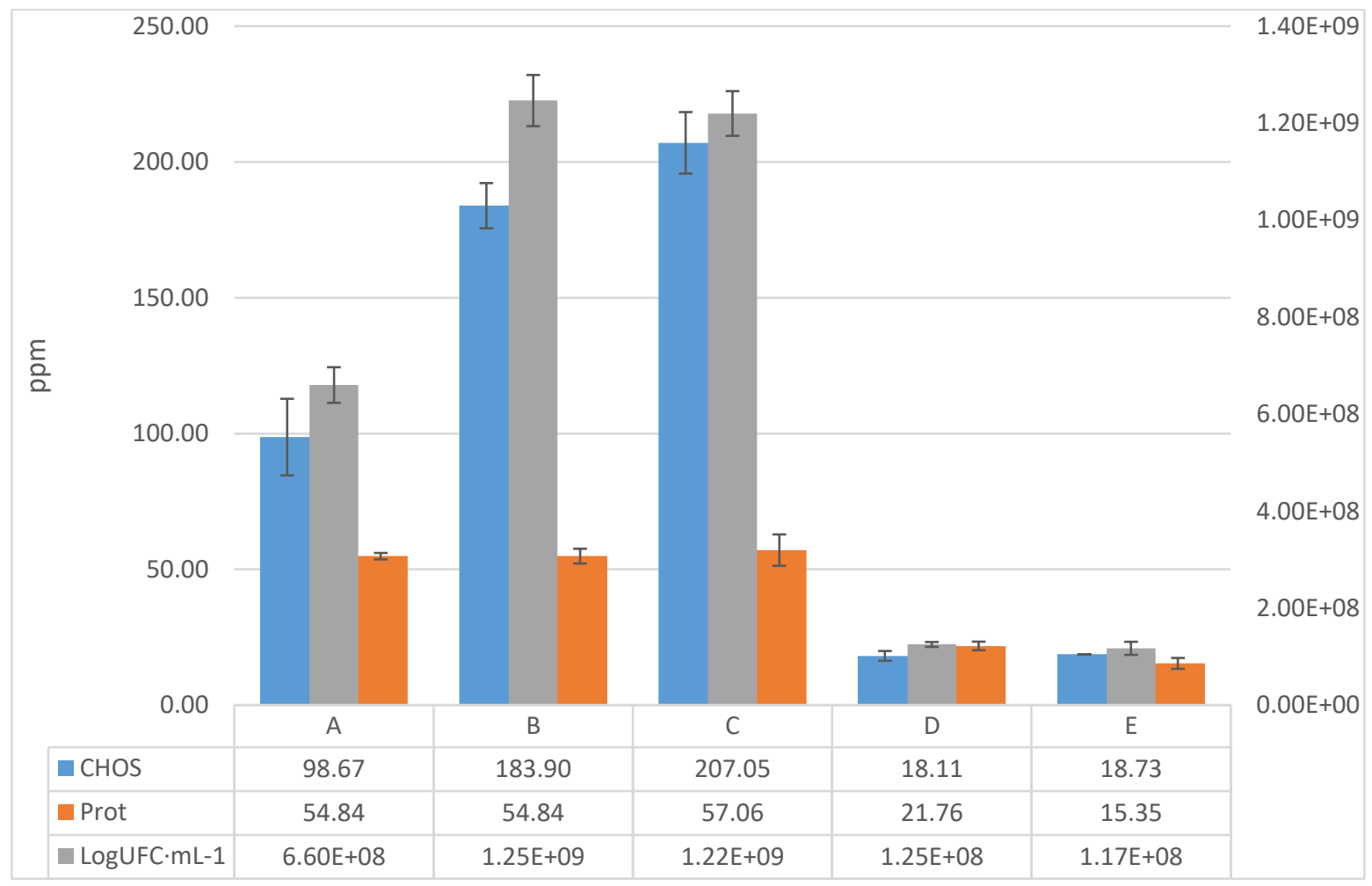

Figura 27 Evaluación de los diferentes tratamientos a través de la concentración de los carbohidratos totales (CHOS), de proteína (Prot) y crecimiento celular después de 48 h. 
No se encontraron diferencias significativas en la AE entre los tratamientos A, B y C (Fig 28, 5x6, 10x6, 10x7 respectivamente) con un máximo cercano a 11 unidades de emulsificación, mientras los tratamientos D y E mostraron menor AE sin diferencia significativa entre ellos $(\alpha=0.05)$. No se observó correlación directa entre la AE y la concentración de carbohidratos (Fig 29). Aun cuando la concentración de proteína se elevó de manera similar a la AE, al aumentar la concentración de $\mathrm{MM}$, la concentración de proteína no superó las 60 ppm en ningún tratamiento. Los BEs de Acinetobacter en los cuales su AE es resultado de la composición proteica, presentan una mayor proporción de proteína con respecto al carbohidrato, tal es el caso del BE Alasan reportado por Navon-Venezia et al., (1995). Para el caso de A. bouvetii UAM25 la concentración de carbohidratos demostró ser un factor con mayor relevancia en relación con su AE y producción de biomasa.

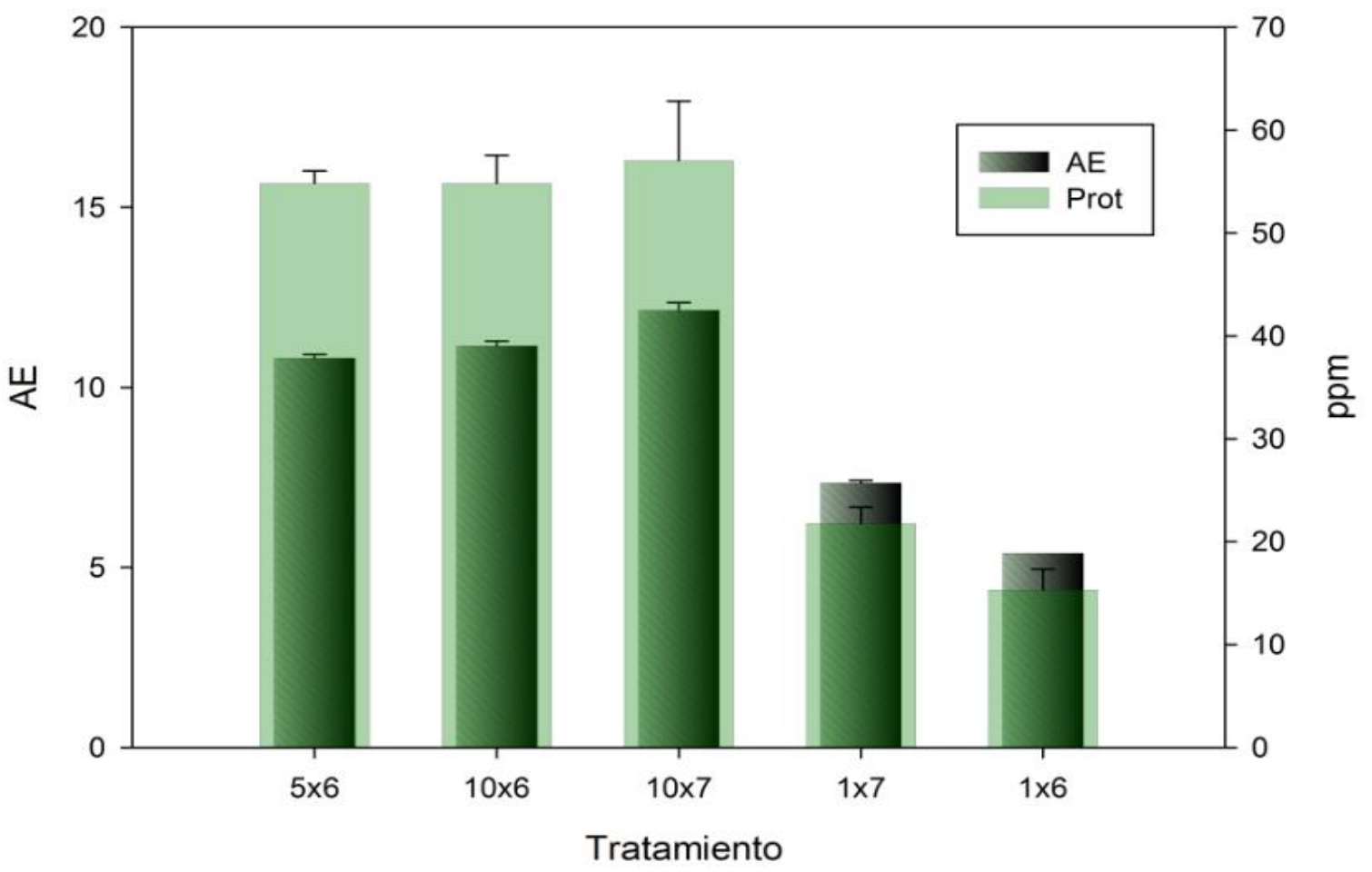

Figura 28 Relación AE con concentración de proteínas. Concentración y unidades de actividad emulsificante indicadas como partes por millón (ppm) y AE respectivamente. 


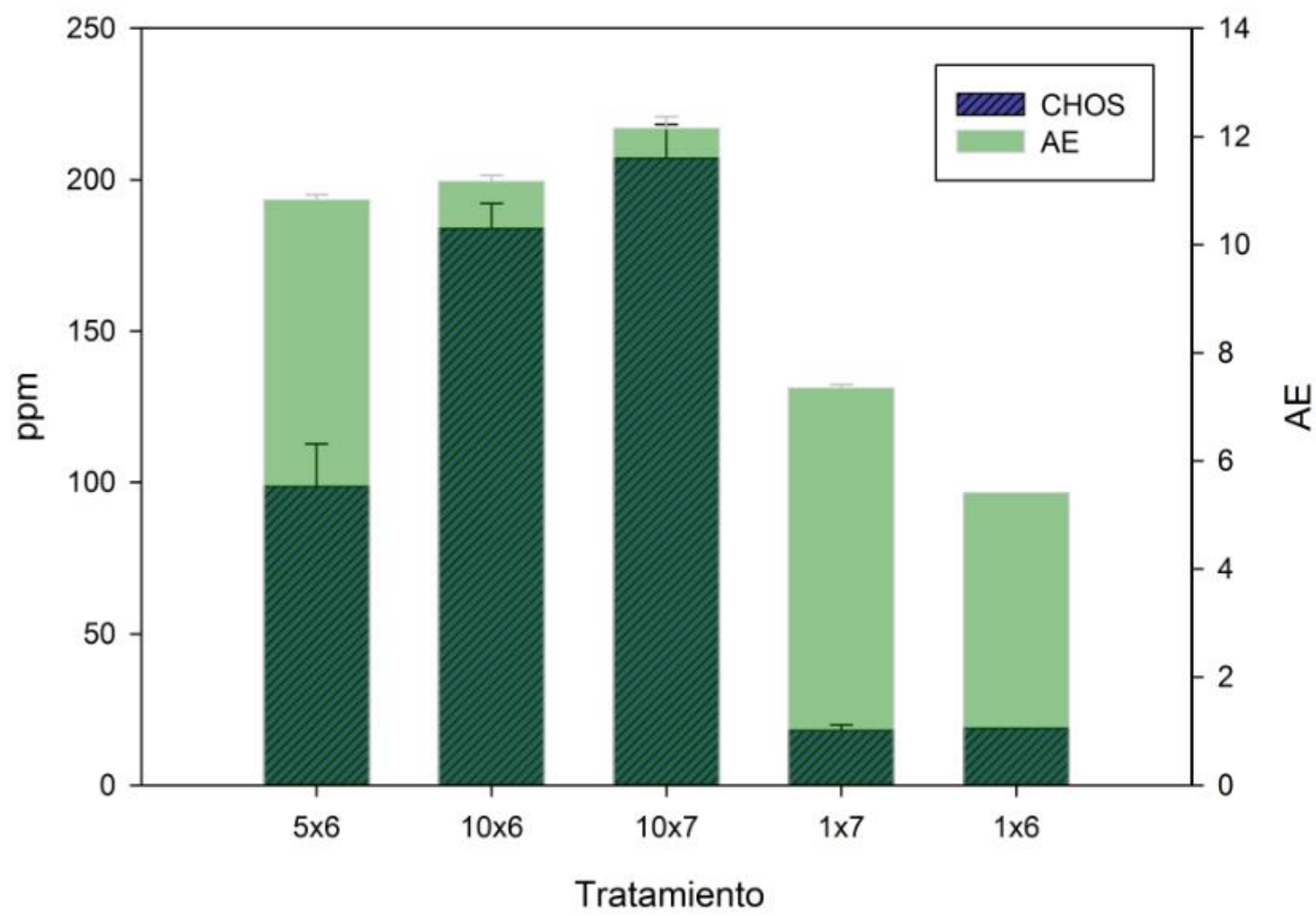

Figura 29 Relación de AE con la concentración de Carbohidratos totales. Concentración y unidades de actividad emulsificante indicadas como partes por millón (ppm) y AE respectivamente.

Los resultados de la primera etapa demostraron que después de aumentar la concentración del MM 5 veces existió aumento en la AE de manera no proporcional, logrando duplicar la AE al utilizar el tratamiento A. La falta de proporcionalidad de la variable AE con respecto a la biomasa y concentración de carbohidratos podría ser explicada por la máxima capacidad emulsificante del BE, la cual podría alcanzarse a las condiciones 5X de MM y mantenerse sin cambio significativo aun cuando la concentración aumentó 10 veces. El tratamiento A fue seleccionado para realizar la siguiente etapa en el BAL, con la relación C/N y Ug anteriormente seleccionadas.

En la Figura 30 se muestran las cinéticas de crecimiento celular, AE y de HXD residual, al utilizar BAL para evaluar el tratamiento "A", seleccionado en los experimentos en botellas serológicas. Con este experimento se encontró la fase de crecimiento en la cual el BE tiene la mejor AE. El patrón de crecimiento pudo ser explicado con $\mathrm{R}^{2}=0.99$ por el modelo re- 
parametrizado de Gompertz: no se detectó fase lag, la $\mu_{\max }$ fue de $0.395 \pm 0.073 \mathrm{~h}^{-1}$ con un máximo crecimiento de $8.6 \pm 0.17 \mathrm{Log} \mathrm{UFC} \cdot \mathrm{mL}^{-1}$ sin diferencias significativas después de $20 \mathrm{~h}$ de crecimiento $(\alpha=0.05)$. La AE aumentó significativamente después de $15 \mathrm{~h}$ de cultivo y después permaneció sin cambios, con una AE máxima de $12.51 \pm 0.72$ unidades después de 48 h. A las 72 h, $47 \pm 2.4 \%$ del HXD fue consumido; sin embargo, $24 \pm 3.7 \%$ fue removido en un lapso posterior de $20 \mathrm{~h}$. El resto del HXD (23\%) requirió 52 h más para ser consumido, este último lapso corresponde a la fase estacionaria, mientras las etapas anteriores se correlacionaron con la fase exponencial. La AE se elevó significativamente $5 \mathrm{~h}$ antes del final de la fase exponencial, alcanzando un máximo en la fase estacionaria mientras la tasa de desaparición del HXD permanecía baja.

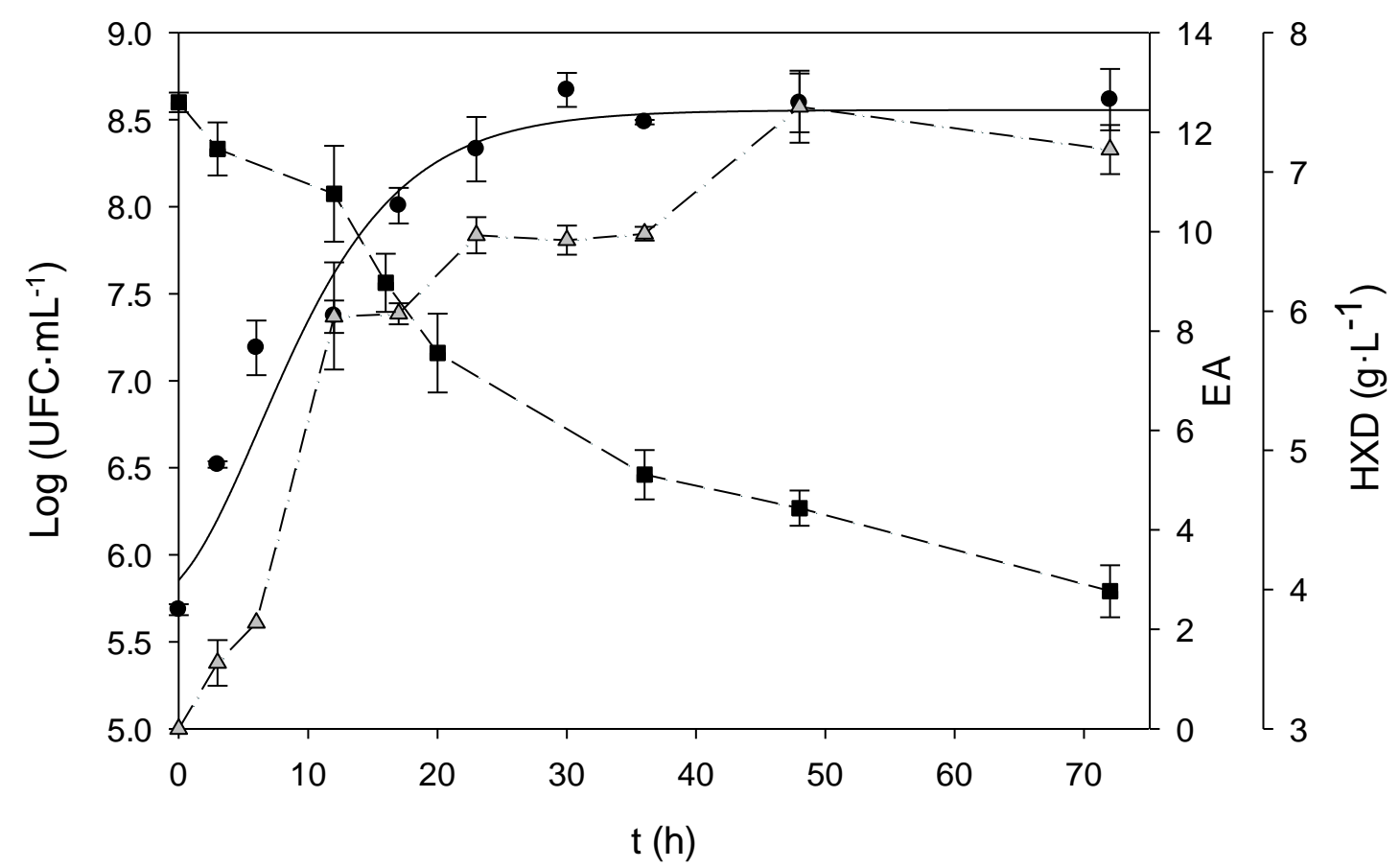

Figura 30 Crecimiento celular en BAL $(-\bullet), \mathrm{AE}\left(\bullet^{-}-\right)$y HXD residual $\left({ }^{-}-\cdot\right)$. La línea continua corresponde al ajuste del crecimiento por el modelo de Gompertz

A pesar de la baja capacidad emulsificante en el medio durante las horas iniciales de cultivo, no significa que no existiera producción de BE, ya que pudo ser producido asociado a la pared celular como una biopelícula, esto antes a su desprendimiento cuando las condiciones lo favorecieron (Goldman et al. 1982). Por lo tanto, la AE fue baja en el MM en las horas iniciales 
de la cinética. La presencia de BE en la pared celular también pudo aumentar la hidrofobicidad celular y en consecuencia favorecer el contacto y consumo de la fuente de carbono (Baldi et al. 1999). De manera similar Mehdi \& Giti, (2008) observaron incremento en la afinidad hacia el HXD y otros hidrocarburos por parte de bacterias Gram negativas en la etapas tempranas de crecimiento con producción de biopelícula. En nuestro estudio, la producción de BE ocurrió asociada al crecimiento. La correlación entre crecimiento bacteriano y AE ya se ha reportado antes, por ejemplo, cuando se produce el biosurfactante de Halomonas sp. MB-30 (Dhasayan et al. 2014), de tal forma que la AE puede ser utilizada como una medida indirecta de la concentración de BE. Nuestros resultados demostraron que un lapso de 48 h es adecuado para detener la cinética y purificar el BE con la mejor AE, además, los resultados indican que el BE pudo ser principalmente liberado al medio al final de la fase exponencial y durante la fase estacionaria, cuando la bacteria y BE son forzados a desprenderse de las superficies del BAL. Los microorganismos dentro del género Acinetobacter han sido reportados como consumidores de HXD como fuente de carbono, con un consecuente aumento en el pH del medio (Chen et al. 2012). Nuestros datos experimentales concuerdan con estos reportes, ya que el pH aumentó de 6.5 a 7.4 (Fig 31). En la cinética de la cepa UAM25 Se observó una producción relativamente baja de proteína, contrario a lo que ocurre con otras cepas del mismo género en cultivos a un periodo similar de tiempo, como es el caso de Acinetobacter radioresistens, donde la producción de proteína está directamente relacionada con el aumento en la capacidad emulsificante (NavonVenezia et al. 1995). Sin embargo, se observa que para la cepa UAM25 la producción de carbohidratos (Fig 31) fue superior que otras reportadas para los BE de tipo polisacárido. Su et al., (2009) reportaron una producción total de Emulsan de $60 \mathrm{mg} \cdot \mathrm{L}^{-1}$ después de $120 \mathrm{~h}$ de crecimiento celular, considerando los carbohidratos totales directamente como la concentración de Emulsan. La producción de carbohidratos por A. bouvetii UAM25 incrementó significativamente después de $20 \mathrm{~h}$ con un valor de $144.62 \pm 6.77 \mathrm{mg} \cdot \mathrm{L}^{-1}$, este valor correlacionado con la respuesta $\mathrm{AE}$ y con la producción de $\mathrm{BE}$. 


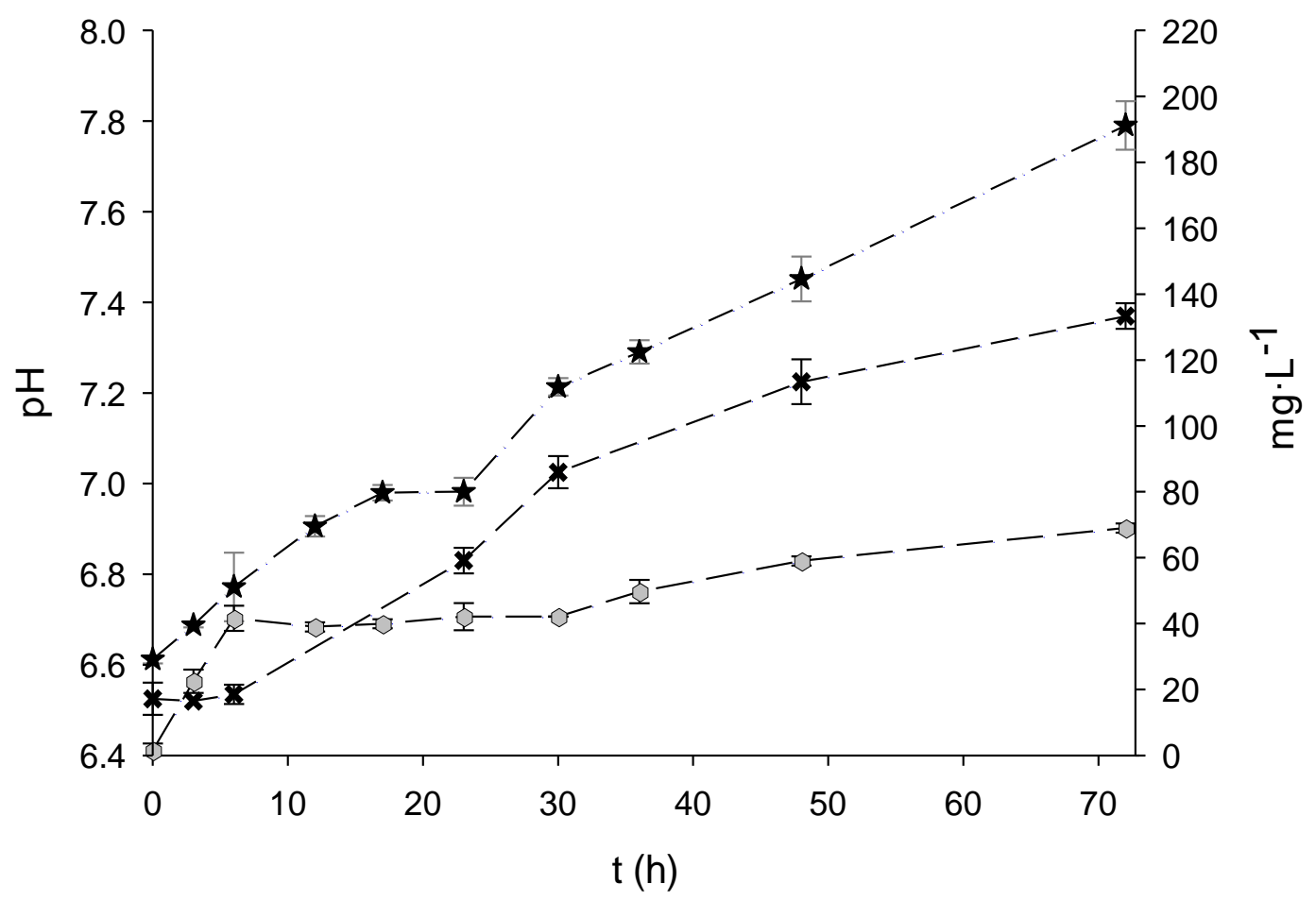

Figura 31 Evaluación de la concentración de Carbohidratos $(\cdot-\star-\cdot)$, proteína $(-\rightarrow-)$ y del $\mathrm{pH}\left(\left(^{-\boldsymbol{x}--}\right)\right.$ con respecto al tiempo (h)

La respuesta de las diferentes variables se incrementó al realizar la producción en BAL (Cuadro IX). Las respuestas fueron superiores en BAL incluso para la concentración de MM de 1x. Cuando las condiciones de optimización se aplicaron en BAL (5X) se obtuvieron los resultados más altos en la concentración de carbohidratos y AE, con incremento en la concentración de proteína. 
Cuadro IX Producción de carbohidratos, proteína y cambio de $\mathrm{pH}$ a las 48 h, utilizando botellas serológicas y BAL

\begin{tabular}{|c|c|c|c|c|}
\hline & $\mathrm{C} / \mathrm{N} 1 \times \mathrm{BAL}^{\mathrm{a}}$ & C/N 5x BAL & C/N 1x Botella & C/N 5x Botella \\
\hline U Actividad & $7.6 \pm 0.56$ & $13.25 \pm 0.1$ & $4.4 \pm 0.01$ & $10.82 \pm 0.09$ \\
\hline Crecimiento $^{c}$ & $7.87 \pm 0.01$ & $8.6 \pm 0.17$ & $8.06 \pm 0.05$ & $8.82 \pm 0.023$ \\
\hline $\mathrm{pH}$ & $7.06 \pm 0.001$ & $7.19 \pm .01$ & $7.5 \pm .01$ & $7.67 \pm .01$ \\
\hline Carbohidratos & $18.91 \pm 1.04^{d}$ & $144.62 \pm 6.78$ & $18.72 \pm 2.01$ & $98.67 \pm 14.1$ \\
\hline Proteína & ND & $59 \pm 1.41$ & $21.76 \pm 1.58$ & $54.84 \pm 1.18^{e}$ \\
\hline $\begin{array}{l}{ }^{\mathrm{b}} \text { Concentración de } \\
\mathrm{c} \text {, d, e Unidades de cr } \\
\text { está dada en ppm } \\
\text { ND: no se detectó r }\end{array}$ & $\begin{array}{l}\text { fuente de car } \\
\text { ento celular en }\end{array}$ & $\begin{array}{l}1 \cdot \mathrm{s}^{-1} \\
5 \text { veces super } \\
\left(\mathrm{UFC} \cdot \mathrm{mL}^{-1}\right) .\end{array}$ & entración de & drat \\
\hline
\end{tabular}

\subsection{Purificación del BE}

Una vez conocidos los componentes principales de los BE producidos, se compararon los métodos de extracción tanto para proteína (precipitación con sulfato de amonio) como para carbohidratos (precipitación con iso-propanol y extracción con formaldehido- $\mathrm{NaOH}$ ). Se observó que, por la técnica de extracción con iso-propanol no se logró la extracción total de carbohidratos, y solo el 30\% del extracto obtenido se identificó como carbohidrato, siendo la masa restante un componente no identificado, probablemente correspondiente a sales remanentes o a lípidos. La máxima cantidad de carbohidratos obtenida por tratamientos diferentes a la ultrafiltración, fue $30 \mathrm{mg}$ por reactor (Cuadro X), lo que corresponde a la cuarta parte de los carbohidratos totales por reactor, calculados por la técnica de DuBois et al, (1956). Por las técnicas de precipitación de proteínas y extracción con formaldehido no se obtuvieron cifras superiores. De acuerdo a Ron y Rosenberg, (2001) la técnica de precipitación con sulfato de amonio sólo es eficiente para la extracción de carbohidratos si éstos están asociados a proteínas. La técnica de extracción con formaldehido no fue eficiente, esta técnica se basa en la extracción de exopolisacáridos de la pared celular de los microorganismos, posiblemente los carbohidratos responsables de la actividad emulsificante migraron principalmente al medio de cultivo. Por la técnica de precipitación con sulfato de amonio sólo fue posible identificar un 10 $\%$ de proteína del extracto de BE precipitado $(158 \mathrm{mg})$ siendo la masa restante un compuesto no identificado, posiblemente sales no eliminadas durante la diálisis y carbohidratos, esto considerando que la concentración de extracto obtenida por esta técnica fue similar a la concentración obtenida por ultrafiltración. Navon-Venezia et al., (1995) y Rosenberg et al., 
(1979) purificaron emulsificantes de tipo polisacárido con la técnica de precipitación con sulfato de amonio, aunque la técnica es preferible cuando las moléculas objetivo son proteínas, por ello, agregan un paso adicional de corte de fracción proteica.

La concentración de proteína por reactor correspondió a alrededor de 22 mg por litro similar a la concentración determinada en el sobrenadante libre de células, por lo que el componente proteico del sobrenadante pudo ser aislado con alrededor de $80 \%$ de eficiencia por la técnica de precipitación con sulfato de amonio. Este extracto demostró ser responsable del $11 \%$ de la $\mathrm{AE}$ en el reactor (Cuadro X) y no se obtuvo de manera pura ya que sólo $9 \%$ del extracto correspondió a proteína y la proporción restante no fue identificada, la fracción no identificada pudiera desempeñar un papel importante como componente estructural del BE y podría tratarse de una fracción de carbohidrato.

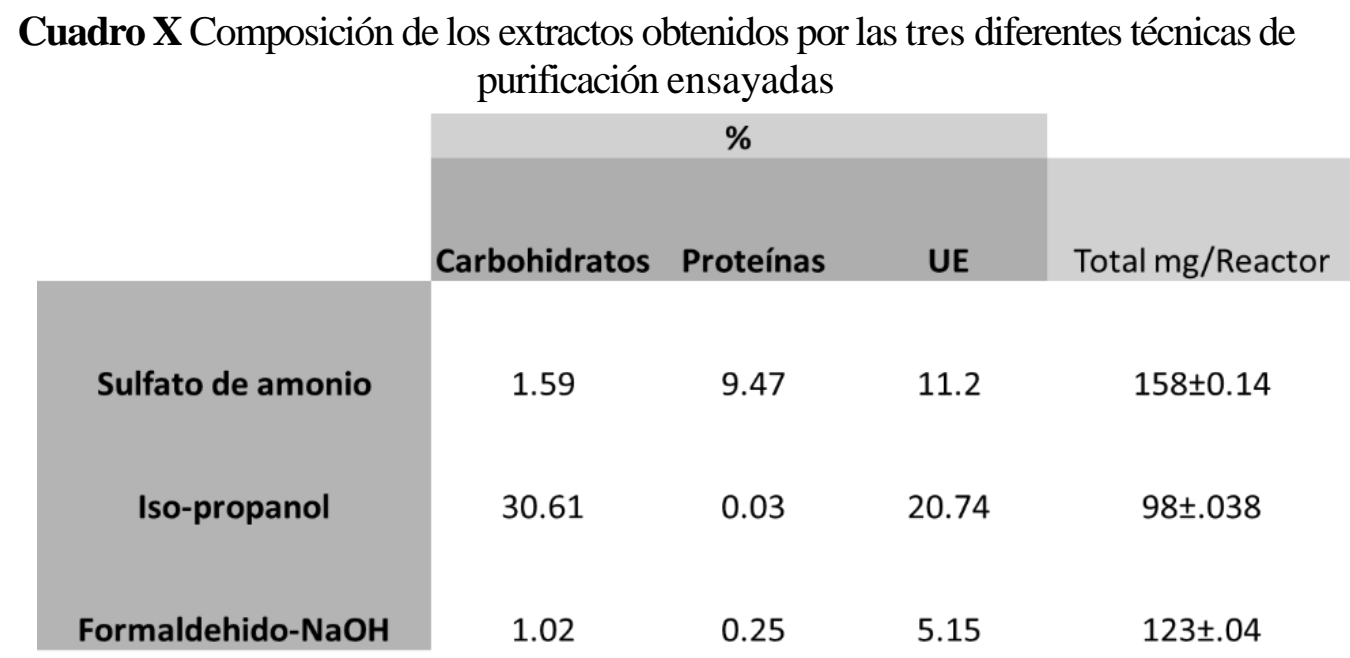

\subsubsection{Evaluación de las proteínas del extracto crudo}

Las proteínas concentradas por el método de precipitación con diferentes saturaciones de sulfato de amonio fueron evaluadas por su AE, esta última fue correlacionada a su vez con la proporción de carbohidrato de los extractos. Por este método es posible obtener no sólo la fracción proteica, sino también los carbohidratos asociados (Cuadro XI). Se logró extraer mayor cantidad de proteína $\left(71.5 \pm 3.7 \mathrm{mg} \cdot \mathrm{L}^{-1}\right)$ con las saturaciones de sulfato de amonio más elevadas, pero estos extractos mostraron menor AE conforme se aumentó la saturación, a su vez, la concentración 
de carbohidratos fue disminuyendo, mostrando una correlación entre la concentración de carbohidratos y la AE.

Cuando la saturación con sulfato fue la máxima, los extractos proteicos no mostraron AE, posiblemente debido a la ausencia de carbohidratos en los extractos. Dado que los factores de purificación (Fold P y C) decrecieron y estos son calculados por medio de la relación de unidades de emulsificación por $\mathrm{mg}$ de carbohidrato o proteína $\left(\mathrm{UE} \cdot \mathrm{mg}^{-1}\right.$ ) de los precipitados (pp) y las $\mathrm{UE} \cdot \mathrm{mg}^{-1}$ del extracto libre de células, significa que las proteínas obtenidas no presentan $\mathrm{AE}$ y por tanto estas no forman parte del BE en el sobrenadante.

Con la finalidad de comparar las proteínas obtenidas con aquellas reportadas con AE para otras especies de Acinetobacter spp. los extractos también fueron evaluados utilizando SDS-PAGE 1D (Fig 32).

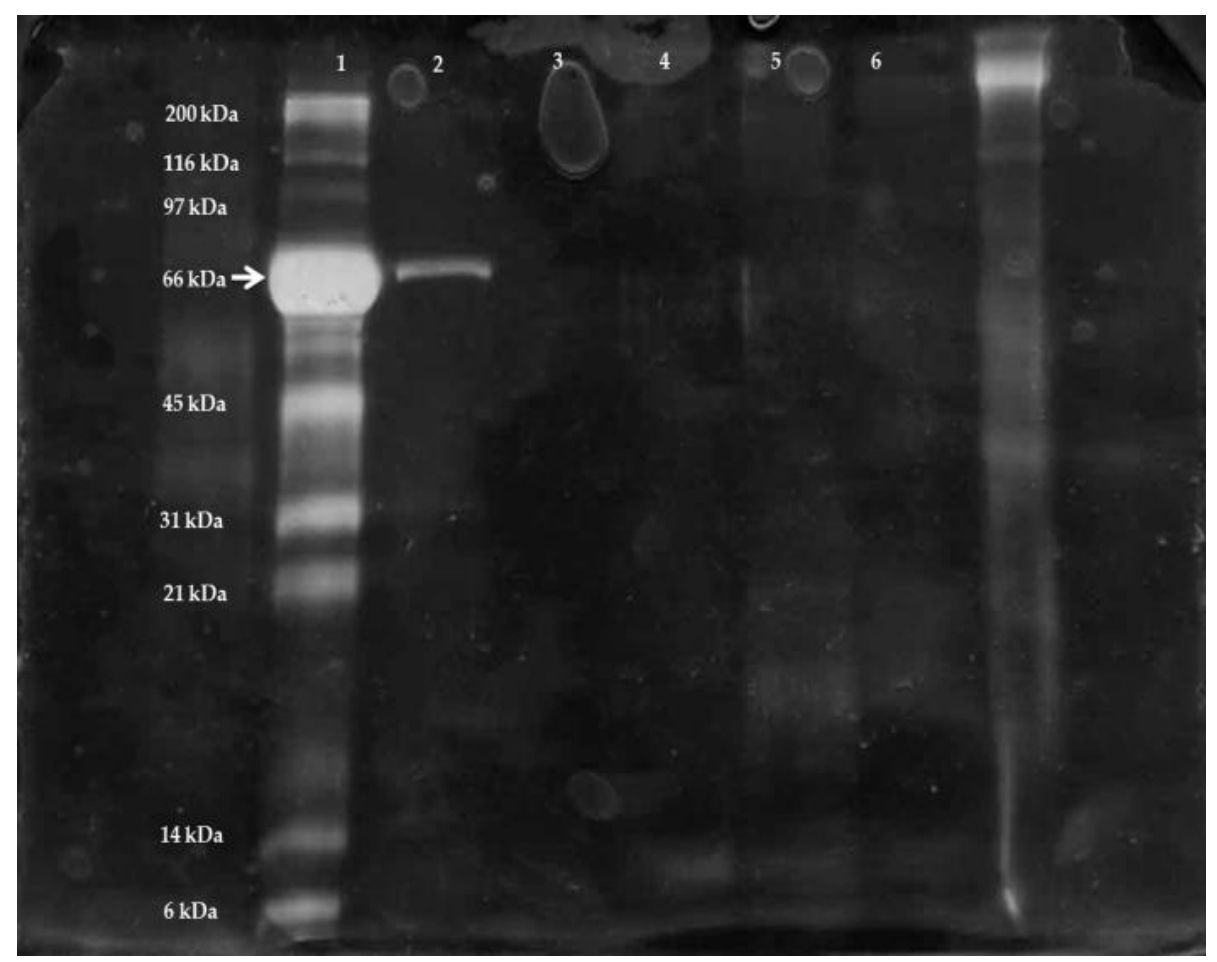

Figura 32 SDS-PAGE de las proteínas obtenidas a 50, 60 y $70 \%$ de saturación con sulfato de amonio, en los carriles 4.5 y 6 respectivamente. Carril 1: marcador de peso molecular, Carril 2: albumina sérica bovina, Carril 3: $\mathrm{H}_{2} \mathrm{O}_{\mathrm{d}}$ 
Cuadro XI Purificación de proteínas con carbohidratos asociados y su AE

\begin{tabular}{|c|c|c|c|c|c|c|c|c|c|c|c|c|}
\hline \multirow[b]{2}{*}{ Fracción } & \multirow[b]{2}{*}{$\begin{array}{l}\text { Volumen } \\
\text { de la } \\
\text { fracción } \\
\quad(m L)\end{array}$} & \multicolumn{2}{|l|}{ Proteína } & \multicolumn{2}{|c|}{ Carbohidratos } & \multicolumn{5}{|c|}{$A E$} & \multirow[b]{2}{*}{$\begin{array}{c}\text { Factor de } \\
\text { purificación } \\
\text { proteína } \\
\text { (Fold } P \text { ) }\end{array}$} & \multirow[b]{2}{*}{$\begin{array}{c}\text { Factor de } \\
\text { purificación } \\
\text { carbohidratos } \\
(\text { Fold } C)\end{array}$} \\
\hline & & $\begin{array}{c}\text { Concentración } \\
\left(\mathrm{mg} \cdot \mathrm{L}^{-1}\right)\end{array}$ & $\begin{array}{c}\text { Total } \\
(\mathrm{mg})\end{array}$ & $\begin{array}{c}\text { Concentración } \\
\left(m g \cdot L^{-1}\right)\end{array}$ & $\begin{array}{l}\text { Total } \\
(\mathrm{mg})\end{array}$ & $\begin{array}{c}\text { Concentración } \\
\left(U E \cdot m L^{-1}\right)\end{array}$ & $\begin{array}{c}\text { Proteína } \\
\left(U E \cdot m^{-1}\right)\end{array}$ & $\begin{array}{c}\text { Carbohidrato } \\
\left(\boldsymbol{U} E \cdot \boldsymbol{m g}^{-1}\right)\end{array}$ & $\begin{array}{c}\text { Unidades } \\
\text { Totales }\end{array}$ & $\underset{\%}{\text { Rendimiento }}$ & & \\
\hline $\begin{array}{l}\text { Extracto } \\
\text { libre de } \\
\text { células }\end{array}$ & 50 & $59.2 \pm 2.2$ & 2.96 & $23.1 \pm 4.20$ & 1.16 & $12 \pm 2.40$ & 202.703 & 519.48 & 600 & 100 & 1 & 1 \\
\hline pp $30 \%$ & 10 & $59.0 \pm 2.3$ & 0.59 & $20.3 \pm 3.20$ & 0.20 & $8 \pm 1.10$ & 135.593 & 394.09 & 80 & 13.33 & 0.67 & 0.76 \\
\hline pp $40 \%$ & 10 & $59.2 \pm 2.2$ & 0.59 & $10.5 \pm 1.20$ & 0.11 & $4 \pm 0.56$ & 67.568 & 380.95 & 40 & 6.67 & 0.33 & 0.73 \\
\hline pp 50\% & 10 & $62.4 \pm 3.5$ & 0.62 & ND & 0 & 0 & 0 & 0 & 0 & 0 & 0 & 0 \\
\hline pp 60\% & 10 & $69.1 \pm 3.2$ & 0.69 & ND & 0 & 0 & 0 & 0 & 0 & 0 & 0 & 0 \\
\hline pp $70 \%$ & 10 & $71.5 \pm 3.7$ & 0.72 & $\mathrm{ND}$ & 0 & 0 & 0 & 0 & 0 & 0 & 0 & 0 \\
\hline
\end{tabular}


Por la técnica SDS-PAGE, se observaron bandas borrosas por debajo de los 21 kDa (Fig 32, Carriles 4-6), estas proteínas no mostraron capacidad emulsificante. Con estos resultados fue posible descartar a la proteína como componente estructural químico del BE. Esto lo hace diferente a otros BE ampliamente estudiados del género, como el Alasan reportado por Toren et al., (2001), donde el componente emulsificante principal es de carácter proteico, específicamente una proteína de $45 \mathrm{kDa}$. Se encontró que el BE de la cepa UAM25 carece de este tipo de proteínas y tiene mayor parecido con los BE reportados; Emulsan, Ethapolan (Pirog et al. 2004) y Biodispersan (Shabtai 1990), con la diferencia en que el BE UAM25 tiene una consistencia gelosa.

\subsection{Caracterización química y evaluación del BE}

Dado que el BE producido en BAL en medio mineral con fuente de carbono en concentraciones óptimas, mostró AE asociada a la producción de carbohidratos, tanto en forma de carbohidrato soluble de consistencia gelosa, como en forma de biopelícula, se utilizó ultrafiltración como método de purificación. Con este método fue posible concentrar el BE al tiempo que se eliminaron las sales en un sistema de diafiltración, obteniendo un rendimiento BE concentrado puro de $150 \pm 1.12 \mathrm{mg} \cdot \mathrm{L}^{-1}$ después de $48 \mathrm{~h}$ de cultivo, con una AE de $160 \mathrm{UE} \cdot \mathrm{mg}^{-1}$ (24 $000 \mathrm{UE}$ por reactor), la cual duplica la $\mathrm{AE}$ del $\mathrm{BE}$ cuando está en el sobrenadante en forma cruda. Esto pudo ser por que la presencia de impurezas en el medio mineral, tales como proteínas de bajo peso molecular y sales, tuvieron efecto negativo en la estabilidad de las emulsiones y su AE, dado que estas impurezas pueden afectar las cargas superficiales promoviendo la coalescencia de las gotas dispersas.

\subsubsection{SEC, $\mathrm{H}^{1}$ y $\mathrm{C}^{13} \mathrm{RMN}$}

Muestras secas de BE se resuspendieron en agua desionizada para su análisis por SEC, la mayoría de los extractos analizados presentaron una señal típica (Fig 33) que corresponde a un peso molecular de $1010 \mathrm{kDa}$ con un índice de polidispersidad (PDI) de 1.38 contra los estándares PEG, similar al peso reportado por Rosenberg et al., (1979b) para el Emulsan. 


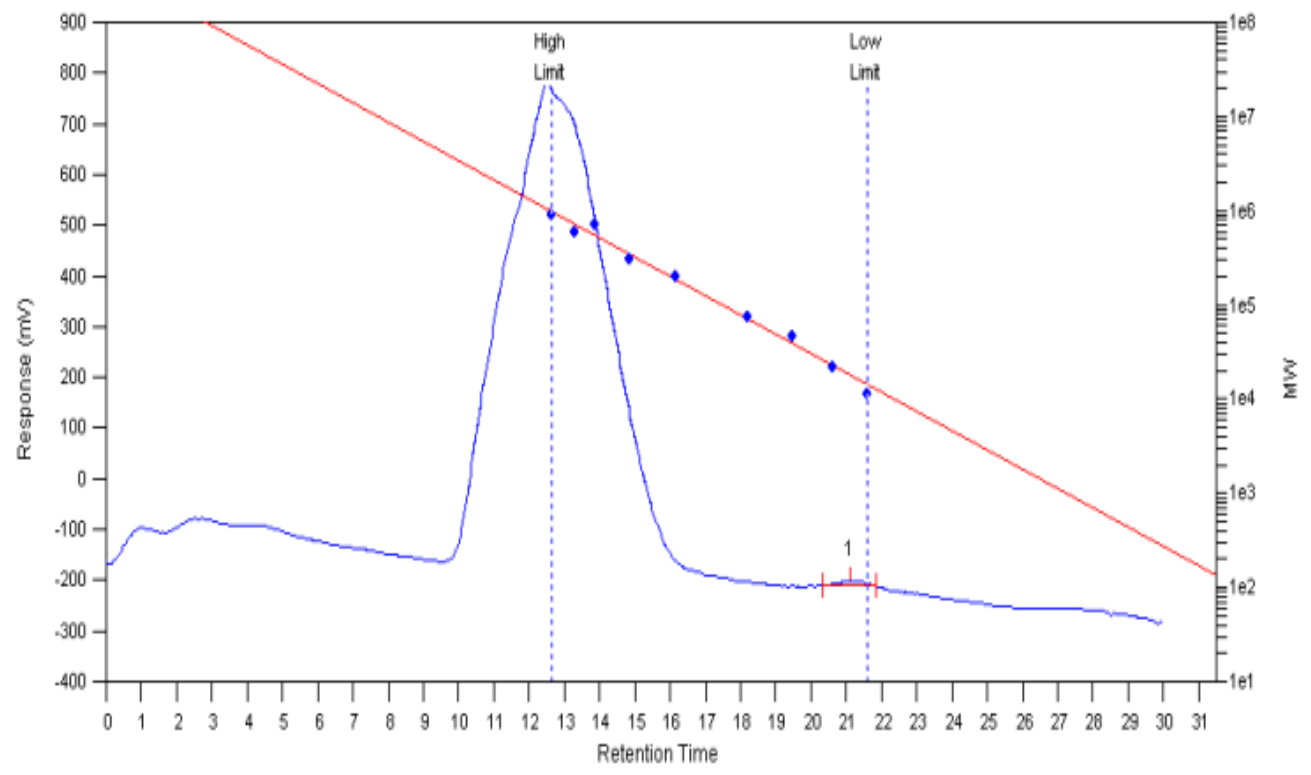

Figura 33 Cromatograma SEC de BE puro de A. bouvetii UAM25. Se indican los puntos de la curva patrón y la señal del BE puro

Algunas de las muestras liofilizadas, al no disolverse totalmente dado la consistencia en gel del BE concentrado, después de filtrarse conservaron cierta turbidez, por lo que se obtenían 4 señales diferentes incluyendo la señal característica (Fig 34). Se detectaron señales para componentes con 1684, 565, 17, $10 \mathrm{kDa}$ con PDIs de 1.37, 1.33, 1.32 y 1.00 respectivamente. Esto pudo ocurrir por una disolución incompleta del BE en agua provocando formación de agregados. 


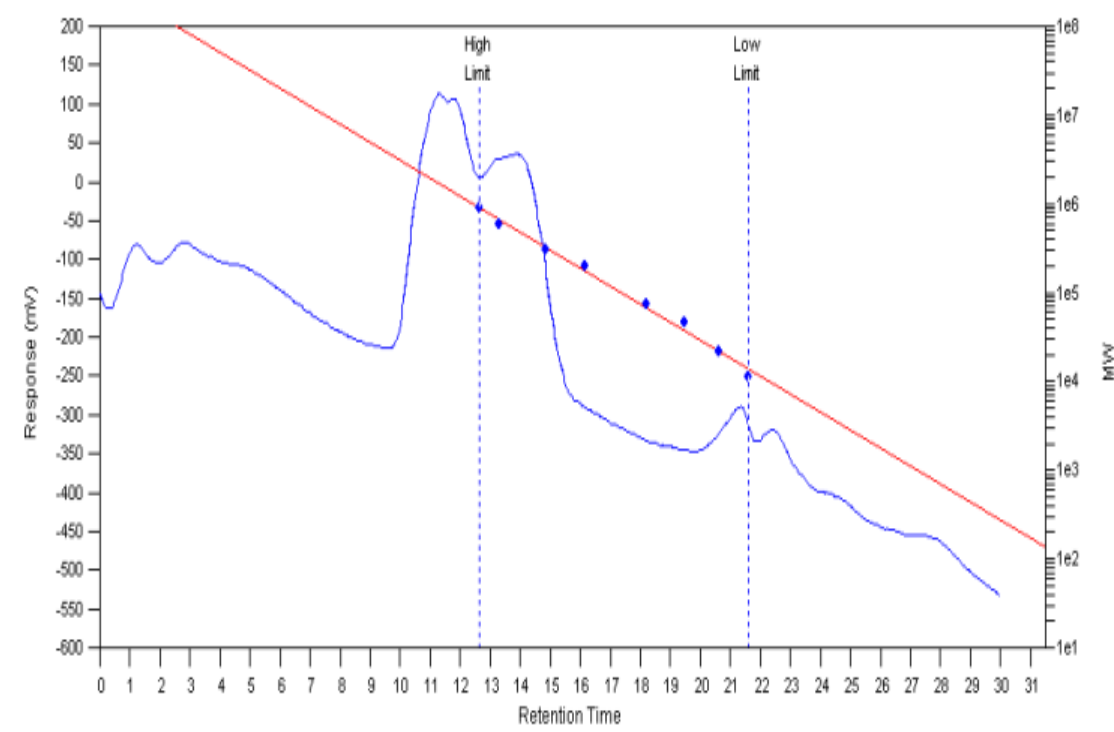

Figura 34 Señal RID para el BE de A. bouvetii UAM25 aglomerado. Se indican los puntos de la curva patrón y la señal del BE puro

Si se consideran a los dos picos de mayor tamaño (Fig 34) como una sola señal se estima una PD de 1.38. Se registraron además señales que corresponden a componentes con peso molecular inferior a los $50 \mathrm{kDa}$ para todas las disoluciones de BE, esta señal podría ocurrir por el componente proteico detectado en los geles de SDS-PAGE, donde se observó un barrido debajo de la marca de los $21 \mathrm{kDa}$. Se observó que sólo algunos extractos BE presentaron una señal para componente de peso molecular de $565 \mathrm{kDa}$ la cual no pudo ser analizada por separado, esta podría ser un subcomponente o fracción del BE.

Con la finalidad de obtener la mejor resolución e intensidad en los espectros RMN, fue necesario aplicar diferentes métodos de hidrólisis a las muestras de BE para solubilizarlos y realizar su posterior análisis. En el Cuadro XII se presentan los resultados de la hidrólisis por los diferentes métodos ensayados. Se seleccionó el método ácido ( $\mathrm{HCl}$ y calor por $10 \mathrm{~min}$ ), con el que se observó licuefacción total de la muestra. La hidrólisis con $\mathrm{NaOH}$ también solubilizó la muestra, por lo que también se evaluaron estos espectros; sin embargo, los tratamientos con $\mathrm{NaOH}$ generaron espectros con señales de menor intensidad (Fig 35). 
Cuadro XII Resultados de hidrólisis de BE

\begin{tabular}{|lccc|}
\hline \multicolumn{1}{c}{ a Método } & Tiempo & Calor & Hidrólisis \\
\hline Agitación Vortex & $10 \mathrm{~min}$ & & - \\
\hline$\Delta$ & $10 \mathrm{~min}$ & & - \\
\hline$\Delta$ & $20 \mathrm{~min}$ & & - \\
\hline EDTA 2\% & $12 \mathrm{~h}$ & $\Delta$ & - \\
\hline EDTA 2\% & $10 \mathrm{~min}$ & $\Delta$ & + \\
\hline EDTA 2\% & $20 \mathrm{~min}$ & & - \\
\hline NaOH 1N & $12 \mathrm{~h}$ & $\Delta$ & ++ \\
\hline NaOH 1N & $20 \mathrm{~min}$ & $\Delta$ & ++ \\
\hline NaOH 1N & $10 \mathrm{~min}$ & & - \\
\hline EDTA 2\% + NaOH 1N & $12 \mathrm{~h}$ & & ++ \\
\hline HCl 2N & $12 \mathrm{~h}$ & $\Delta$ & ++ \\
\hline HCl 2N & $2 \mathrm{~h}$ & $\Delta$ & ++ \\
\hline HCl 2N & $20 \mathrm{~min}$ & $\Delta$ & - \\
\hline HCl 2N & $10 \mathrm{~min}$ & & ++ \\
\hline
\end{tabular}

$\Delta:$ Tratamiento en agua en ebullición

${ }^{a}$ Los tratamientos fueron diseñados de acuerdo a métodos clásicos de hidrólisis de biopelículas (More et al. 2014)

- : Hidrólisis negativa

+ : Hidrólisis parcial

++: Hidrólisis positiva 


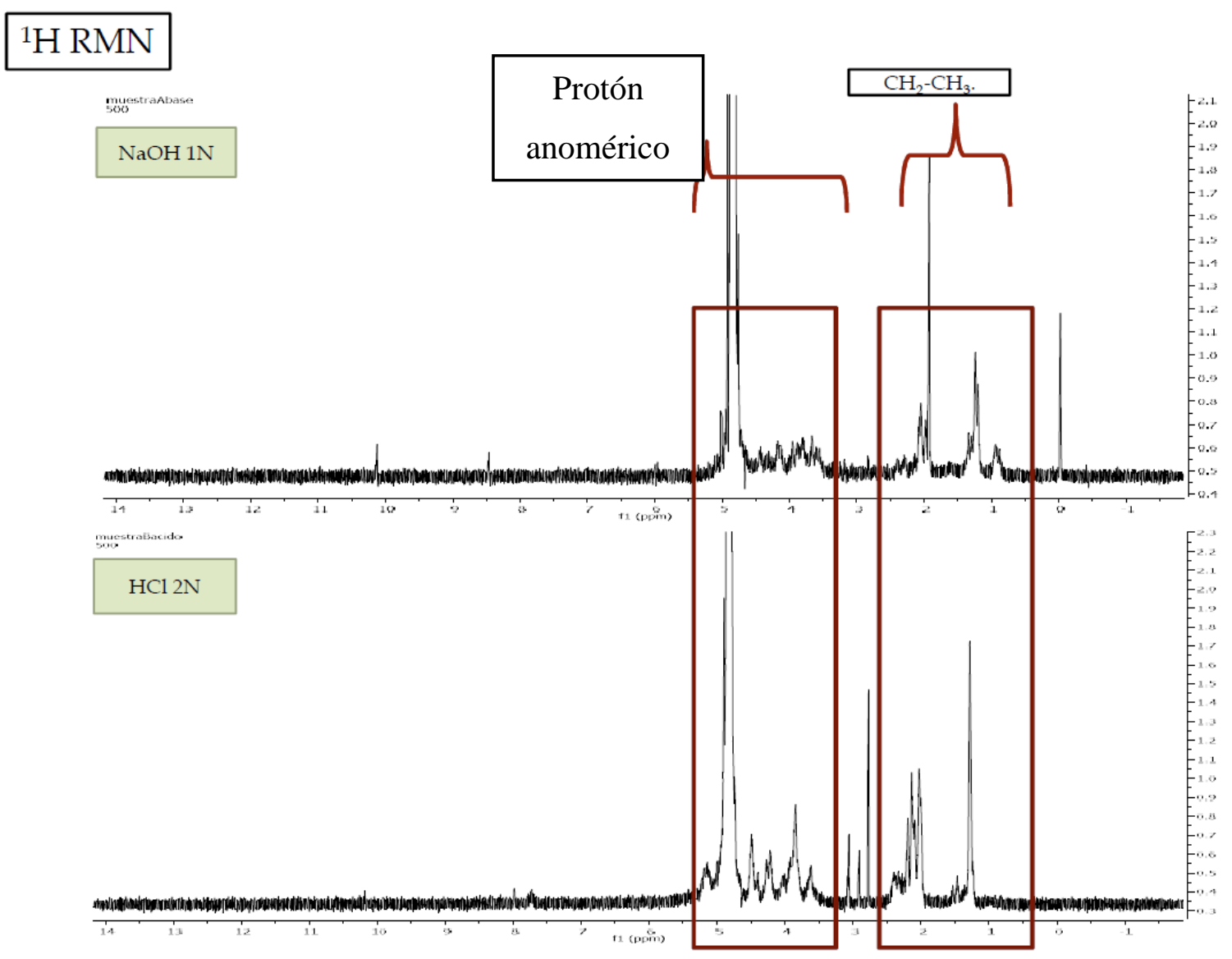

Figura 35 Espectros de RMN de los hidrolizados de los tratamientos a) con $\mathrm{NaOH}$ y b) con $\mathrm{HCl}$ : en ambos casos se calentaron las muestras durante $10 \mathrm{~min}$

Los análisis de resonancia para las muestras hidrolizadas con $\mathrm{HCl}$ mostraron señales de baja intensidad $(\delta) 8$ ppm en el espectro ${ }^{1} \mathrm{H}$ RMN, los cuales sugieren la presencia de insaturaciones (Fig 36a), para este espectro se notó la presencia de singuletes en 2.76, 2.89 y 3.05 ppm, que pueden ser asignados a las impurezas metil-cloradas originadas por el tratamiento hidrolítico ácido y por lo tanto no están relacionadas con una estructura molecular polimérica como la del BE.

Las señales dentro del rango en campo bajo (5-5.5 ppm) pueden ser asignadas a protones anoméricos de carbohidratos, de acuerdo a Jain et al., (2013). En correspondencia con la base 
de datos para la asignación de señales, el patrón $(\delta)(\mathrm{ppm})$ de 5.18, 3.78, 4.04, 4.18, 4.11, y 3.74 corresponde a la $\alpha$-D-galactosa (DGalp) en una cadena de seis azúcares. De manera similar las señales $(\delta \mathrm{ppm})$ a $5.09,4.10,4.00,3.58,3.95$, y 1.33 fueron asignados a una cadena lateral de $\alpha$-L-ramnosa (LRhap) que se ramificó desde el esqueleto del polisacárido. Es de destacar, que se observó un patrón de señales en ( $\delta$ ppm) 4.49, 3.61, 3.80, 4.33, y 4.27 que corresponde a una $\beta$-D-galactosa (DGalpA) unida a ácido urónico. En reportes previos por Vinogradov et al. (2010) y Uzoigwe et al. (2015) se ha observado la presencia de ácido urónico al final de la cadena principal de carbohidratos, la presencia de este componente está relacionada con la capacidad de los BEs para detoxificar y emulsificar hidrocarburos. La señal a $2.1 \mathrm{ppm}$ indica la presencia de grupos metilo de O-acetilos, lo que puede indicar la presencia de residuos acetilados. Más importante, la señales a $\delta(\mathrm{ppm}) 1.26\left(-(\mathrm{CH} 2)_{\mathrm{n}^{-}}\right), 1.44-1.46\left(-\mathrm{CH} 2-(\mathrm{CH} 2)_{\mathrm{n}^{-}}\right)$, y $2.00-2.30\left(-\mathrm{CH} 2-\mathrm{CH} 2-(\mathrm{CH} 2)_{\mathrm{n}}-\right)$ evidencian la presencia de una estructura alifática que podría ser asignada a ramificaciones alquílicas desde la estructura del polisacárido (Dhasayan et al. 2014). Adicionalmente, los espectros de 2D-RMN mostraron evidencia de la presencia de unión entre las cadenas alifáticas (Fig 37).
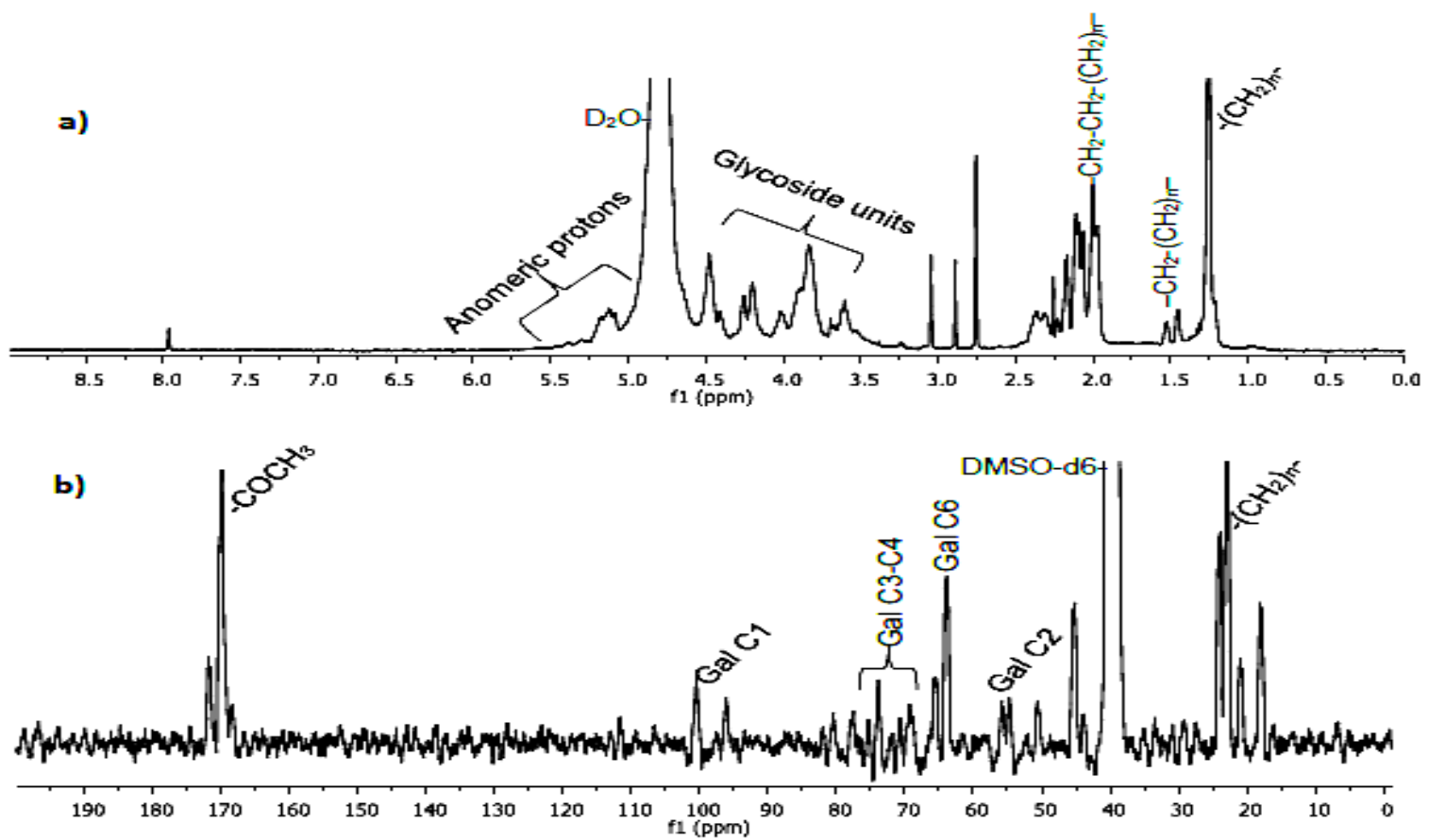

Figura 36 Espectros a) $1 \mathrm{H}$ RMN y b) $13 \mathrm{C}$ RMN de BE puro 
Los espectros revelaron que los hidrógenos $\mathrm{H} 1$ y H2 de la fracción de carbohidratos están unidos a la fracción alifática (Fig 37, Int A, B y C) destacando la propiedad anfipática del BE. La muestra solubilizada en DMSO-d6 también mostró desplazamientos en el rango de 7.00-7.50 ppm, que corresponden a el desplazamiento $\mathrm{H} 2$ de la galactosa que además interacciona con los protones anoméricos (Fig 37, Int D y Int C). El espectro ${ }^{13} \mathrm{C}$ RMN corroboró los resultados anteriores, donde los desplazamientos a $\delta$ (ppm) de 96-100, 54-56, 71-78 y 65 se correlacionan con los carbonos C1, C2, C3-C4, y C6 de la galactosa. La señal a 17 ppm se relaciona con el C6 de una unidad de ramnosa; ambas azúcares fueron también identificadas en el espectro de protón $\left({ }^{1} \mathrm{H}\right.$ RMN). Además, el espectro de carbono $\left({ }^{13} \mathrm{C}\right.$ RMN $)$ mostró señales intensas entre 168-172 ppm asignadas a grupos carbonilos en la zona de desplazamiento de grupos éster, por lo que podría entreverse que la unión de las cadenas alifáticas con el polisacárido pueda tener lugar a través de enlaces éster con grupos hidroxilos de las unidades glucosídicas.

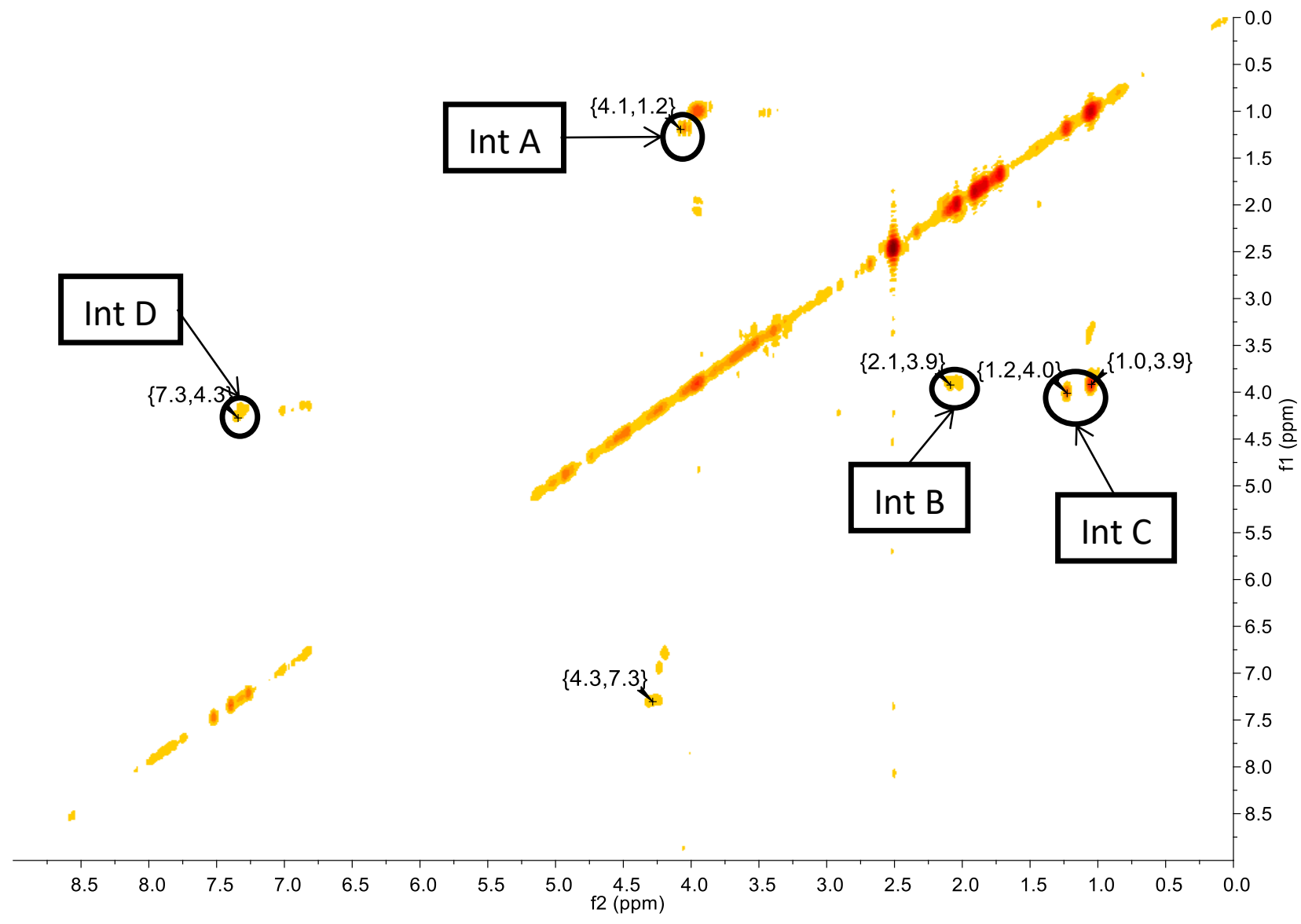

Figura 37 Espectro 2D COSY RMN del BE puro con interacciones entre desplazamientos (int) 
El BE fue entonces identificado como un polímero de alto peso molecular con estructura de tipo polisacárido compuesto principalmente por unidades repetidas de ramnosa y galactosa unidas a cadenas alifáticas.

\subsubsection{Emulsificación de HPAs y estabilidad cinética de emulsiones}

Después de evaluar la capacidad emulsificante en las mezclas, que simularon agua contaminada con diésel, no se encontraron diferencias significativas $(\alpha=0.05)$ en la emulsificación de HPAs (Fig 38). Por lo tanto la emulsificación ocurrió de manera inespecífica (emulsificación independiente del tipo HPA) evitando la coalescencia de las gotas dispersas y mejorando la estabilidad debido a impedimento estérico, similar a lo que ocurre para otros EPS BEs reportados (Jain et al. 2012). Se comprobó la presencia de los HPAs dispersos en la emulsión (Fig 38b y c) al medir la absorbancia a 276 nm (región de pico máximo para los HPAs). Los emulsificantes Tween 80 y Triton X-100 no fueron capaces de emulsificar HPAs diferentes a $\beta$-metilnaftaleno, con menor AE que el BE (Fig 38b), esto indica que los emulsificantes comerciales mostraron especificidad por este hidrocarburo. No se registró AE cuando el HXD sin HPAs fue evaluado a 276 nm, con esto se comprobó que el HXD no contenía impurezas en forma de otros HPAs diferentes a los ensayados en las demás mezclas. El BE emulsificó HXD con AE 4.5 y 3.3 veces superior a la registrada para Triton X-100 cuando pireno y fenantreno estaban en la mezcla, respectivamente.

Es de destacar, que la AE fue superior en presencia de HPAs en las mezclas, Rosenberg et al., (1979a) reportaron que la cepa RAG-1 emulsificó pobremente hidrocarburos alifáticos y aromáticos evaluados por separado, pero cuando se mezclaron la capacidad emulsificante aumentó. En nuestro caso, la presencia de $\beta$-metilnaftaleno, PYR o PHE favoreció la respuesta de AE para el BE, no así para Tween 80 y Triton X-100.

Tween 80 no emulsificó HXD cuando PYR y/o PHE estaban presentes en la mezcla. Triton X-100 mostró poca capacidad emulsificante de HXD comparado contra el BE. La capacidad de pseudosolubilización por Triton X-100 fue antes reportada por Zhong et al. (2016). Aunque el Triton X-100 ha sido reportado como eficiente en la remoción de HXD en remediación de sitios contaminados, éste es un emulsificante difícil de biodegradar en comparación con los BE EPS, debido a su estructura química, que presenta un anillo aromático y una estructura polimérica de óxido de etileno (Cheng et al. 2016). 

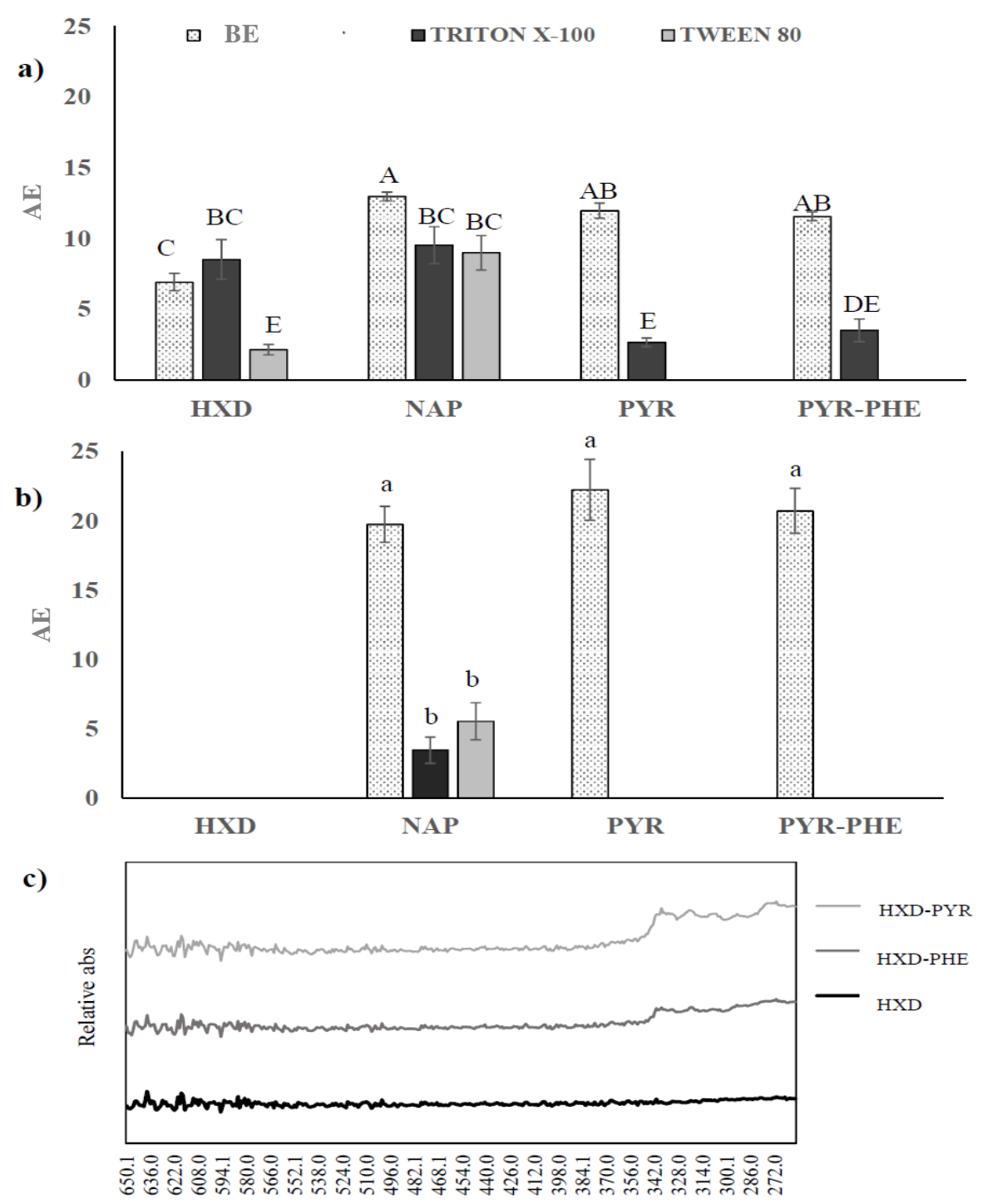

Figura 38 AE del BE mezclado con; HXD, HXD: $\beta$-metilnaftaleno (NAP), HXD: pireno (PYR), y HXD: pireno: fenantreno (PYR-PHE). Las lecturas se realizaron a) $600 \mathrm{~nm}$; y b) $276 \mathrm{~nm}$, cada valor corresponde a la media de seis réplicas \pm desviaciones estándar (barras de error), con post-hoc Tukey, en donde letras diferentes (mayúsculas y minúsculas) indican diferencia significativa $(\alpha=0.05)$; y c) Barrido espectrofotométrico de las mezclas de hidrocarburos.

Beltrani et al., (2015) también reportaron especificidad por ciertos hidrocarburos cuando utilizaron Tween 80 y Triton X-100 y los compararon contra el BE EPS, Pdb-Z, producido por Pedobacter sp. MCC- Z.

La emulsificación se correlaciona con la capacidad de solubilizar hidrocarburos, y por lo tanto, también con la capacidad de degradarlos; por ejemplo, Mahanty et al. (2006) 
describieron un incremento linear de la solubilización de PYR y antraceno en medio acuoso, en paralelo a la producción de BE al tiempo que se observó degradación de estos hidrocarburos. La capacidad emulsificante no específica, es decir, la emulsificación eficiente de hidrocarburos independiente del tipo de HPA, es una característica que sugiere al BE como un buen candidato para ser utilizado en técnicas de biorremediación y recuperación de hidrocarburos.

Con el objeto de correlacionar las características fisicoquímicas del BE y la estabilidad de las emulsiones formadas, se realizaron ensayos a diferentes $\mathrm{pH}$, incluyendo el potencial $\mathrm{Z}$. La Figura 39a muestra que el BE fue capaz de formar emulsiones estables que permanecieron durante las 96 h de ensayo. El cambio de pH no influyó en la AE y la estabilidad de manera significativa $(\alpha=0.05)$ en el rango 4-8; sin embargo, a pH 3 se observó un decremento en la estabilidad, en el potencial Z (Fig 39b) y en la respuesta de AE. A pH 9, la AE fue ligeramente superior y la estabilidad no mostró diferencias significativas $(\alpha=0.05)$. Se observó un ligero decremento en la estabilidad de las emulsiones bajo condiciones ácidas, esto pudo ser debido a la protonación de los grupos carboxilo del BE, lo que provocó la coalescencia entre las gotas dispersas cargadas positivamente (Dhasayan et al. 2014). Concomitantemente, los efectos del $\mathrm{pH}$ fueron reflejados en el potencial $\mathrm{Z}$, dado que este es un indicador del comportamiento de la dispersión tratada como un coloide. Parte de la estabilidad de las emulsiones puede ser atribuida a la ausencia de proteínas en su estructura química y a su inherente precipitación a pH bajos. Cabe destacar que la consistencia gelosa del BE está relacionada con su naturaleza viscosa, y esta a su vez promueve la estabilidad incluso a $\mathrm{pH}$ 9. Con respecto a esta característica, Grinberg et al., (1995) reportaron un BE producido por una cepa ucraniana de Acinetobacter, la cual generaba un BE más viscoso cuando el pH bajaba. Cuando se evaluó potencial $\mathrm{Z}$ del $\mathrm{BE}$ a $\mathrm{pH}$ 9, se observó que la repulsión electroestática (característica de los valores de AE más altos) fue favorecida debido a un incremento en el potencial Z. Wicek y Chibowski, (2002) encontraron una mayor estabilidad (por un total de 7 días) cuando se incrementó la electronegatividad del potencial $\mathrm{Z}$ de las gotas dispersas de n-tetradecano con $\beta$-caseína $(-60.3 \mathrm{mV})$ a pH 11. 

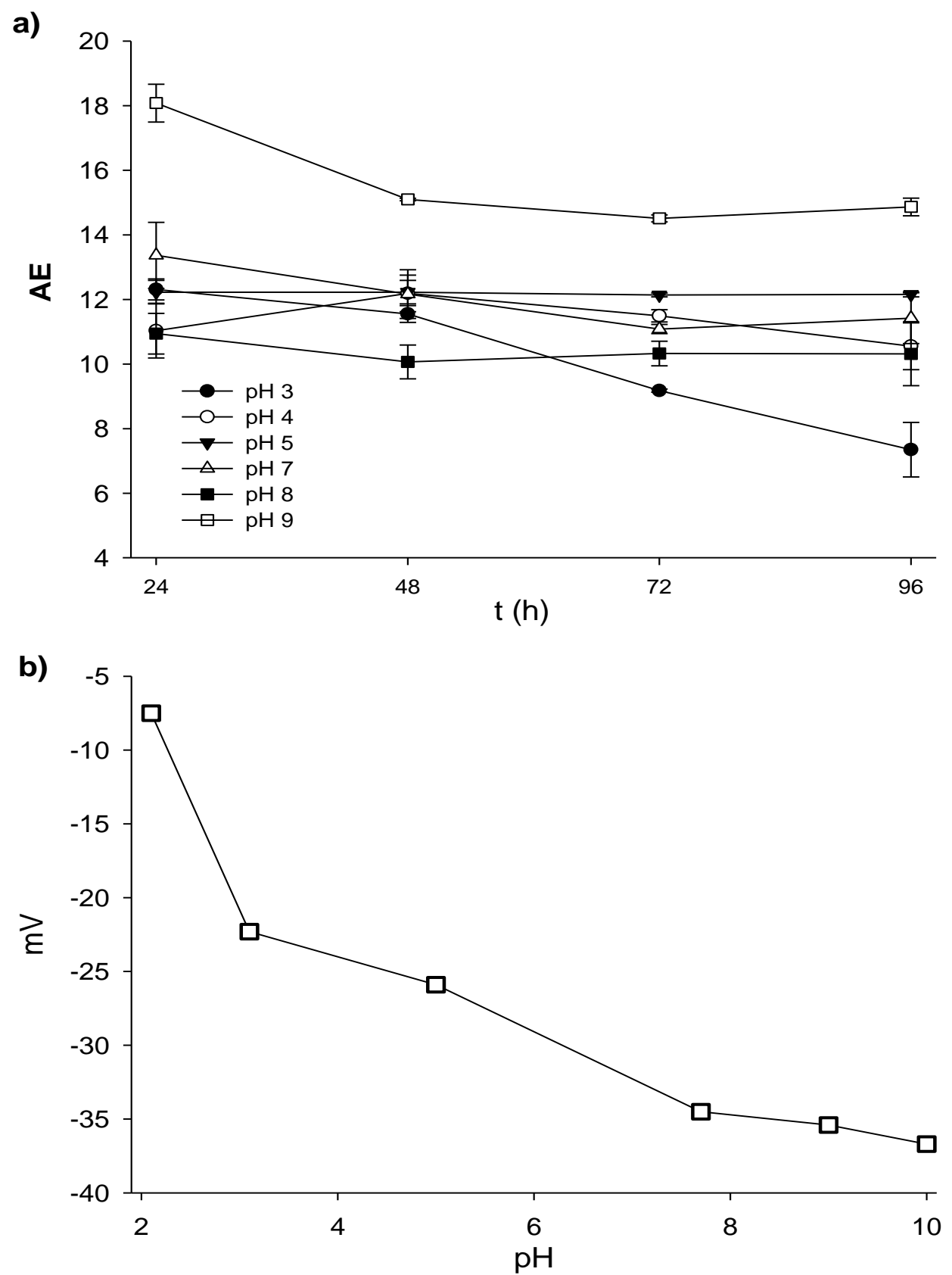

Figura 39 a) Estabilidad cinética de las emulsiones; y b) Potencial $\mathrm{Z}$ a diferentes valores de $\mathrm{pH}$

Con respecto a la estabilidad del bioemulsificante, en nuestro trabajo, se observaron dos aspectos relevantes: (i) la estabilidad de la emulsión en un rango amplio de pH; y (ii) la emulsificación efectiva inespecífica, independiente del tipo de hidrocarburo policíclico aromático, ambas características atribuidas principalmente al impedimento estérico que a su vez es una propiedad de los exopolisacáridos. 


\section{CONCLUSIONES}

- La identificación a nivel especie de la cepa UAM25 fue confirmada como Acinetobacter bouvetii, descartando propiedades patogénicas propias de otras especies dentro del género.

- La cepa UAM25 fue capaz de crecer y producir BE en diferentes fuentes de carbono, tanto hidrofílicas como hidrofóbicas, sin capacidad metabólica para degradar glucosa.

- El crecimiento y producción de $\mathrm{BE}$, así como la respuesta $\mathrm{AE}$, resultaron dependientes de la relación $\mathrm{C} / \mathrm{N}$. En el presente estudio se encontraron las mejores condiciones de producción en biorreactores airlift.

- Acinetobacter bouvetii UAM25 produce una biopelícula con la capacidad de emulsificar hidrocarburos, actuando como un bioemulsificante de tipo exopolisacárido.

- La hidrodinámica en los biorreactores airlift tiene efecto en la producción de la biopelícula reflejada como despolimerización de esta en forma de BE activo.

- El método de ultrafiltración resultó efectivo para la purificación del BE, superando el rendimiento de otros métodos ensayados en este trabajo y otros reportados en la literatura.

- El BE es de alto peso molecular, su producción ocurre asociada al crecimiento celular, tanto en biorreactores airlift como en botellas serológicas.

- El BE resultó químicamente compuesto por unidades repetidas de carbohidratos, galactosa y ramnosa, asociados a cadenas alifáticas.

- El BE fue capaz de emulsificar diferentes HPAs, así como HXD de manera efectiva, superando en 4.5 veces la $\mathrm{AE}$ de los emulsificantes comerciales, Tween 80 y Triton X-100, cuando el PYR estaba presente en la mezcla.

El presente trabajo es el primer estudio sobre la estructura química del BE de Acinetobacter bouvetii UAM25 y su relación funcional en la capacidad de emulsificación de HPAs. Se demostraron propiedades del BE que sugieren potenciales aplicaciones biotecnológicas, para su aplicación en el mejoramiento de técnicas de biorremediación de suelos, agua y sedimentos. 


\section{RECOMENDACIONES}

- Realizar estudios por SEM y otras técnicas de microscopia para caracterizar la biopelícula producida bajo diferentes condiciones.

- Evaluar de forma exhaustiva las características del BE tanto por técnicas de imagenología como por análisis de sus propiedades fisicoquímicas.

- Mejorar la hidrólisis y solubilización del BE puro, con el fin de obtener mejores espectros de RMN con mayor resolución.

- Evaluar la producción del BE a partir de fuentes de carbono de menor costo y/o de interés biotecnológico.

- Optimizar la producción del BE considerando mayor cantidad de factores, como los son la relación de fosfatos.

- Cuantificar la concentración de BE en forma de biopelícula por medio de la técnica estándar con cristal violeta, y a la vez evaluar la afinidad del BE por superficies con diferente polaridad, y con ello comparar con respecto a los BEs comerciales.

- Producir el BE en BAL bajo un régimen de Ug discontinuo, aumentando la intensidad de esta variable conforme la viscosidad del medio aumenta, para con ello mejorar el consumo de la fuente de carbono, con una consecuente mejora en la producción de BE.

- Considerando las propiedades estructurales químicas reportadas en el presente estudio, evaluar la capacidad del BE como quelante de metales pesados.

- Diseñar tratamientos de bioaumnetación y bioestimulación, con la finalidad de evaluar tanto a la cepa UAM25 como a su BE para la biorremediación de suelos contaminados con hidrocarburos.

- Realizar evaluación de costos de producción de BE en su forma de extracto crudo y en forma pura, para su futura comercialización.

- Evaluar el efecto de una corriente eléctrica sobre la forma en la que A. bouvetii UAM25 produce el BE, así como en las características fisicoquímicas del mismo.

- Identificar los genes responsables de la producción del BE, para producir clonas sobreproductoras de este.

- Evaluar las propiedades biodispersantes y gelificantes del BE UAM25. 


\section{REFERENCIAS BIBLIOGRÁFICAS}

Ashraf W, Mihdhir A, Murrell JC (1994) Bacterial oxidation of propane. FEMS Microbiol Lett 122:1-6. doi: 10.1111/j.1574-6968.1994.tb07134.x

Baldi F, Ivos N, Minacci A, Pepi M, Fani R, Svetlic V, Vera Z (1999) Adhesion of Acinetobacter venetianus to Diesel Fuel Droplets Studied with In Situ Electrochemical and Molecular Probes Adhesion of Acinetobacter venetianus to Diesel Fuel Droplets Studied with In Situ Electrochemical and Molecular Probes. 65:2041-2048.

Barkay T, Navon-Venezia S, Ron EZ, Rosenberg E (1999) Enhancement of solubilization and biodegradation of polyaromatic hydrocarbons by the bioemulsifier alasan. Appl Environ Microbiol 65:2697-2702.

Beebe JL, Umbreit WW (1971) Extracellular lipid of Thiobacillus thiooxidans. J Bacteriol 108:612-614.

Beltrani T, Chiavarini S, Cicero DO, Grimaldi M, Ruggeri C, Tamburini E, Cremisini C (2015) Chemical characterization and surface properties of a new bioemulsifier produced by Pedobacter sp. strain MCC-Z. Int J Biol Macromol 72:1090-1096. doi: 10.1016/j.ijbiomac.2014.10.025

Bodour AA, Guerrero-Barajas C, Jiorle BV, Malcomson ME, Paull AK, Somogyi A, Trinh LN, Bates RB, Maier RM (2004) Structure and Characterization of Flavolipids, a Novel Class of Biosurfactants Produced by Flavobacterium sp. Strain MTN11. Appl Environ Microbiol 70:114-120. doi: 10.1128/AEM.70.1.114-120.2004

Bradford MM (1976) A rapid and sensitive method for the quantitation of microgram quantities of protein utilizing the principle of protein-dye binding. Anal Biochem 72:248-254. doi: 10.1016/0003-2697(76)90527-3

Bubb WA. (2003) NMR spectroscopy in the study of carbohydrates: Characterizing the structural complexity. Concepts Magn Reson Part A Bridg Educ Res 19:1-19. doi: 10.1002/cmr.a.10080

Carr EL, Kämpfer P, Patel BKC, Gürtler V, Seviour RJ (2003) Seven novel species of Acinetobacter isolated from activated sludge. Int J Syst Evol Microbiol 53:953-963. doi: 10.1099/ijs.0.02486-0

Chen J, Huang PT, Zhang KY, Ding FR (2012) Isolation of biosurfactant producers, optimization and properties of biosurfactant produced by Acinetobacter sp. from 
petroleum-contaminated soil. J Appl Microbiol 112:660-671. doi: 10.1111/j.13652672.2012.05242.x

Cheng Y, He H, Yang C, Yan Z, Zeng G, Qian H (2016) Effects of anionic surfactant on nhexane removal in biofilters. Chemosphere 150:248-253. doi: 10.1016/j.chemosphere.2016.02.027

Choi JW, Choi HG, Lee WH (1996) Effects of ethanol and phosphate on emulsan production by Acinetobacter calcoaceticus RAG-1. J Biotechnol 45:217-225. doi: 10.1016/01681656(95)00175-1

Cirigliano MC, Carman GM (1985) Purification and characterization of liposan, a bioemulsifier from Candida lipolytica. Appl Environ Microbiol 50:846-850.

Dhasayan A, Kiran GS, Selvin J (2014) Production and Characterisation of Glycolipid Biosurfactant by Halomonas sp. MB-30 for Potential Application in Enhanced oil Recovery. Appl Biochem Biotechnol 174:2571-2584

Donlan RM (2002) Biofilms: Microbial life on surfaces. Emerg Infect Dis 8:881-890. doi: 10.3201/eid0809.020063

Doughari HJ, Ndakidemi PA, Human IS, Benade S (2011) The ecology, biology and pathogenesis of Acinetobacter spp.: an overview. Microbes Environ 26:101-112. doi: 10.1264/jsme2.ME10179

DuBois M, Gilles KA, Hamilton JK, Rebers PA, Smith F (1956) Colorimetric method for determination of sugars and related substances. Anal Chem 28:350-356. doi: $10.1021 / \mathrm{ac} 60111 \mathrm{a} 017$

Easterling ER, French WT, Hernandez R, Licha M (2009) The effect of glycerol as a sole and secondary substrate on the growth and fatty acid composition of Rhodotorula glutinis. Bioresour Technol 100:356-361. doi: 10.1016/j.biortech.2008.05.030

Egorova KS, Toukach PV. (2014) Expansion of coverage of Carbohydrate Structure Database (CSDB). Carbohydr Res 389:112-114. doi: 10.1016/j.carres.2013.10.009

Elkeles A, Rosenberg E, Ron EZ (1994) Production and secretion of the polysaccharide biodispersan of Acinetobacter calcoaceticus A2 in protein secretion mutants. Appl Environ Microbiol 60:4642-4645.

Franzetti A, Gandolfi I, Bestetti G, Smyth TJP, Banat IM (2010) Production and applications of trehalose lipid biosurfactants. Eur J Lipid Sci Technol 112:617-627. doi: 


\subsection{2/ejlt.200900162}

Gargouri B, Karray F, Mhiri N, Aloui F, Sayadi S (2014) Bioremediation of petroleum hydrocarbons-contaminated soil by bacterial consortium isolated from an industrial wastewater treatment plant. J Chem Technol Biotechnol 89:978-987. doi: $10.1002 /$ jctb.4188

Ghosh I, Mukherji S (2016) Diverse effect of surfactants on pyrene biodegradation by a Pseudomonas strain utilizing pyrene by cell surface hydrophobicity induction. Int Biodeterior Biodegrad 108:67-75. doi: 10.1016/j.ibiod.2015.12.010

Goldman S, Shabtai Y, Rubinovitz C (1982) Emulsan in Acinetobacter calcoaceticus RAG1: Distribution of cell-free and cell-associated cross-reacting material. Appl Environ Microbiol 44:165-170. doi: 0099-2240/82/070165

Grinberg TA., Pirog TP, Malashenko YR, Vlasov SA. (1995) Ethapolan: a new microbial exopolysaccharide for oil industry. Energy \& Fuels 9:1086-1089. doi: 10.1021/ef00054a023

Guermouche M'rassi A, Bensalah F, Gury J, Duran R (2015) Isolation and characterization of different bacterial strains for bioremediation of n-alkanes and polycyclic aromatic hydrocarbons. Environ Sci Pollut Res 22:15332-15346. doi: 10.1007/s11356-0154343-8

Guo X, Yao L, Huang Q (2015) Aeration and mass transfer optimization in a rectangular airlift loop photobioreactor for the production of microalgae. Bioresour Technol 190:189-195. doi: 10.1016/j.biortech.2015.04.077

Haritash AK, Kaushik CP (2009) Biodegradation aspects of Polycyclic Aromatic Hydrocarbons (PAHs): A review. J Hazard Mater 169:1-15. doi: 10.1016/j.jhazmat.2009.03.137

Hashimoto W, Murata K (1998) $\alpha$-L-Rhamnosidase of Sphingomonas sp. R1 Producing an Unusual Exopolysaccharide of Sphingan. Biosci Biotechnol Biochem 62:1068-1074. doi: 10.1271/bbb.62.1068

Henry ND, Abazinge M (2009) In vitro analysis of enhanced phenanthrene emulsification and biodegradation using rhamnolipid biosurfactants and Acinetobacter calcoaceticus. Appropr Technol Environ Prot Dev World Sel Pap from ERTEP 2007, July 17-19 2007, Ghana, Africa 317-323. doi: 10.1007/978-1-4020-9139-1_30 
Holt SC, Doundowlakis J, Takacs BJ (1979) Phospholipid composition of gliding bacteria: Oral isolates of Capnocytophaga compared with Sporocytophaga. Infect Immun 26:305-310.

Ivera OPO, Orrado AT, Nguez JMDOMI, Oldes ABM (2008) Stability and Emulsifying Capacity of Biosurfactants Obtained from Lignocellulosic Sources Using Lactobacillus pentosus. 8074-8080.

Jain RM, Mody K, Joshi N, Mishra A, Jha B (2013) Production and structural characterization of biosurfactant produced by an alkaliphilic bacterium, Klebsiella sp.: Evaluation of different carbon sources. Colloids Surfaces B Biointerfaces 108:199-204. doi: 10.1016/j.colsurfb.2013.03.002

Jain RM, Mody K, Mishra A, Jha B (2012) Isolation and structural characterization of biosurfactant produced by an alkaliphilic bacterium Cronobacter sakazakii isolated from oil contaminated wastewater. Carbohydr Polym 87:2320-2326. doi: 10.1016/j.carbpol.2011.10.065

Janek T, Łukaszewicz M, Rezanka T, Krasowska A (2010) Isolation and characterization of two new lipopeptide biosurfactants produced by Pseudomonas fluorescens BD5 isolated from water from the Arctic Archipelago of Svalbard. Bioresour Technol 101:61186123. doi: 10.1016/j.biortech.2010.02.109

Javaheri M, Jenneman GE, Mcinerney MJ, Knapp RM (1985) Anaerobic Production of a Biosurfactant by Bacillus-Licheniformis Jf-2. Appl Environ Microbiol 50:698-700.

Jung J, Noh J, Park W (2011) Physiological and metabolic responses for hexadecane degradation in Acinetobacter oleivorans DR1. J Microbiol 49:208-215. doi: $10.1007 / \mathrm{s} 12275-011-0395-8$

Kannisto M, Aho T, Karp M, Santala V (2014) Metabolic engineering of Acinetobacter baylyi ADP1 for improved growth on gluconate and glucose. Appl Environ Microbiol 80:7021-7027. doi: 10.1128/AEM.01837-14

Kaplan N, Rosenberg E (1982) Exopolysaccharide distribution of and bioemulsifier production by Acinetobacter calcoaceticus BD4 and BD413. Appl Environ Microbiol 44:1335-1341.

Kim P, Oh DK, Kim SY, Kim JH (1997) Relationship between emulsifying activity and carbohydrate backbone structure of emulsan from Acinetobacter calcoaceticus RAG-1. 
Biotechnol Lett 19:457-459. doi: 10.1023/A:1018348227965

Konishi M, Yoshida Y, Horiuchi J ichi (2015) Efficient production of sophorolipids by Starmerella bombicola using a corncob hydrolysate medium. J Biosci Bioeng 119:317322. doi: 10.1016/j.jbiosc.2014.08.007

Laemmli UK (1970) Cleavage of structural proteins during the assembly of the head of bacteriophage T4. Nature 227:680-685. doi: 10.1038/227680a0

Liu X, Ren B, Chen M, Wang H, Kokare CR, Zhou X, Wang J, Dai H, Song F, Liu M, Wang J, Wang S, Zhang L (2010) Production and characterization of a group of bioemulsifiers from the marine Bacillus velezensis strain H3. Appl Microbiol Biotechnol 87:18811893. doi: 10.1007/s00253-010-2653-9

Lizardi-Jiménez MA, Leal-Bautista RM, Ordaz A, Reyna-Velarde R (2014) Airlift bioreactors for hydrocarbon water pollution remediation in a tourism development pole. Desalin Water Treat 44-49. doi: 10.1080/19443994.2013.876670

Lizardi-Jiménez MA, Saucedo-Castañeda G, Thalasso F, Gutiérrez-Rojas M (2012) Simultaneous hexadecane and oxygen transfer rate on the production of an oildegrading consortium in a three-phase airlift bioreactor. Chem Eng J 187:160-165. doi: 10.1016/j.cej.2012.01.114

Mahanty B, Pakshirajan K, Dasu VV (2006) Production and properties of a biosurfactant applied to polycyclic aromatic hydrocarbon solubilization. Appl Biochem Biotechnol 134:129-41. doi: 10.1385/ABAB:134:2:129

Marin M, Pedregosa A, Laborda F (1996) Emulsifier production and microscopical study of emulsions and biofilms formed by the hydrocarbon-utilizing bacteria Acinetobacter calcoaceticus MM5. Appl Microbiol Biotechnol 44:660-667. doi: 10.1007/BF00172500

Mehdi H, Giti E (2008) Investigation of alkane biodegradation using the microtiter plate method and correlation between biofilm formation, biosurfactant production and crude oil biodegradation. Int Biodeterior Biodegrad 62:170-178. doi: 10.1016/j.ibiod.2008.01.004

Meisen S, Wingender J, Telgheder U (2008) Analysis of microbial extracellular polysaccharides in biofilms by HPLC. Part I: Development of the analytical method using two complementary stationary phases. Anal Bioanal Chem 391:993-1002. doi: 
10.1007/s00216-008-2068-y

Monteiro AS, Bonfim MRQ, Domingues VS, Corrêa A, Siqueira EP, Zani CL, Santos VL (2010) Identification and characterization of bioemulsifier-producing yeasts isolated from effluents of a dairy industry. Bioresour Technol 101:5186-5193. doi: 10.1016/j.biortech.2010.02.041

More TT, Yadav JSS, Yan S, Tyagi RD, Surampalli RY (2014) Extracellular polymeric substances of bacteria and their potential environmental applications. J Environ Manage 144:1-25. doi: 10.1016/j.jenvman.2014.05.010

Navon-Venezia S, Zosim Z, Gottlieb A, Legmann R, Carmeli S, Ron EZ, Rosenberg E (1995) Alasan, a new bioemulsifier from Acinetobacter radioresistens. Appl Environ Microbiol 61:3240-3244.

Nielsen PH, Jahn A (1999) In: Neu T, Flemming HC, Wingender J (eds), Microbial Extracellular Polymeric Substances Characterization, Structure and Function, Springer Berlin Heidelberg, pp 49-72

Pacwa-Płociniczak M, Płaza GA, Piotrowska-Seget Z, Cameotra SS (2011) Environmental applications of biosurfactants: Recent advances. Int J Mol Sci 12:633-654. doi: 10.3390/ijms12010633

Paisio CE, Talano MA, González PS, Magallanes-Noguera C, Kurina-Sanz M, Agostini E (2016) Biotechnological tools to improve bioremediation of phenol by Acinetobacter sp. RTE1.4. Environ Technol (United Kingdom). doi: 10.1080/09593330.2016.1150352

Pan X, Liu J, Zhang D, Chen XI, Li L, Song W, Yang J (2010) A comparison of five extraction methods for extracellular polymeric substances (EPS) from biofilm by using three-dimensional excitation-emission matrix (3DEEM) fluorescence spectroscopy. Water SA 36:111-116. doi: 10.4314/wsa.v36i1.50914

Park AJ, Cha DK, Holsen TM (1998) Enhancing solubilization of sparingly soluble organic compounds by biosurfactants produced by Nocardia erythropolis. Water Environ Res 70:351-355. doi: 10.2175/106143098X124984

Picioreanu C, Van Loosdrecht MCM, Heijnen JJ (2001) Two-dimensional model of biofilm detachment caused by internal stress from liquid flow. Biotechnol Bioeng 72:205-218. doi: 10.1002/1097-0290(20000120)72:2<205::AID-BIT9>3.0.CO;2-L 
Pirog TP, Kovalenko MA, Kuzminskaya YV., Votselko SK (2004) Physicochemical properties of the microbial exopolysaccharide ethapolan synthesized on a mixture of growth $\quad$ substrates. $\quad$ Microbiology 73:14-18. doi: 10.1023/B:MICI.0000016361.71744.6f

Ras M, Lefebvre D, Derlon N, Hamelin J, Bernet N, Paul E, Girbal-Neuhauser E (2013) Distribution and hydrophobic properties of Extracellular Polymeric Substances in biofilms in relation towards cohesion. J Biotechnol 165:85-92. doi: 10.1016/j.jbiotec.2013.03.001

Ron EZ, Rosenberg E (2001) Natural roles of biosurfactants. Environ Microbiol 3:229-236. doi: 10.1046/j.1462-2920.2001.00190.x

Rosenberg E, Perry A, Gibson DT, Gutnick DL (1979a) Emulsifier of Arthrobacter RAG1: Specificity of hydrocarbon substrate. Appl Environ Microbiol 37:409-413. doi: 10.1016/0014-5793(79)81320-4

Rosenberg E, Rubinovitz C, Gottlieb A, Rosenhak S, Ron EZ (1988) Production of Biodispersan by Acinetobacter calcoaceticus A2. Appl Environ Microbiol 54:317-322. Rosenberg E, Zuckerberg A, Rubinovitz C, Gutnick DL (1979b) Emulsifier of Arthrobacter RAG-1: Isolation and emulsifying properties. Appl Environ Microbiol 37:402-408.

Saini HS, Barragán-Huerta BE, Lebrón-Paler A, Pemberton JE, Vázquez RR, Burns AM, Marron MT, Seliga CJ, Gunatilaka AAL, Maier RM (2008) Efficient purification of the biosurfactant viscosin from Pseudomonas libanensis strain M9-3 and its physicochemical and biological properties. J Nat Prod 71:1011-1015. doi: $10.1021 / \mathrm{np} 800069 \mathrm{u}$

Satpute SK, Banpurkar AG, Dhakephalkar PK, Banat IM, Chopade BA (2010) Methods for investigating biosurfactants and bioemulsifiers: a review. Crit Rev Biotechnol 30:127144. doi: $10.3109 / 07388550903427280$

Shabtai Y (1990) Production of exopolysaccharides by Acinetobacter strains in a controlled fed-batch fermentation process using soap stock oil (SSO) as carbon source. Int J Biol Macromol 12:145-152. doi: 10.1016/0141-8130(90)90066-J

Singh V (2012) Biosurfactant - Isolation, Production, Purification \& Significance. Int J Sci Res Publ 2:2250-3153.

Sjögren M, Li H, Rannug U, Westerholm R (1995) A multivariate statistical analysis of 
chemical composition and physical characteristics of ten diesel fuels. Fuel 74:983-989. doi: 10.1016/0016-2361(95)00056-B

Smyth TJP, Perfumo A, McClean S, Marchant R, Banat IM (2010) Handbook of Hydrocarbon and Lipid Microbiology. Handb Hydrocarb Lipid Microbiol 1:1-6. doi: $10.1007 / 978-3-540-77587-4$

Sousa M, Melo VMM, Rodrigues S, Sant'ana HB, Goncalves LRB (2012) Screening of biosurfactant-producing Bacillus strains using glycerol from the biodiesel synthesis as main carbon source. Bioprocess Biosyst Eng 35:897-906. doi: 10.1007/s00449-0110674-0

Souza EC, Vessoni-Penna TC, De Souza Oliveira RP (2014) Biosurfactant-enhanced hydrocarbon bioremediation: An overview. Int Biodeterior Biodegrad 89:88-94. doi: 10.1016/j.ibiod.2014.01.007

Speight JG, Arjoon KK (2012) Bioremediation of Petroleum and Petroleum Products.

Su WT, Chen WJ, Lin YF (2009) Optimizing emulsan production of A. venetianus RAG-1 using response surface methodology. Appl Microbiol Biotechnol 84:271-279. doi: 10.1007/s00253-009-1957-0

Sun Y, Lu S, Zhao X, Ding A, Wang L (2017) Long-Term Oil Pollution and In Situ Microbial Response of Groundwater in Northwest China. Arch Environ Contam Toxicol 72:519_ 529. doi: 10.1007/s00244-017-0405-X

Tamura K, Peterson D, Peterson N, Stecher G, Nei M, Kumar S (2011) MEGA5: Molecular evolutionary genetics analysis using maximum likelihood, evolutionary distance, and maximum parsimony methods. Mol Biol Evol 28:2731-2739. doi: $10.1093 / \mathrm{molbev} / \mathrm{msr} 121$

Toren A, Navon-Venezia S, Ron EZ, Rosenberg E (2001) Emulsifying Activities of Purified Alasan Proteins from Acinetobacter radioresistens KA53. Appl Environ Microbiol 67:1102-1106. doi: 10.1128/AEM.67.3.1102-1106.2001

Tsai Y-P (2005) Impact of flow velocity on the dynamic behaviour of biofilm bacteria. Biofouling 21:267-77. doi: 10.1080/08927010500398633

Tzintzun-Camacho O, Loera O, Ramírez-Saad HC, Gutiérrez-Rojas M (2012) Comparison of mechanisms of hexadecane uptake among pure and mixed cultures derived from a bacterial consortium. Int Biodeterior Biodegrad 70:1-7. doi: 
10.1016/j.ibiod.2012.01.009

Uzoigwe C, Burgess JG, Ennis CJ, Rahman PKSM (2015) Bioemulsifiers are not biosurfactants and require different screening approaches. Front Microbiol. doi: 10.3389/fmicb.2015.00245

Velasco-Alvarez N, González I, Damian-Matsumura P, Gutiérrez-Rojas M (2011) Enhanced hexadecane degradation and low biomass production by Aspergillus niger exposed to an electric current in a model system. Bioresour Technol 102:1509-1515. doi: 10.1016/j.biortech.2010.07.111

Vinogradov E, Maclean LL, Perry MB (2010) Structural determination of the O-antigenic polysaccharide of enteropathogenic Escherichia coli O103:H2. Can J Microbiol 56:366-372. doi: 10.1139/w10-015

Whyte LG, Schultz A, Van Beilen JB, Luz AP, Pellizari V, Labbé D, Greer CW (2002) Prevalence of alkane monooxygenase genes in Arctic and Antarctic hydrocarboncontaminated and pristine soils. FEMS Microbiol Ecol 41:141-150. doi: 10.1016/S0168-6496(02)00282-9

Wicek AE, Chibowski E (2002) Zeta potential and droplet size of n-tetradecane/ethanol (protein) emulsions. Colloids Surfaces B Biointerfaces 25:55-67. doi: 10.1016/S09277765(01)00304-6

Wrenn BA, Venosa AD (1996) Selective enumeration of aromatic and aliphatic hydrocarbon degrading bacteria by a most-probable-number procedure. Can J Microbiol 42:252-258. doi: $10.1139 / \mathrm{m} 96-037$

Yalçin E, Ergene A (2009) Screening the antimicrobial activity of biosurfactants produced by microorganisms isolated from refinery wastewaters. J Appl Biol Sci 3:148-153. doi: 10.1080/09593330903426695

Yuan H, Yao J, Masakorala K, Wang F, Cai M, Yu C (2014) Isolation and characterization of a newly isolated pyrene-degrading Acinetobacter strain USTB-X. Environ Sci Pollut Res 21:2724-2732. doi: 10.1007/s11356-013-2221-9

Zambry NS, Ayoib A, Md Noh NA, Yahya ARM (2017) Production and partial characterization of biosurfactant produced by Streptomyces sp. R1. Bioprocess Biosyst Eng 40:1007-1016. doi: 10.1007/s00449-017-1764-4

Zhong H, Wang Z, Liu Z, Liu Y, Yu M (2016) Degradation of hexadecane by Pseudomonas 
aeruginosa with the mediation of surfactants: Relation between hexadecane solubilization and bioavailability. Int Biodeterior Biodegradation 115:141-145. doi: 10.1016/j.ibiod.2016.08.008

Zwietering MH, Jongenburger I, Rombouts FM, van 't Riet K (1990) Modeling of the bacterial growth curve. Appl Environ Microbiol 56:1875-1881. 


\section{ANEXOS}

Anexo A. Secuencias de DNA utilizadas para los análisis filogenéticos

- Acinetobacter radioresistens WC-A-157 clone 1061064341598 16S ribosomal RNA gene, GenBank: JN669146.1

- Acinetobacter radioresistens strain G23 16S ribosomal RNA gene, GenBank: JX293298.1

- Acinetobacter radioresistens strain FO-1 16S ribosomal RNA gene, NCBI Reference Sequence: NR_026210.1

- Acinetobacter radioresistens strain FO-1 16S ribosomal RNA gene, NCBI Reference Sequence: NR_026210.1

- Acinetobacter radioresistens strain FO-1 16S ribosomal RNA gene, NCBI Reference Sequence: NR_026210.1

- Acinetobacter lwoffii strain IARI-ABSL-33 16S ribosomal RNA gene, GenBank: JX428987.1

- Acinetobacter calcoaceticus strain McR-2 16S ribosomal RNA gene, GenBank: JF894158.1

- Acinetobacter calcoaceticus strain NCCB 22016 16S ribosomal RNA, NCBI Reference Sequence: NR_042387.1

- Acinetobacter calcoaceticus strain PUCM1019 16S ribosomal RNA gene, GenBank: FJ816066.1

- Acinetobacter calcoaceticus strain PUCM1024 16S ribosomal RNA gene, GenBank: FJ816071.1

- Acinetobacter calcoaceticus strain PUCM1505 16S ribosomal RNA gene, GenBank:FJ816082.1

- Acinetobacter haemolyticus strain M116 16S ribosomal RNA gene, GenBank: HQ407291.1

- Acinetobacter haemolyticus strain DSM 6962 16S ribosomal RNA gene, NCBI Reference Sequence: NR_026207.1

- Acinetobacter haemolyticus strain AR-46 16S ribosomal RNA gene, GenBank: AY586400.2

- Acinetobacter haemolyticus strain MJ1 16S ribosomal RNA gene, GenBank: GU991530.1

- Acinetobacter bouvetii strain UAM25 16S ribosomal RNA gene, GenBank: HQ424441.1

- Acinetobacter haemolyticus strain BA56 16S ribosomal RNA gene, GenBank: FJ263930.1

- Acinetobacter johnsonii strain MA19 16S ribosomal RNA gene, GenBank: DQ864703.1

- Acinetobacter johnsonii strain Mannheim 3865/60 16S ribosomal RNA gene, NCBI Reference Sequence: NR_044975.1

- Acinetobacter bouvetii strain EU40 16S ribosomal RNA gene, GenBank: JF681285.1

- Acinetobacter bouvetii strain CCM 7196 16S ribosomal RNA gene, GenBank: HQ180181.1

- Acinetobacter bouvetii 16S ribosomal RNA gene, GenBank: AF509827.1

- Acinetobacter bouvetii strain 4B02 16S ribosomal RNA gene, NCBI Reference Sequence: NR_028851.1

- Acinetobacter tandoii strain DSM 14970 16S ribosomal RNA gene, GenBank: GU388381.1

- Acinetobacter tandoii strain 4N13 16S ribosomal RNA gene, NCBI Reference Sequence: NR_028853.1

- Acinetobacter tandoii strain CCM 7199 16S ribosomal RNA gene, GenBank: HQ180189.1

- Bacillus sp. R7-532 16S ribosomal RNA gene, GenBank: JQ659884.1 
Anexo B. Análisis de varianza y efectos principales del diseño central compuesto.

\begin{tabular}{|c|c|c|c|c|c|c|}
\hline \multicolumn{7}{|l|}{ Tabla ANOVA } \\
\hline Fuente de Variación & Grados de Libertad & Suma de Cuadrados [ & Media Cuadrada [Parcial] & Tasa F & Valor P & \\
\hline Modelo & 5 & 8,1267 & 1,6253 & 14,4925 & 0,0014 & \\
\hline Efectos Lineales & 2 & 0,8177 & 0,4089 & 3,6457 & 0,0822 & \\
\hline Efectos de Interacción & 1 & 1,836 & 1,836 & 16,3711 & 0,0049 & \\
\hline Efectos Cuadráticos & 2 & 5,473 & 2,7365 & 24,4001 & 0,0007 & \\
\hline Residual & 7 & 0,7851 & 0,1122 & & & \\
\hline Falta de Ajuste & 3 & 0,7798 & 0,2599 & 196,9124 & $8,46 \mathrm{E}-05$ & \\
\hline Error Puro & 4 & 0,0053 & 0,0013 & & & \\
\hline Total & 12 & 8,9118 & & & & \\
\hline$S=$ & 0,3349 & & PRESS = & 5,5533 & & \\
\hline$R-s q=$ & $91,19 \%$ & & $\mathrm{R}-\mathrm{sq}($ pred $)=$ & $37,69 \%$ & & \\
\hline$R-s q(a j)=$ & $84,90 \%$ & & & & & \\
\hline \multicolumn{7}{|l|}{ Información de Regresión } \\
\hline Término & Coeficiente & Error Estándar & Cl Inferior & Cl Superior & Valor T & Valor P \\
\hline Interceptar & 5,358 & 0,1498 & 5,0039 & 5,7121 & 35,7756 & $3,46 \mathrm{E}-09$ \\
\hline$A: C$ & $-0,3011$ & 0,1184 & $-0,5811$ & $-0,0211$ & $-2,5431$ & 0,0385 \\
\hline $\mathrm{B}: \mathrm{N}$ & $-0,1075$ & 0,1184 & $-0,3875$ & 0,1725 & $-0,9078$ & 0,3942 \\
\hline$A B$ & 0,6775 & 0,1674 & 0,2816 & 1,0734 & 4,0461 & 0,0049 \\
\hline AA & $-0,754$ & 0,127 & $-1,0542$ & $-0,4538$ & $-5,9384$ & 0,0006 \\
\hline BB & $-0,5615$ & 0,127 & $-0,8617$ & $-0,2613$ & $-4,4223$ & 0,0031 \\
\hline
\end{tabular}

Anexo B.1 ANOVA del DCC y regresión: donde A: C es el factor Carbono y B:N es el factor nitrógeno 


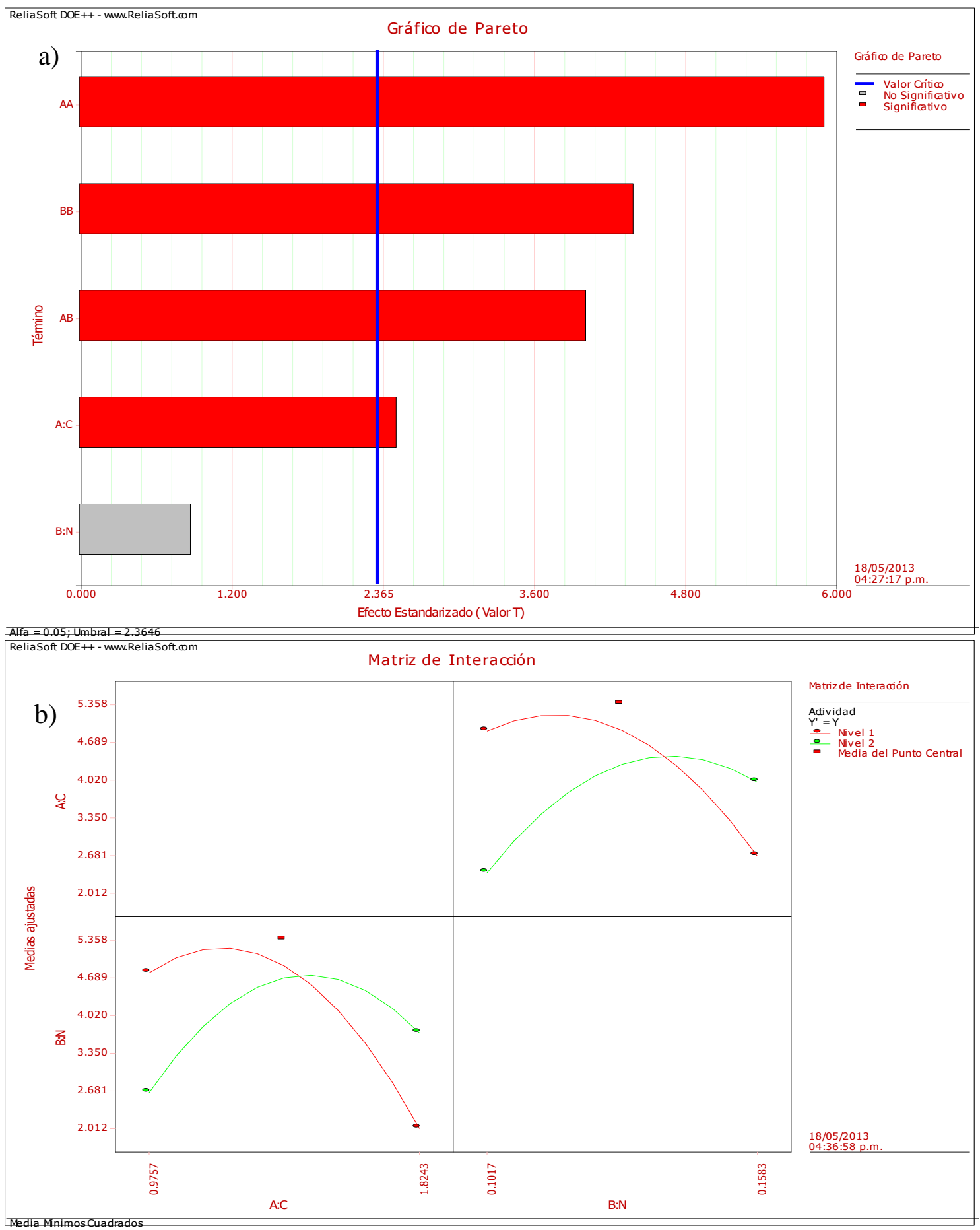

Anexo B.2 a) Gráfico de Pareto: Factores con efectos principales del modelo DCC. b) Matriz de interacción de factor A (concentración de carbono) con B (concentración de nitrógeno) 


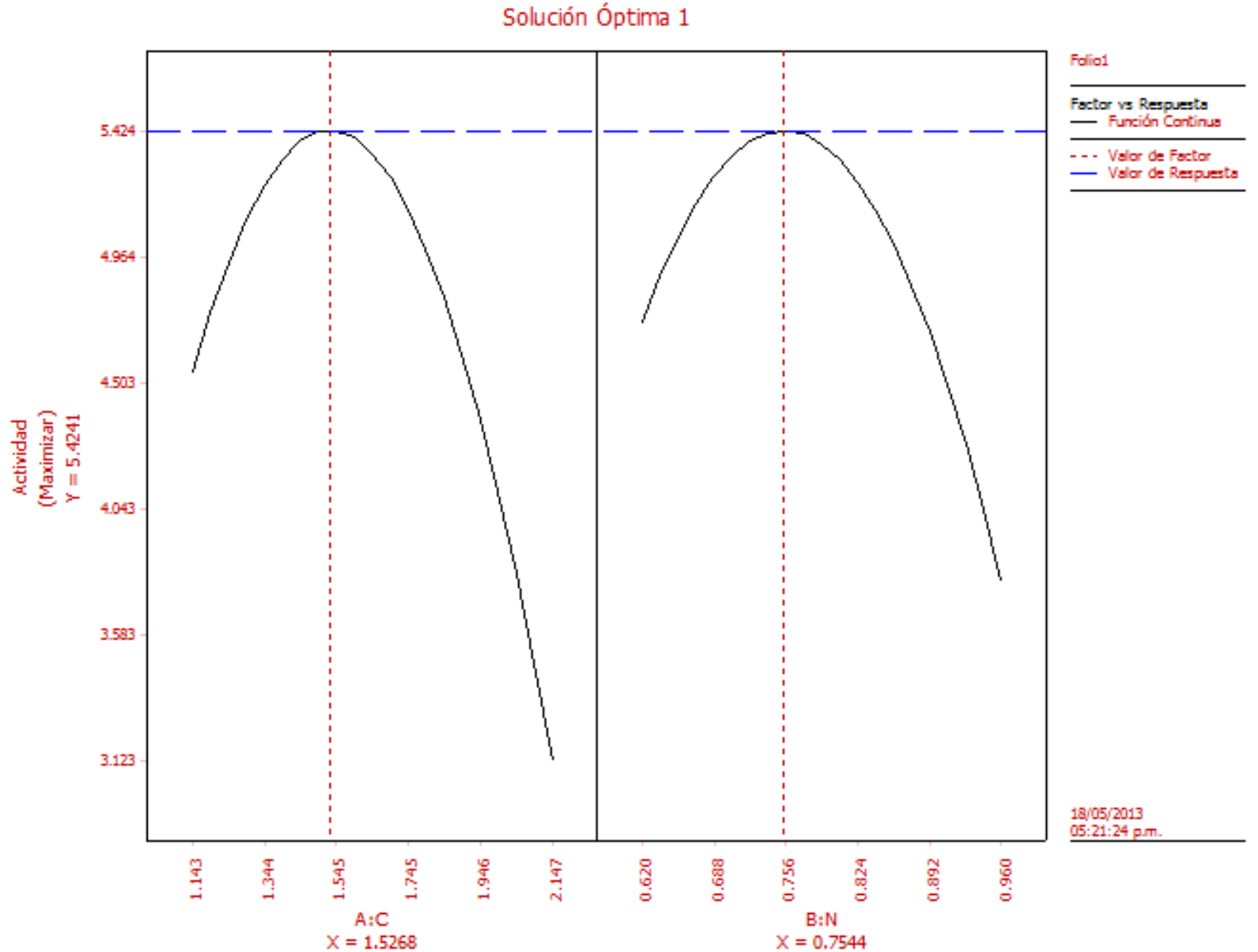

Anexo B.3 Resultado de optimización para los factores: concentración de carbono (A) y de nitrógeno $(\mathrm{B})$ 
Anexo C Espectro NOESY del BE purificado, la interacción (int) entre componentes anoméricos y alifáticos, señalada en un círculo.

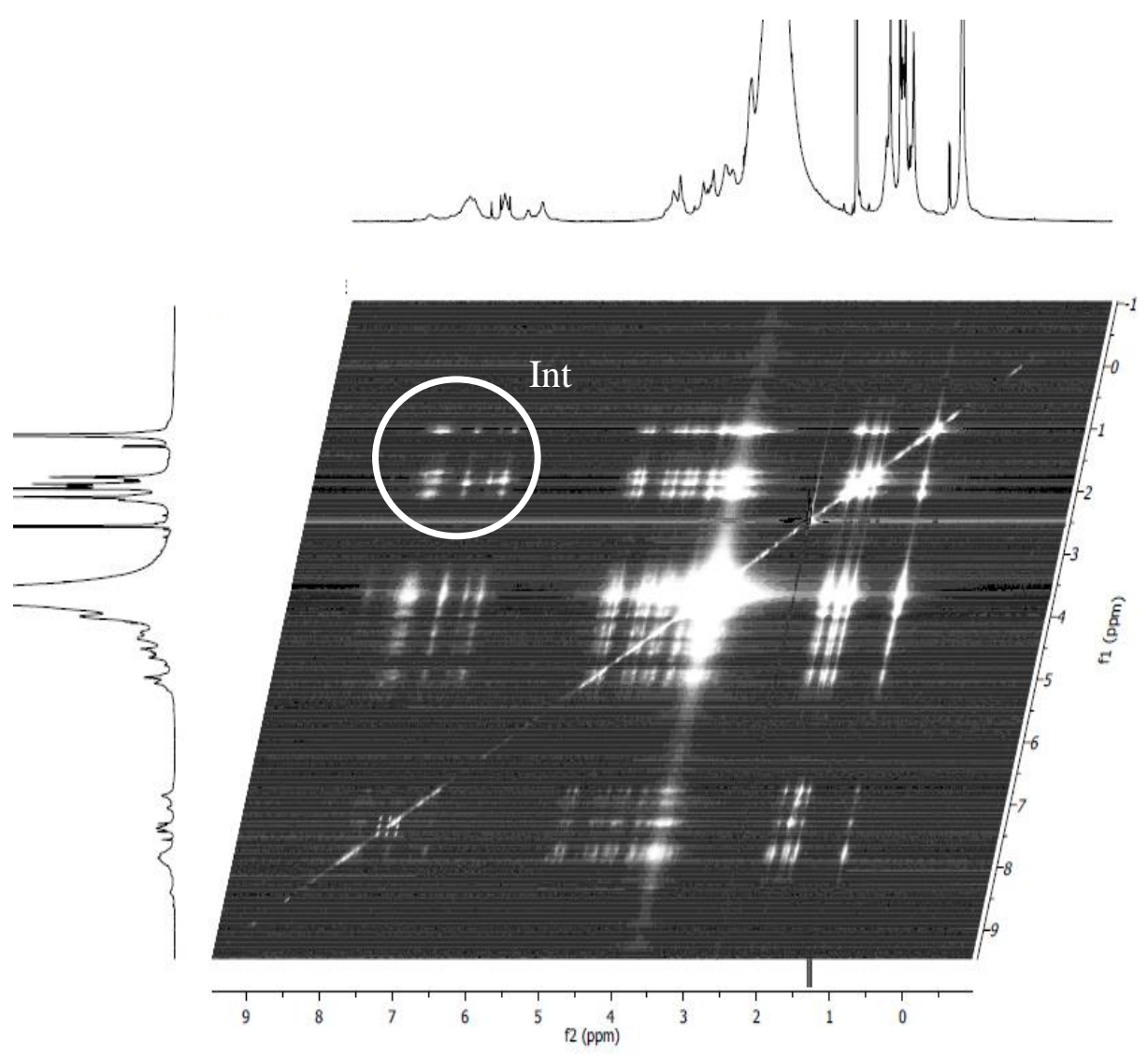


Anexo D Artículo de investigación

Vol. 16, No. 3 (2017) 721-733

Revista Mexicana de Ingeniería Química

\title{
NOVEL EXOPOLYSACCHARIDE PRODUCED BY Acinetobacter bouvetii UAM25: PRODUCTION, CHARACTERIZATION AND PAHS BIOEMULSIFYING CAPABILITY
}

\section{NUEVO EXOPOLISACARIDO PRODUCIDO POR Acinetobacter bouvetii UAM25: PRODUCCIÓN, CARACTERIZACIÓN Y CAPACIDAD BIOEMULSIFICANTE DE HPAs}

\author{
J.L. Vázquez-Vázquez ${ }^{1}$, N.D. Ortega-de la Rosa ${ }^{1}$, S. Huerta-Ochoa ${ }^{1}$, M. Gimeno ${ }^{2}$, M. Gutiérrez-Rojas ${ }^{1}$ * \\ ${ }^{1}$ Departamento de Biotecnología, Universidad Autónoma Metropolitana-Iztapalapa, Av. San Rafael Atlixco 186, Col. Vicentina, \\ Iztapalapa 09340, DF, México. \\ ${ }^{2}$ Departamento de Alimentos y Biotecnología, Facultad de Química, Universidad Nacional Autónoma de México, Ciudad \\ Universitaria 04510, DF, México \\ Received May 5, 2017; Accepted June 1, 2017
}

Abstract

Environmental pollution that polycyclic aromatic hydrocarbons (PAHs) cause, results in ecological damage. Bioremediation tackles this issue by using living organisms and metabolites such as bioemulsifiers (BEs) which can pseudo-solubilise hydrocarbons making them more accessible for biodegradation. The aims of this work were (i) to produce in an airlift bioreactor a novel BE through the UAM25 strain, (ii) to evaluate the BE emulsifying activity and stability against commercial emulsifiers using three PAHs, and (iii) to characterize the biomolecule after purification. The UAM25 strain, produced a high molecular weight $(1,010 \mathrm{kDa})$ macromolecule when grown in an airlift bioreactor with n-hexadecane as its sole carbon and energy source. Under these conditions, the yield was $150 \mathrm{mg} \cdot \mathrm{L}^{-1}$ of pure BE with 160 emulsifying activity units. The BE emulsified nhexadecane and $\beta$-methylnaphthalene, as well as blends of pyrene and phenanthrene in a non-specific mode. This novel BE displays an exopolysaccharide (repeated rhamnose and galactose units) structure different from previously reported within the same bacterial genus. We observed remarkable PAH-emulsifying capabilities in the $\mathrm{BE}$, compared to commercial emulsifiers such as Tween 80 and Triton X-100. Our work suggests potential biotechnological applications to enhance the bioremediation of soil, sediments, and water.

Keywords: Acinetobacter bouvetii, bioemulsifier, polycyclic aromatic hydrocarbons, exopolysaccharide, airlift bioreactor.

\section{Resumen}

Los hidrocarburos aromáticos policíclicos (HPAs) causan contaminación ambiental provocando daño ecológico. La biorremediación resuelve este problema utilizando organismos vivos y metabolitos tales como los bioemulsificantes (BEs) los cuales pueden pseudo-solubilizar hidrocarburos facilitando su biodegradación. Los objetivos de este trabajo fueron: (i) producir en un biorreactor airlift un nuevo BE utilizando la cepa UAM25; (ii) evaluar la actividad del BE contra emulsificantes comerciales utilizando tres HPAs; y (iii) caracterizar la biomolécula después de su purificación. La cepa UAM25 produjo un BE macromolecular $(1,010 \mathrm{kDa})$ cuando se inoculó en un biorreactor airlift, con n-hexadecano como única fuente de carbono y energía. Bajo estas condiciones, el rendimiento fue de $150 \mathrm{mg} \cdot \mathrm{L}^{-1}$ de BE puro con 160 unidades de actividad emulsificante. El BE fue capaz de emulsificar n-hexadecano y $\beta$-metilnaftaleno, así como mezclas de pireno y fenantreno de manera inespecífica. Este nuevo BE muestra una estructura de exopolisacárido (unidades repetidas de ramnosa y galactosa) diferente de las previamente reportadas para este mismo género bacteriano. Se observó una alta capacidad del BE para emulsificar HPAs, al compararlo con emulsificantes comerciales, tales como Tween 80 y Triton X-100. Las propiedades de este BE, demuestran su potencial para mejorar técnicas de biorremediación de suelos, sedimentos y agua.

Palabras clave: Acinetobacter bouvetii, bioemulsificante, hidrocarburos policíclicos aromáticos, ex opolisacárido, reactor airlift.

\footnotetext{
* Corresponding author. E-mail: : mgraxanum.uam.mx
} 
Vázquez-Vázquez et al./ Revista Mexicana de Ingeniería Química Vol. 16, No. 3 (2017) 721-733

\section{Introduction}

Pollution of the environment by hydrocarbons derived from petroleum-industry activities results in damage to various ecological systems. The bioremediation approach aims to tackle this issue by using living organisms such as bacteria to reduce or eliminate environmental hazards resulting from the accumulation of toxic chemical wastes (Cisneros-de La Cueva et al., 2016, 2014; Souza et al., 2014). In this regard, hydrocarbons low solubility result in a mass transfer limitation which directly affects microbial growth (Jiménez-González et al., 2015). However, some microorganisms can produce one of the most extensively studied secondary metabolites, bioemulsifiers (BEs), which are metabolites that affect surfaces and can pseudo-solubilise pollutants such as polycyclic aromatic hydrocarbons (PAHs), making them more accessible for biodegradation (Martínez Trujillo et al., 2015). BEs are polymeric amphipathic molecules of high molecular weight that can form and stabilize emulsions, since they bind tightly to aqueous, dispersed hydrocarbons and oils, preventing them from merging (Ron and Rosenberg, 2001). The resulting emulsifying activity (EA) is related to the chemical composition and structure of the BE (Uzoigwe et al., 2015). PAHs such as pyrene, naphthalene, and phenanthrene, are persistent organic compounds with two or more fused aromatic rings. In the environment, they have high carcinogenic and mutagenic potential, which makes their elimination a critical need. Interest in BEs has increased because of their different functional properties, such as wetting, foaming, oil solubilizing, enhancing PAH biodegradation (which benefits the rheological characteristics), high biodegradability, and low toxicity compared to chemically synthesized emulsifiers (Monteiro et al., 2010). On the other hand, effective $\mathrm{BE}$ production in bioreactors is a challenge due to the shear stress that rotating impellers impose and outcome to be detrimental to cells growth depending on the level of intensity. However, pneumatic airlift bioreactors (ALBs) improves the mixing performance and reduces the mechanical forces on cells, additionally, it generates well-defined fluid flow patterns, high gas-liquid mass-transfer rates, low operating costs, with less dead zones and cell clumping in the bioreactor (Guo et al., 2015; Villegas et al., 2016).
The Acinetobacter spp. are widely studied macromolecular BE producers, this genus, depending on the species, could produce BEs with differences in molecular structure and emulsifying mechanisms. For example, the emulsifying capacity of the BE that Acinetobacter sp. RAG-1 forms is mainly due to its polysaccharide and lipidic components, whereas the emulsifying capacity of the $\mathrm{BE}$ from $A$. radioresistens results from the presence of protein in the macromolecule (Ron and Rosenberg, 2001; Toren et al., 2001). In this regard, Acinetobacter bouvetii UAM25, isolated from the rhizosphere of Cyperus laxus Lam in a highly polluted swamp, showed BE production capacity, but these capabilities had not been described so far (Díaz-Ramírez et al., 2008; Tzintzun-Camacho et al., 2012).

The aims of this work were: (i) to produce, in an airlift bioreactor, a BE with a high EA by the strain UAM25; (ii) to evaluate the BE emulsifying activity and stability against commercial emulsifiers using three PAHs; and (iii) to characterize the biomolecule after purification. The insight into the relationship between the BE's emulsification capabilities and chemical structure may enable us to shade light on emulsifying hydrocarbons to design new and better hydrocarbon-emulsifying and degradation methods for bioremediation.

\section{Materials and methods}

\subsection{Microorganisms and chemicals}

Microbiological media and salts (J.T. Baker, Mexico) were used. Tween 80 and Triton X-100 (HYCEL, México) were also used to compare the BE's performance as a hydrocarbon emulsifier. Solvents were $99 \%$ pure reagents purchased from Sigma Aldrich, USA. The Acinetobacter bouvetii UAM 25 strain (Tzintzun-Camacho et al., 2012) (GenBank accession number HQ424441.1) is available at the WDCM449 culture collection from The National Polytechnic Institute (Mexico) with the number ENCB-MG-076.

\subsection{Bacterial growth and residual HXD}

The Bacterial growth and kinetic studies were done in ALBs. Culture medium consisted of mineral medium with the following composition: $\left(\mathrm{g} \cdot \mathrm{L}^{-1}\right) ; 3.87 \mathrm{NaNO}_{3}$; $1.08 \mathrm{~K}_{2} \mathrm{HPO}_{4} ; 0.56 \mathrm{KCl}$; and $0.55 \mathrm{MgSO}_{4} \cdot 7 \mathrm{H}_{2} \mathrm{O}$ 
Vázquez-Vázquez et al./ Revista Mexicana de Ingeniería Química Vol. 16, No. 3 (2017) 721-733

with $7.6 \mathrm{~g} \cdot \mathrm{L}^{-1}$ of $\mathrm{n}$-hexadecane (HXD) as the sole carbon source. The initial $\mathrm{pH}$ was adjusted to 6.5 with $1.0 \mathrm{~N} \mathrm{HCl}$. Kinetic studies were modelled with the re-parameterized sigmoidal Gompertz model (Zwietering et al., 1990) calculated from colony forming units $\left(\mathrm{CFU} \cdot \mathrm{mL}^{-1}\right)$. Culture growth was determined by viable counts on Petri dishes containing TSA incubated at $30{ }^{\circ} \mathrm{C}$. Colonies were quantified after $24 \mathrm{~h}$. Cells and residual HXD were separated from the broth in the ALB by centrifugation at 10000 $\mathrm{x} g$ for $20 \mathrm{~min}$ at $4{ }^{\circ} \mathrm{C}$ (Eppendorf; Centrifuge 5810 $\mathrm{R}$; Germany), then the supernatant was analysed for total carbohydrates by the sulfuric acid phenol method (DuBois et al., 1956) and for proteins by Bradford, (1976) method. Residual HXD was separated from the cell-free broth by liquid-liquid extraction with a hexane-acetone $(1: 1, v / v)$ mixture. Funnels were left $30 \mathrm{~min}$ at room temperature until the mixture reached complete phase separation. The recovered HXD was quantified by gas chromatography in a Varian Star 3900 GC (USA) equipped with an ionization detector and an AT-1HT column (15 m x $0.25 \mathrm{~mm} \times 0.10$ $\mu \mathrm{m}$, Alltech Heliflex, USA) with helium as carrier (30 $\mathrm{mL} \cdot \mathrm{min}^{-1}$; $\left.40 \mathrm{psi}\right)$. The oven was heated to $120^{\circ} \mathrm{C}$ $\left(30^{\circ} \mathrm{C} \cdot \mathrm{min}^{-1}\right)$, then increased to $150^{\circ} \mathrm{C}\left(10^{\circ} \mathrm{C} \cdot \mathrm{min}^{-1}\right)$ and finally increased to $170{ }^{\circ} \mathrm{C}\left(15^{\circ} \mathrm{C} \cdot \mathrm{min}^{-1}\right)$. Injected volume sample was $2 \mu \mathrm{L}$.

\subsection{BE production and purification}

The BE was produced in glass ALB vessel equipped with stainless steel concentric draft tube. The dimensions and geometric relationships were previously reported (Lizardi-Jiménez and GutiérrezRojas 2011; Lizardi-Jiménez et al., 2014). Mineral medium $(1 \mathrm{~L})$ with carbon $(\mathrm{HXD})$ to nitrogen ratio of 10.5 was inoculated with $1 \times 10^{6} \mathrm{CFU} \cdot \mathrm{mL}^{-1}$ of Acinetobacter bouvetii UAM25. To purify the BE, aliquots $(100 \mathrm{~mL})$ were taken from the ALB after $48 \mathrm{~h}$. Cells were separated by two sequential centrifugation steps: (i) $8000 \mathrm{x} g$ for $30 \mathrm{~min}$ at $4{ }^{\circ} \mathrm{C}$; the supernatant was collected and (ii) centrifuged again at $10000 \mathrm{x}$ $g$ for $20 \mathrm{~min}$ at $4{ }^{\circ} \mathrm{C}$, then the resulting supernatant was filtered through cellulose acetate membranes $(0.45 \mu \mathrm{m})$. The supernatant was diafiltrated and concentrated by ultrafiltration with a stirred cell system using an Omega polyethersulfone $30 \mathrm{kDa}$ cutoff ultrafiltration membrane (PALL, USA). The air injected into the ultrafiltration system passed through a polytetrafluoroethylene membrane $(20 \mu \mathrm{m})$ at 20 psi. Diafiltration was conducted in a non-continuous regimen, such that every $100 \mathrm{~mL}$ concentrated 50 times, was then diluted to the original volume until the conductivity of the filtered solution was less than $0.01 \mathrm{mS} \cdot \mathrm{cm}^{-1}$, using distilled water's conductivity as reference.

\subsection{Emulsifying activity}

To evaluate the EA of the purified and non-pure BEs in the cell-free mineral medium, a modification of the standard assay by Rosenberg et al., (1979) was used. Samples $(0.4 \mathrm{~mL})$ were introduced into $10 \mathrm{~mL}$ glass tubes containing $2.6 \mathrm{~mL}$ of buffer mix (20 mM Tris- $\mathrm{HCl}, 10 \mathrm{mM} \mathrm{MgSO}_{4}, \mathrm{pH} 7.0$ ), then $40 \mu \mathrm{L}$ of a 1:1 (v/v) mixture of HXD and $\beta$-methylnaphthalene were added. The tubes were vortexed at room temperature for $2 \mathrm{~min}$ and allowed to standing for $10 \mathrm{~min}$ before measuring optical density (OD) (Deng et al., 2010), determined in a Varian Cary $50 \mathrm{UV}-\mathrm{Vis}$ spectrophotometer (Agilent, USA). One unit of EA was defined as the capacity of $1 \mathrm{~mL}$ of supernatant to raise the OD measured at $600 \mathrm{~nm}$ by 0.1 units.

\subsection{Emulsification of PAHs, stability assays, and zeta potential}

EA was assayed with blends of HXD: pyrene (PYR) at $1 \%(\mathrm{w} / \mathrm{v})$, HXD: $\beta$-methylnaphthalene $1: 1(\mathrm{v} / \mathrm{v})$, and HXD mixed with PYR and phenanthrene (PHE), both at $1 \%$. PAHs assayed were mixed with HXD in proportions that mimicked common environmental contaminants, such as diesel fuels (Sjögren et al., 1995). Control emulsion was formed using individual HXD. PAHs within the emulsion were detected at $276 \mathrm{~nm}$ (PAHs maximum peak), the emulsion OD was measured at $600 \mathrm{~nm}$ (standard assay). Synthetic surfactants suitable for oil in water PAHs emulsification, Tween 80 and Triton X-100, with respective hydrophilic lipophilic balances (HLB) of 13.4 and 15 , were used as synthetic commercial references (Ghosh and Mukherji, 2016). The assayed concentrations were $150 \mathrm{mg} \cdot \mathrm{L}^{-1}$ for both the $\mathrm{BE}$ and the reference samples. Cell-free medium $(1 \mathrm{~mL})$ was diluted to a 1:10 ratio, deionized water was used for zeta potential determinations, in the $2-10 \mathrm{pH}$ range, using a Zetasizer Nano ZS ZEM3500 (Malvern Instruments, UK) (Sotelo-Boyas et al., 2015).

\subsection{BE characterization by NMR analyses}

The ${ }^{1} \mathrm{H},{ }^{13} \mathrm{C}$ and bi-dimensional (COSY and NOE) NMR spectra were recorded in a unity spectrometer 
(Varian, USA) at 400 or $100 \mathrm{MHz}$ using deuterated water and DMSO-d6 as solvents. The BE purified samples were previously hydrolysed by an acidic method, mixing concentrated $\mathrm{BE}$ with a $2.0 \mathrm{~N} \mathrm{HCl}$ solution in a $1: 1$ ratio $(\mathrm{v} / \mathrm{v})$, later the mixture was heated in a water bath for $15 \mathrm{~min}$. The hydrolysate was then lyophilized to a translucent soluble film prior to analyses. Signals were assigned according to the bacterial carbohydrate structure database (Egorova and Toukach, 2014).

\subsection{Protein analysis}

Proteins in the cell-free media were precipitated by the addition of different ratios of water saturated with ammonium sulphate at $4{ }^{\circ} \mathrm{C}$. After $12 \mathrm{~h}$ at $4{ }^{\circ} \mathrm{C}$ the tubes were centrifuged ( $8000 \times \mathrm{g}$ for $30 \mathrm{~min}$ ) to obtain a pellet that was later dialyzed against water with a cellulose regenerated dialysis membrane (10 kDa). Samples were analysed by the Laemmli, (1970) method. The EA of purified proteins was also tested.

\subsection{Size exclusion chromatography (SEC)}

Molecular weight distributions (number-average molecular weight, $M_{n}$, and polydispersity index, PDI) of the dried non-hydrolysed $\mathrm{BE}$ concentrate samples $(5 \mathrm{mg})$ were acquired in an Agilent 1260 series liquid chromatograph equipped with a refractive index detector (RID) and two PL aquagel-OH (Waters, USA) columns in series placed in a thermostat at $25^{\circ} \mathrm{C}$ and calibrated with polyethylene glycol (PEG) standards (Agilent, USA). Deionised water (MilliQ-UV, Merck) was used as the mobile phase at $0.8 \mathrm{~mL} \cdot \mathrm{min}^{-1}$ flow. Samples were dissolved in the mobile phase and filtered $(0.45 \mu \mathrm{m})$ prior to chromatographer injection. Results were analysed with Cirrus GPC/SEC software (Agilent, USA).

\subsection{Statistical analysis}

One-way ANOVA with Tukey's post hoc tests were performed to make all pair-wise comparisons ( $\alpha=$ 0.05 ) with SPSS v.15.0 statistical software (IBM, USA).
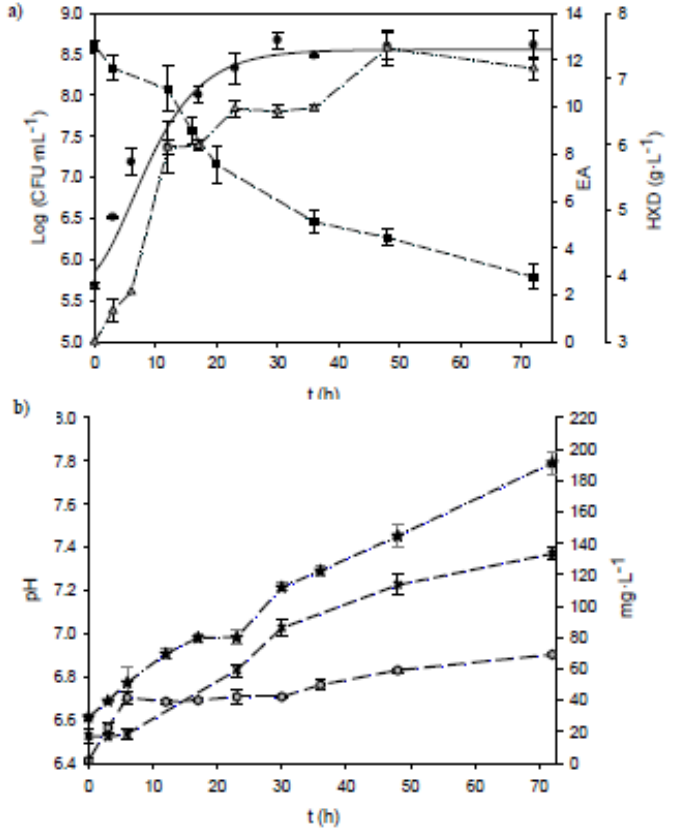

Fig. 1. a) Cell growth (- - -), emulsifying activity (EA) (---1---), and residual HXD (- - - - ). b) Carbohydrates $(--\star--)$, protein (- - - -), and $\mathrm{pH}$ kinetics $(--\times--)$; each value is the mean of three replicates \pm standard deviations (error bars).

\section{Results}

\subsection{Cell-growth, EA and residual HXD kinetics in $A L B$}

To determine the growth phase in which the BE was produced with the highest EA in the shortest time, growth kinetics were analysed. Figure 1a shows cellgrowth, residual $\mathrm{HXD}$, and BE production kinetics. BE attachment was observed on ALB surfaces. Growth pattern was fully explained by the reparameterized sigmoidal Gompertz model with $R^{2}=$ 0.99: no lag phase was detected, the maximum specific growth rate $\left(\mu_{\max }\right)$ was $0.395 \pm 0.073 \mathrm{~h}^{-1}$ with a maximum growth of $8.6 \pm 0.17 \mathrm{Log} C F U \cdot \mathrm{mL}^{-1}$, and no significant differences were observed after $20 \mathrm{~h}$ of growth $(\alpha=0.05)$. A maximum EA value $(12.51 \pm 0.72$ units) after $48 \mathrm{~h}$ was observed. The EA rose significantly after $15 \mathrm{~h}$ of culture and remained without significant changes. At the end of 
Vázquez-Vázquez, et al./ Revista Mexicana de Ingeniería Química Vol. 16, No. 3 (2017) 721-733

the kinetic growth phase, $47 \pm 2.4 \%$ of the HXD was consumed, however, $24 \pm 3.7 \%$ was removed after 20 h (exponential phase). The remaining $23 \%$ of HXD required $52 \mathrm{~h}$ time lapse (stationary growth phase) to be consumed. EA rose significantly five hours before the end of the exponential phase, reaching a maximum in the stationary phase while the HXD uptake rate remained low.

\subsection{Protein, carbohydrates, and pH kinetics in $A L B$}

A preliminary characterization of the $\mathrm{BE}$ was performed through an analysis of the protein, carbohydrate, and $\mathrm{pH}$ kinetic variables in ALB. Carbohydrate concentrations increased significantly after $20 \mathrm{~h}$ with a value of $144.61 \pm 6.77 \mathrm{mg} \cdot \mathrm{L}^{-1}$ at $48 \mathrm{~h}$, which correlates to the BE yield production and EA with $\mathrm{pH}$ increase up to 7 (Fig 1b). The purified protein content from the culture broth showed low EAs (less than 0.5 units) with yields of less than $1 \%$ of the total purified BE. Additionally, the SDS-PAGE of these purified proteins (data not shown) revealed blurry bands with molecular weights below $21 \mathrm{kDa}$.

\subsection{PAHs emulsification and zeta potential}

Figure 2a shows that $A$. bouvetii UAM25 BE emulsified different aromatic compounds with no significant differences among the three PAHs tested ( $\alpha$ $=0.05$ ). The presence of PAHs within the emulsion were evidenced (Fig 2, b and c) at a $276 \mathrm{~nm}$ wavelength. Tween 80 and Triton X-100 were unable to emulsify PAHs other than $\beta$-methylnaphthalene, in a low extent compared to the BE (Fig 2b). Emulsification of the HXD component by BE folded 4.5 and 3.3 times the EA of Triton X-100 when PYR and PHE were in the mix, respectively.

The $\mathrm{pH}$ and zeta potential were correlated to get insight on physicochemical BE properties. Figure $3 \mathrm{a}$ shows that the $\mathrm{BE}$ was able to form a stable emulsion that remained after $96 \mathrm{~h}$. The $\mathrm{pH}$ change had no significant effect on stability from $\mathrm{pH} 4$ to 8 , but at $\mathrm{pH} 3$, a decrease in stability, zeta potential electronegativity (Fig $3 \mathrm{~b}$ ) and EA response was observed. At pH 9, the EA response was slightly higher and the stability was not significantly different to that at $\mathrm{pH}$ levels of 4,5 , and $7(\alpha=0.05)$.

\subsection{SEC and NMR analyses}

The BE yield was $150 \pm 1.12 \mathrm{mg} \cdot \mathrm{L}^{-1}$ after $48 \mathrm{~h}$ of culture. The purified BE exhibited an EA of 160
$\mathrm{U} \cdot \mathrm{mg}^{-1}$ (24 $000 \mathrm{U}$ per ALB). The molecular weight distribution analysis by SEC revealed a high molecular weight molecule by only one narrow peak in the chromatogram with a weight of $1,010 \mathrm{kDa}$ and a PDI of 1.38 against PEG standards. Resonance analyses showed a low intensity signal at $(\delta) 8 \mathrm{ppm}$ in the ${ }^{1} \mathrm{H}$ NMR spectra that might indicate the presence of unsaturation to a low extent (Fig 4a). It is noteworthy that the singlets at $2.76,2.89$, and $3.05 \mathrm{ppm}$ might be assigned to chlorinated methyl impurities due to the hydrolytic treatment and therefore are not related to the molecular structure of the BE. The signals at low field (5-5.5 ppm) within this massive broad signal could be assigned to the anomeric protons of the saccharide region according to Jain et al., (2013). In agreement with the database, the pattern of signals at $(\delta)(\mathrm{ppm})$ of $5.18,3.78,4.04,4.18$, 4.11 , and 3.74 correlates to $\alpha$-D-galactose (DGalp) in a chain of six sugars. Similarly, the signals ( $\delta$ ppm) at $5.09,4.10,4.00,3.58,3.95$, and 1.33 were assigned to an $\alpha$-L-rhamnose (LRhap) side chain of the polysaccharide backbone. Interestingly, the shifts at $(\delta \mathrm{ppm}) 4.49,3.61,3.80,4.33$, and 4.27 corresponded to a $\beta$-D-galactose (DGalpA) with an uronic acid unit. The signal at $2.1 \mathrm{ppm}$ suggested methyl groups of $\mathrm{O}$-acetyl moieties, which might indicate the presence of acetylated residues. More importantly, the signal at $\delta(\mathrm{ppm})$ of $1.26\left(-\left(\mathrm{CH}_{2}\right)_{n^{-}}\right)$, $1.44-1.46\left(-\mathrm{CH}_{2}-\left(\mathrm{CH}_{2}\right)_{n^{-}}\right)$, and $2.00-2.30\left(-\mathrm{CH}_{2}-\mathrm{CH}_{2}-\right.$ $\left.\left(\mathrm{CH}_{2}\right)_{n^{-}}\right)$evidenced the presence of an aliphatic region that might be attributed to alkyl side chains (Dhasayan et al., 2014) in a branched structure. Additionally, 2D-NMR studies might evidence the presence of cross-linking between chains, as Figure 5 shows. The analysis of the spectrum revealed that the $\mathrm{H} 1$ and $\mathrm{H} 2$ hydrogens of the carbohydrate component are attached to the aliphatic component (Fig 5, Int A, B, and C). The sample solubilized in DMSO-d6 also showed shifts in the 7.00-7.50 ppm range, corresponding to the $\mathrm{H} 2$ shift of galactose, which interacted with anomeric protons (Fig 5, Int D and Int C). Interpreting the ${ }^{13} \mathrm{C}$ NMR gives further evidence (as the spectrum of Fig 4b shows) where signals at $\delta$ (ppm) of 96-100, 54-56, 7178 , and 65 correlated to the carbons $\mathrm{C} 1, \mathrm{C} 2, \mathrm{C} 3-\mathrm{C} 4$, and $\mathrm{C} 6$ of galactose. The signal at $17 \mathrm{ppm}$ relates to a C6 rhamnose unit; both sugars were also identified in the ${ }^{1} \mathrm{H}$ NMR spectra. More importantly, the ${ }^{13} \mathrm{C}$ NMR spectra displayed intense signals between 168$172 \mathrm{ppm}$ assigned to carbonyl groups. This intense signal in the ${ }^{13} \mathrm{C}$ NMR spectrum and the absence of aldehyde protons in the ${ }^{1} \mathrm{H}$ NMR suggest the presence of either acetyl or ester moieties forming ester-type linkages between chains. 
Vázquez-Vazquez et al./ Revista Mexicana de Ingeniería Química Vol. 16, No. 3 (2017) 721-733
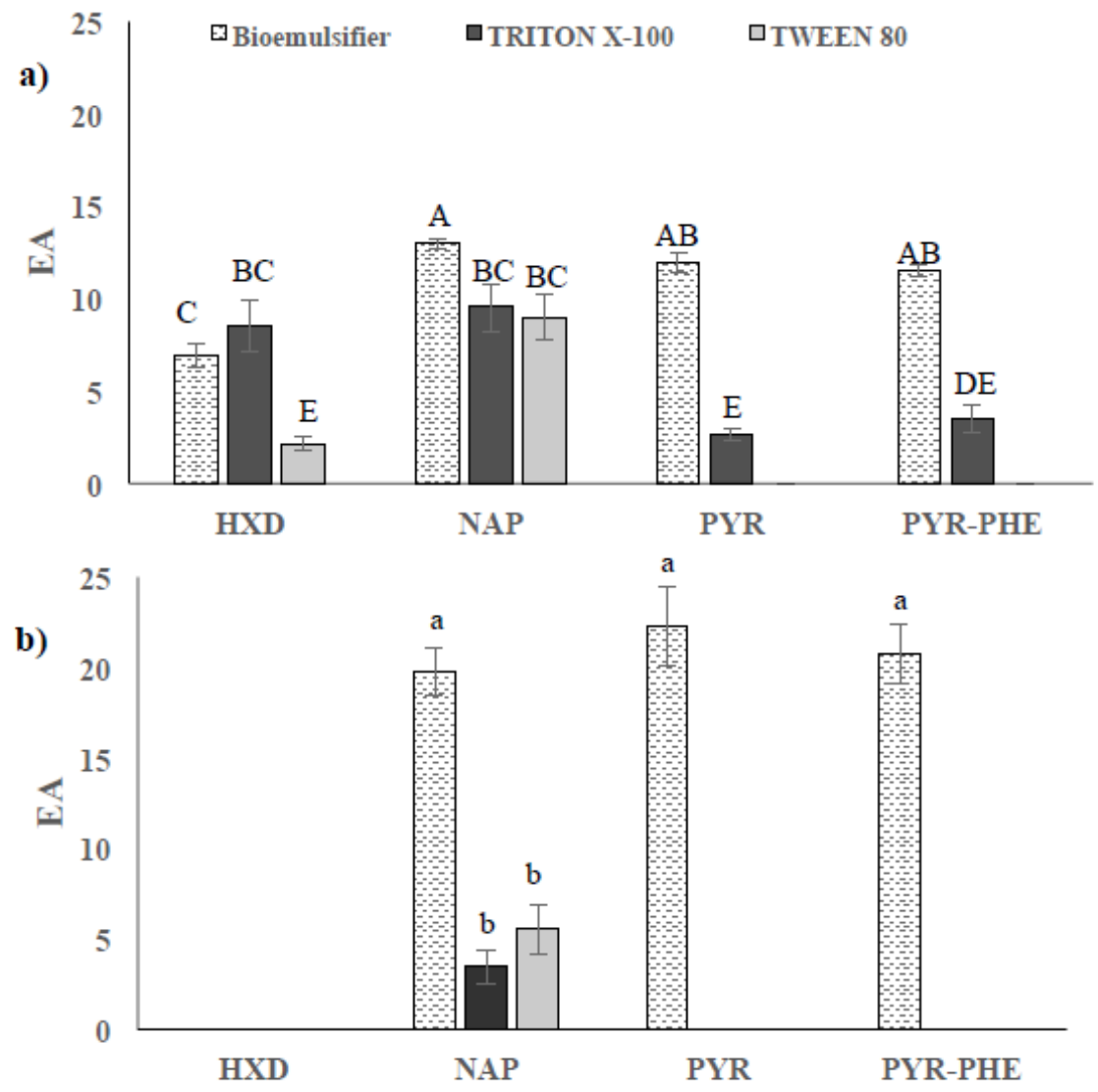

c)

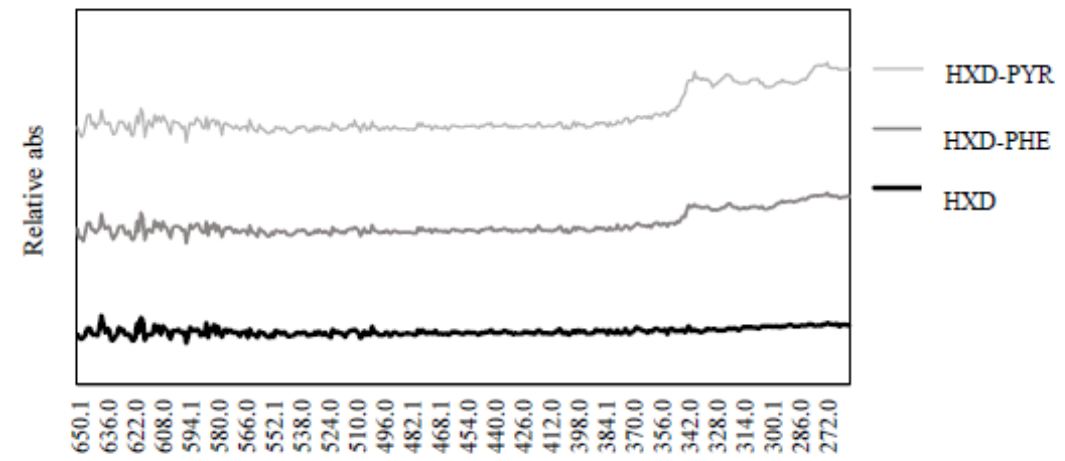

Fig. 2. EA of the BE mixed with sole HXD, HXD: $\beta$-methylnaphthalene (NAP), HXD: pyrene (PYR), and HXD: pyrene: phenanthrene (PYR-PHE). Measurements were done at a) $600 \mathrm{~nm}$; and b) $276 \mathrm{~nm}$ (each value is the mean of six replicates \pm standard deviations (error bars), pair-wise comparisons by Tukey's post hoc, different letters (capital or lowercase) designate significant differences $(\alpha=0.05)$ ); and c) Spectrophotometric scan of hydrocarbon blends. 
Vázquez-Vázquez et al./ Revista Mexicana de Ingeniería Química Vol. 16, No. 3 (2017) 721-733

a)
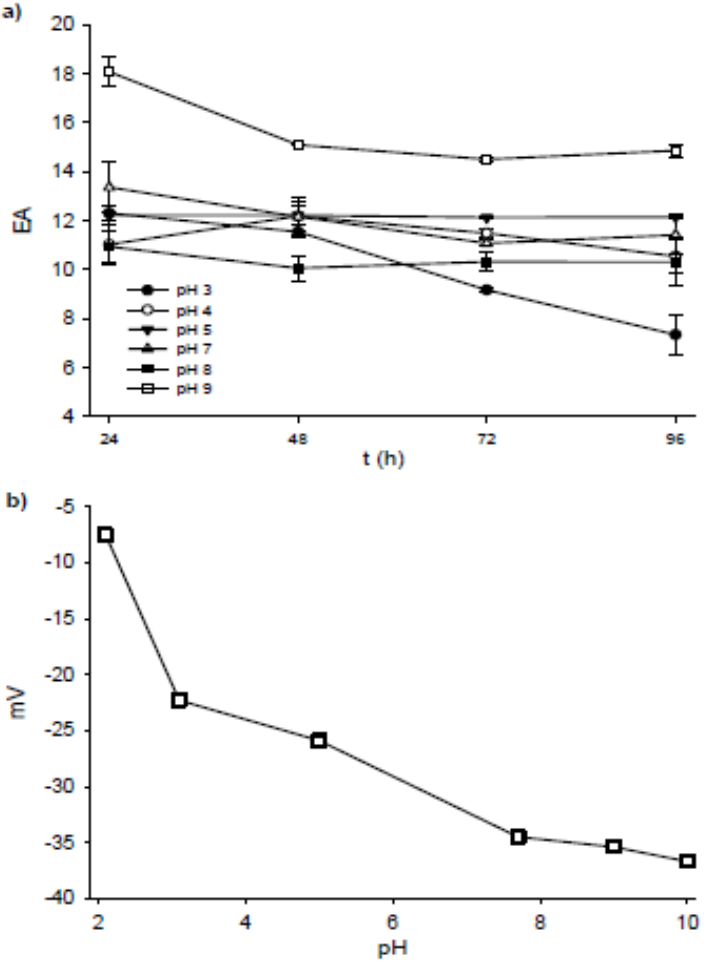

Fig. 3. a) Kinetic emulsion stability of $\mathrm{BE}$; and b) zeta potential at different $\mathrm{pH}$ values.
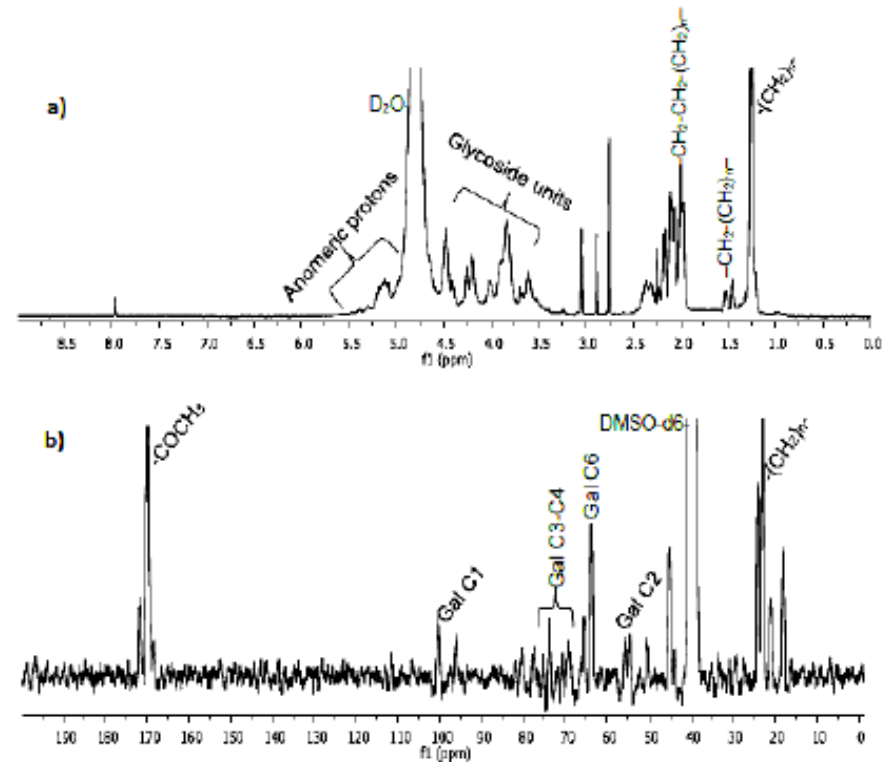

Fig. 4. a) ${ }^{1} \mathrm{H}$ NMR; and b) ${ }^{13} \mathrm{C}$ NMR spectra of the purified $\mathrm{BE}$. 


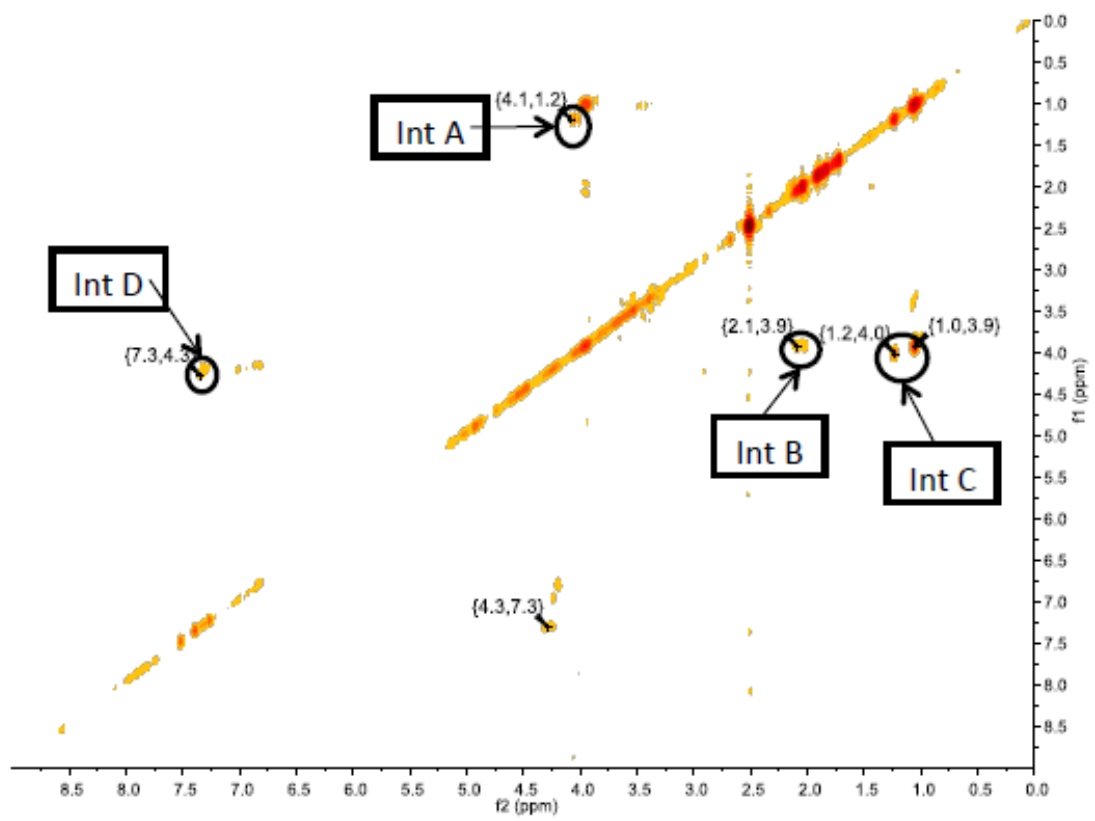

Fig. 5. COSY NMR spectrum of purified BE; the interactions (Int) are represented.

\section{Discussion}

\subsection{EA kinetics and BE production in $A L B$}

Figure 1a shows the low emulsifying capacity in the medium during the initial hours of culture. Despite this, the culture could produce $\mathrm{BE}$ in association with the cell wall as a biofilm before its detachment upon favourable conditions (Goldman et al., 1982), in which case the detected EA was low in the mineral medium at this initial stage. The presence of the BE on the cell wall also enhanced the cell hydrophobicity, and consequently its initial contact and carbon source consumption (Baldi et al., 1999). Likewise, Mehdi and Giti, (2008) observed increased affinity towards HXD and various hydrocarbons for Gram-negative microorganisms as the culture reached the early stationary phase, with biofilm production. In our study, correlation between cell growth and EA was observed, similar results were reported for biosurfactant production by Halomonas sp. MB-30 (Dhasayan et al., 2014). Thereby, we can ascribe the EA activity as an indirect measure of BE production. Additionally, after a lapse of $48 \mathrm{~h}$, its EA maintained and showed no significant changes $(\alpha=0.05)$, which correlates with growth behaviour and strengthens $\mathrm{BE}$ production association with cell growth. Therefore, this time was adequate to stop the culture and purify the BE with the highest EA. Experimental evidence indicates that the $\mathrm{BE}$ might be released at the late exponential phase and throughout the stationary phase when the bacteria and BE are forced to detach from the ALB wall surfaces. BE production and the EA were therefore associated with growth.

The Acinetobacter genus microorganisms are reported to grow with HXD as organic carbon source, along with a consequent rise of $\mathrm{pH}$, during the culture time (Chen et al., 2012). Our experimental (Fig 1b) data agree with those earlier reports, which show that the strain also raised the $\mathrm{pH}$ from 6.5 to 7.4 . It had a higher rate of protein production before five hours had passed and a $\mathrm{pH}$ level was lower than 6.8. The protein rate production seemed to lower after five hours, when proteins involved in the biodegradation of HXD, fatty acid metabolism, and oxidative stress defence reached proper concentration, which occurs because alkane metabolism includes its terminal oxidation and the $\beta$ oxidation of fatty acids (Jung et al., 2011). Culture media changes were observed by the end of the growth kinetics due to the presence of a gel-like substance which adhered to the ALB walls. Importantly, the recovery of the soluble fraction of $A$. bouvetii $\mathrm{BE}$ in the culture broth is favoured by an airlift-mixing condition 
that allows UAM25 to colonize the reactor surfaces with low shear strength.

In the present work, the protein concentration was low during culture, which contrasts with commercially produced Alasan by A. radioresistens in a similar culture time, in which protein is reported to play the role of emulsifier. On the other hand, the carbohydrate production (Fig 1b) was superior to other yields reported for BEs of the polysaccharide type. Su et al., (2009) reported a total amount of emulsan production of $60 \mathrm{mg} \cdot \mathrm{L}^{-1}$ after $120 \mathrm{~h}$ of cell growth; our BE yield was similar to this sugar concentration for the equivalent culture time.

\subsection{PAHs emulsification}

When emulsifying capabilities were studied in systems that mimic water contamination, no significant differences ( $\alpha=0.05)$ on $\mathrm{PAHs}$ emulsification were observed (Fig 2). Hence, emulsification occurred in a non-specific mode (emulsification independent of PAH type), avoiding coalescing the dispersed droplets and improving the stability due to a steric hindrance effect similar to other exopolysaccharide (EPS) BEs reported (Jain et al., 2012). The hydrocarbons non-specificity of $A$. bouvetii UAM25 BE suggests that it is a good candidate for application in hydrocarbon remediation and oil recovery (Beltrani et al., 2015). In order to compare $\mathrm{BE}$ differences such as specificity and emulsification activity, regarding commercial emulsifiers, Tween 80 and Triton X-100 emulsifiers were assayed. Specificity for $\beta$-methylnaphthalene organic mixture was observed, in contrast for HXD and the rest of the PAHs, when commercial emulsifiers were used. No EA was observed at $276 \mathrm{~nm}$ when HXD was tested individually (Fig 2b), as no aromatics were present. Notwithstanding this, EA increased when aromatics were present in the mixture. Rosenberg et al., (1979) reported that the RAG-1 strain poorly emulsified pure aliphatic and aromatic hydrocarbons, but binary blends containing aliphatic and aromatic hydrocarbons raised the EA. In our case, the presence of $\beta$-methylnaphthalene, PYR, or PHE favoured the EA response for $\mathrm{BE}$ but not for Tween 80 and Triton X-100. Tween 80 could not emulsify HXD when PYR and/or PHE were in the blend. Triton X-100 showed HXD emulsification to a lower extent than the emulsification that BEs produced, which could have been due to Triton X-100 HXD pseudo-solubilization capabilities (Zhong et al., 2016). Although Cheng et al., (2016) reported an enhancement of HXD removal by Triton X-100, its degradation is difficult when compared to EPS $\mathrm{BE}$ because of its chemical composition, which includes an aromatic ring and polymeric ethylene oxide structure. Beltrani et al., (2015) also reported specificity for certain hydrocarbons by Tween 80 and Triton X-100 when compared them to EPS BE, Pdb-Z produced by Pedobacter sp. MCC-Z. It is noteworthy that emulsification could be related to solubilisation, and therefore also related to hydrocarbon degradation. For example, Mahanty et al., (2006) described a linear increment of aqueous solubility of PYR and anthracene alongside $\mathrm{BE}$ production and degradation.

\subsection{BE stability and zeta potential}

$\mathrm{BE}$ was stable at broad range of $\mathrm{pH}$ conditions (Fig $3 a)$, although slight decrease in emulsion stability at acidic conditions was observed, which could be due to the protonation of the EPS BE carboxylic groups that results in coalescence between positively charged droplets (Dhasayan et al., 2014). Concomitantly, the $\mathrm{pH}$ effects were reflected by the zeta potential of the $\mathrm{BE}$ (i.e, they affect the dispersion characteristics of the emulsion as a colloid (Fig 3b)). Stability might be ascribed to the absence of protein and the inherent precipitation. It is worth noting that the viscous nature of the EPS BE gel probably provides stability even at $\mathrm{pH}$ 9. In this regard, Grinberg et al., (1995) reported an Ukrainian Acinetobacter species that produced viscous $\mathrm{BE}$ when $\mathrm{pH}$ was lowered.

At $\mathrm{pH}$ 9, electrostatic repulsion (that higher EA values reflect) was favoured due to the increased electronegativity in the zeta potential. Wicek and Chibowski (2002) found more stability (one-week age) when the zeta potential of dispersed n-tetradecane droplets with $\beta$-casein has increased electronegativity $(-60.3 \mathrm{mV})$ at $\mathrm{pH} 11$. In our work, two remarkable aspects emerged: (i) emulsion stability at a wide range of $\mathrm{pH}$; and (ii) non-specific emulsification manner, both mainly due to steric effects that correspond to physicochemical exopolysaccharide characteristics.

\subsection{Chemical characterization}

The purified BE showed an EA (160 U.mg $\left.{ }^{-1}\right)$, which two-fold that of the non-pure BE. Therefore, the presence of impurities in the mineral medium (low molecular weight proteins and salts) probably had a negative effect on the emulsion stability and EA through its effect on the superficial charges that promote the coalescence of dispersed droplets. The 
low concentration of proteins found, and the lack of correlation with EA, ruled out any relation to protein chemical composition, unlike the BE Alasan reported by Toren et al., (2001), in which the main EA capacity is associated with a protein of $45 \mathrm{kDa}$. With the remarkable difference due to the gel-type consistency, our BE was similar to other polysaccharide-based BEs, such as Emulsan, Ethapolan (Pirog et al., 2009), and Biodispersan, moreover the carbohydrate concentration, which was correlated to the $\mathrm{BE}$ yield production and EA, supported the BE carbohydrate nature. To confirm the polysaccharide structure, NMR analyses were performed. Signals corresponding to $\beta$-D-galactose (DGalpA) with a uronic acid unit. In a previous study by Vinogradov et al., (2010), the presence of uronic acid was identified at the end of the main polysaccharide chain. The presence of uronic acid is related to BEs ability to emulsify and detoxify hydrocarbons (Uzoigwe et al., 2015). This moiety could enhance the hydrocarbon-emulsifying capability over the tested commercial emulsifiers. Aliphatic chain component associated with the carbohydrate moieties was identified (Fig 5) which explains the amphipathic BE nature. The BE was therefore identified as a high-weight molecule with a polysaccharide chemical structure composed mainly of repeated units of rhamnose and galactose linked to an aliphatic side chain.

We have discussed for the first time the EPS characteristics and capabilities of the BE produced by A. bouvetii UAM 25 .

\section{Conclusions}

The $\mathrm{BE}$ is a high-molecular-weight molecule and was produced with the highest emulsifying activity. The BE production was associated with the microbial growth pattern in the ALB. The BE exhibits exopolysaccharides associated with aliphatic compounds and was capable of emulsifying several polycyclic aromatic hydrocarbons, actually was 4.5 times more effective at emulsifying the hydrocarbons than commercial emulsifiers when PYR was in the blend. This is the first study dealing with the BE of A. bouvetii UAM 25 chemical and its functional characterization. Our work suggests potential biotechnological applications of this novel $\mathrm{BE}$ to enhance the bioremediation of soil, sediments, and water.

\section{Acknowledgements}

This work was funded by CONACYT, fellowships 321085 and 419158, and PEMEX-Refinación.

\section{References}

Baldi, F., Ivošević, N., Minacci, A., Pepi, M., Fani, R., Svetlišić, V., Žutić, V., (1999). Adhesion of Acinetobacter venetianus to diesel fuel droplets studied with in situ electrochemical and molecular probes. Applied and Environmental Microbiology 65, 2041-2048.

Beltrani, T., Chiavarini, S., Cicero, D.O., Grimaldi, M., Ruggeri, C., Tamburini, E. Cremisini, C., (2015). Chemical characterization and surface properties of a new bioemulsifier produced by Pedobacter sp. strain MCC-Z. International Journal of Biological Macromolecules 72, 1090-1096. DOI: $10.1016 /$ j.ijbiomac. 2014.10.025

Bradford, M.M., (1976). A rapid and sensitive method for the quantitation of microgram quantities of protein utilizing the principle of protein-dye binding. Analytical Biochemistry 72, 248-254. DOI:10.1016/00032697(76)90527-3

Chen, J., Huang, P.T., Zhang, K.Y., Ding, F.R., (2012). Isolation of biosurfactant producers, optimization and properties of biosurfactant produced by Acinetobacter sp. from petroleum-contaminated soil. Journal of Applied Microbiology 112, 660-671. DOI: $10.1111 / \mathrm{j} .1365-2672.2012 .05242 . \mathrm{x}$

Cheng, Y., He, H., Yang, C., Yan, Z., Zeng, G., Qian, H., (2016). Effects of anionic surfactant on n-hexane removal in biofilters. Chemosphere 150, 248-253. DOI: $10.1016 /$ j.chemosphere. 2016.02.027

Cisneros-de La Cueva, S., Martinez-Prado, M.A., López-Miranda, J., Rojas-Contreras, J.A., Medrano-Roldán, H., (2016). Aerobic degradation of diesel by a pure culture of Aspergillus terreus KP862582. Revista Mexicana de Ingeniería Química 15, 347-360.

Cisneros-de La Cueva, S., Martínez-Prado, M.A., Rojas-Contreras, J.A., Medrano-Roldán, H., 
Vázquez-Vázquez et al./ Revista Mexicana de Ingeniería Química Vol. 16, No. 3 (2017) 721-733

Murillo-Martínez, M.A., (2014). Isolation and characterization of a novel strain, Bacillus sp KJ629314, with a high potential to aerobically degrade diesel. Revista Mexicana de Ingeniería Química 13, 393-403.

Deng, Y., Zhang, Y., Hesham, A.E.-L., Liu, R., Yang, M., (2010). Cell surface properties of five polycyclic aromatic compound-degrading yeast strains. Applied Microbiology and Biotechnology 86, 19331939. DOI: $10.1007 / \mathrm{s} 00253-010-2477-7$

Dhasayan, A., Kiran, G.S., Selvin, J., (2014). Production and characterisation of glycolipid biosurfactant by Halomonas sp. MB-30 for potential application in enhanced oil recovery. Applied Biochemistry and Biotechnology 174, 2571-2584. DOI: $10.1007 / \mathrm{s} 12010-014-1209-3$

Díaz-Ramírez, I.J., Escalante-Espinosa, E., FavelaTorres, E., Gutiérrez-Rojas, M., RamírezSaad, H., (2008). Design of bacterial defined mixed cultures for biodegradation of specific crude oil fractions, using population dynamics analysis by DGGE. International Biodeterioration and Biodegradation 62, 21-30. DOI:10.1016/j.ibiod.2007.11.001

DuBois, M., Gilles, K. A., Hamilton, J.K., Rebers, P. A., Smith, F., (1956). Colorimetric method for determination of sugars and related substances. Analytical Chemistry 28, 350-356. DOI: $10.1021 / \mathrm{ac} 60111 \mathrm{a} 017$

Egorova, K.S., Toukach, P. V., (2014). Expansion of coverage of Carbohydrate Structure Database (CSDB). Carbohydrate Research 389, 112-114. DOI:10.1016/j.carres.2013.10.009

Ghosh, I., Mukherji, S., (2016). Diverse effect of surfactants on pyrene biodegradation by a Pseudomonas strain utilizing pyrene by cell surface hydrophobicity induction. International Biodeterioration and Biodegradation 108, 6775. DOI:10.1016/j.ibiod.2015.12.010

Goldman, S., Shabtai, Y., Rubinovitz, C., (1982). Emulsan in Acinetobacter calcoaceticus RAG-1: Distribution of cell-free and cellassociated cross-reacting material. Applied and Environmental Microbiology 44, 165-170. DOI:0099-2240/82/070165
Grinberg, T. A., Pirog, T.P., Malashenko, Y.R., Vlasov, S. A., (1995). Ethapolan: a new microbial exopolysaccharide for oil industry. Energy \& Fuels 9, 1086-1089. DOI: $10.1021 / \mathrm{ef00054a023}$

Guo, X., Yao, L., Huang, Q., (2015). Aeration and mass transfer optimization in a rectangular airlift loop photobioreactor for the production of microalgae. Bioresource Technology 190, 189195. DOI:10.1016/j.biortech.2015.04.077

Jain, R.M., Mody, K., Mishra, A., Jha, B., (2012). Isolation and structural characterization of biosurfactant produced by an alkaliphilic bacterium Cronobacter sakazakii isolated from oil contaminated wastewater. Carbohydrate Polymers 87, 23202326. DOI: 10.1016/j.carbpol.2011.10.065

Jain, R.M., Mody, K., Joshi, N., Mishra, A., Jha, B., (2013). Production and structural characterization of biosurfactant produced by an alkaliphilic bacterium, Klebsiella sp.: Evaluation of different carbon sources. Colloids and Surfaces B: Biointerfaces 108, 199-204. DOI: 10.1016/j.colsurfb. 2013.03.002

Jiménez-González, A., Vargas-García, V., LizardiJiménez, M.A., Medina-Moreno, S.A., (2015). Evaluation of polyaromatic hydrocarbon and oxygen volumetric transfer coefficient on multiphase system (liquid-liquid and liquid-liquidgas): biocompatible solvent charge effect. Revista Mexicana de Ingeniería Química 14, 723-734.

Jung, J., Noh, J., Park, W., (2011). Physiological and metabolic responses for hexadecane degradation in Acinetobacter oleivorans DR1. Journal of Microbiology 49, 208-215. DOI: $10.1007 / \mathrm{s} 12275-011-0395-8$

Laemmli, U.K., (1970). Cleavage of structural proteins during the assembly of the head of bacteriophage T4. Nature 227, 680-685. DOI: $10.1038 / 227680 \mathrm{a} 0$

Lizardi-Jiménez, M.A., Gutiérrez-Rojas, M., (2011). Assessment of the local hydrodynamic zones in a three-phase airlift reactor: looking for the lowest liquid-phase Re. Revista Mexicana de Ingeniería Química 10, 59-65. DOI: 10.4090/juee.2008.v2n2.033040 
Vázquez-Vázquez et al./ Revista Mexicana de Ingeniería Química Vol. 16, No. 3 (2017) 721-733

Lizardi-Jiménez, M. A., Leal-Bautista, R.M., Ordaz, A., Reyna-Velarde, R., (2014). Airlift bioreactors for hydrocarbon water pollution remediation in a tourism development pole. Desalination and Water Treatment, 44-49. DOI: $10.1080 / 19443994.2013 .876670$

Mahanty, B., Pakshirajan, K., Dasu, V. V., (2006). Production and properties of a biosurfactant applied to polycyclic aromatic hydrocarbon solubilization. Applied Biochemistry and Biotechnology 134, 129-141. DOI:10.1385/ABAB:134:2:129

Martínez Trujillo, M.A., Membrillo Venegas, I., Vigueras-Carmona, S.E., Zafra-Jiménez, G., García-Rivero, M., (2015). Optimization of a bacterial biosurfactant production. Revista Mexicana de Ingeniería Química 14, 355-362.

Mehdi, H., Giti, E., (2008). Investigation of alkane biodegradation using the microtiter plate method and correlation between biofilm formation, biosurfactant production and crude oil biodegradation. International Biodeterioration and Biodegradation 62, 170178. DOI: $10.1016 /$ j.ibiod.2008.01.004

Monteiro, A. S., Bonfim, M.R.Q., Domingues, V.S., Corrêa, A., Siqueira, E.P., Zani, C.L., Santos, V.L., (2010). Identification and characterization of bioemulsifier-producing yeasts isolated from effluents of a dairy industry. Bioresource Technology 101, 51865193. DOI:10.1016/j.biortech.2010.02.041

Pirog, T.P., Korzh, I. V, Shevchuk, T. A., (2009). Effect of cultivation conditions on the physicochemical properties of exopolysaccharide ethapolan. Prikladnaia Biokhimiia I Mikrobiologiia 45, 58-63. DOI: $10.1134 / \mathrm{S} 0003683809010098$

Ron, E.Z., Rosenberg, E., (2001). Natural roles of biosurfactants. Environmental Microbiology 3, 229-236. DOI: 10.1046/j.14622920.2001.00190.x

Rosenberg, E., Perry, A., Gibson, D.T., Gutnick, D.L., (1979). Emulsifier of Arthrobacter RAG1: Specificity of hydrocarbon substrate. Applied and Environmental Microbiology 37, 409-413. DOI:10.1016/0014-5793(79)81320-4
Sjögren, M., Li, H., Rannug, U., Westerholm, R., (1995). A multivariate statistical analysis of chemical composition and physical characteristics of ten diesel fuels. Fuel 74, 983 989. DOI:10.1016/0016-2361(95)00056-B

Sotelo-Boyas, M.E., Valverde-Aguilar, G., Plascencia-Jatomea, M., Correa-Pacheco, Z.N., Jiménez-Aparicio, A., Solorza-Feria, J., Barrera-Necha, L., Bautista-Baños, S., (2015). Characterization of chitosan nanoparticles added with essential oils. In vitro effect on Pectobacterium carotovorum. Revista Mexicana de Ingeniería Química 14, 589-599.

Souza, E.., Vessoni-Penna, T.C., De Souza Oliveira, R.P., (2014). Biosurfactantenhanced hydrocarbon bioremediation: An overview. International Biodeterioration and Biodegradation 89, 88-94. DOI:10.1016/j.ibiod. 2014.01.007

Su, W.T., Chen, W.J., Lin, Y.F., (2009). Optimizing emulsan production of $A$. venetianus RAG-1 using response surface methodology. Applied Microbiology and Biotechnology 84, 271-279. DOI: $10.1007 / \mathrm{s} 00253-009-1957-0$

Toren, A., Navon-Venezia, S., Ron, E.Z., Rosenberg, E., (2001). Emulsifying activities of purified alasan proteins from Acinetobacter radioresistens KA53. Applied and Environmental Microbiology 67, 11021106. DOI:10.1128/AEM.67.3.1102-1106.2001

Tzintzun-Camacho, O., Loera, O., RamírezSaad, H.C., Gutiérrez-Rojas, M., (2012). Comparison of mechanisms of hexadecane uptake among pure and mixed cultures derived from a bacterial consortium. International Biodeterioration and Biodegradation 70, 1-7. DOI: 10.1016/j.ibiod. 2012.01.009

Uzoigwe, C., Burgess, J.G., Ennis, C.J., Rahman, P.K.S.M., (2015). Bioemulsifiers are not biosurfactants and require different screening approaches. Frontiers in Microbiology 6. DOI: $10.3389 /$ fmicb. 2015.00245

Villegas, E., Téllez-Téllez, M., Rodríguez, A., Carreón-Palacios, A.E., Acosta-Urdapilleta, M.L., Kumar-Gupta, V., Díaz-Godínez, G., (2016). Laccase activity of Pycnoporus cinnabarinus grown in different culture systems. 
Vázquez-Vázquez et al./ Revista Mexicana de Ingeniería Química Vol. 16, No. 3 (2017) 721-733

Revista Mexicana de Ingeniería Química 15, 703-710.

Vinogradov, E., Maclean, L.L., Perry, M.B., (2010). Structural determination of the Oantigenic polysaccharide of enteropathogenic Escherichia coli O103:H2. Canadian Journal of Microbiology 56, 366-372. DOI:10.1139/w10015

Wicek, A.E., Chibowski, E., (2002). Zeta potential and droplet size of n-tetradecane/ethanol (protein) emulsions. Colloids and Surfaces B: Biointerfaces 25, 55-67. DOI:10.1016/S0927-

\section{5(01)00304-6}

Zhong, H., Wang, Z., Liu, Z., Liu, Y., Yu, M., Zeng, G., (2016). Degradation of hexadecane by Pseudomonas aeruginosa with the mediation of surfactants: Relation between hexadecane solubilization and bioavailability. International Biodeterioration and Biodegradation 115, 141145. DOI: 10.1016/j.ibiod.2016.08.008

Zwietering, M.H., Jongenburger, I., Rombouts, F.M., van't Riet, K., (1990). Modeling of the bacterial growth curve. Applied and Environmental Microbiology 56, 1875-1881. 


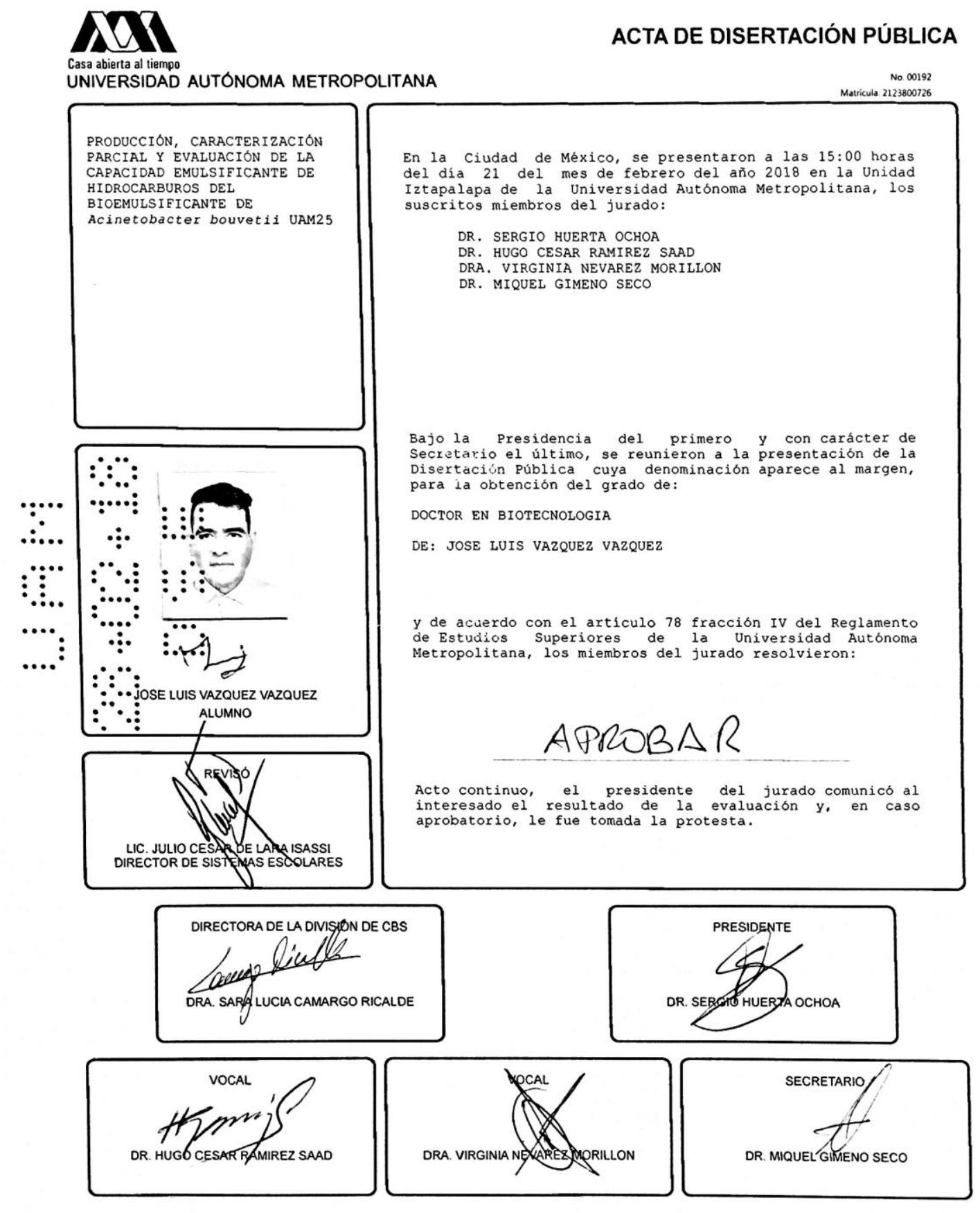

